\title{
THE \\ REGULATORY IMPLICATIONS OF NEW BREEDING TECHNIQUES
}
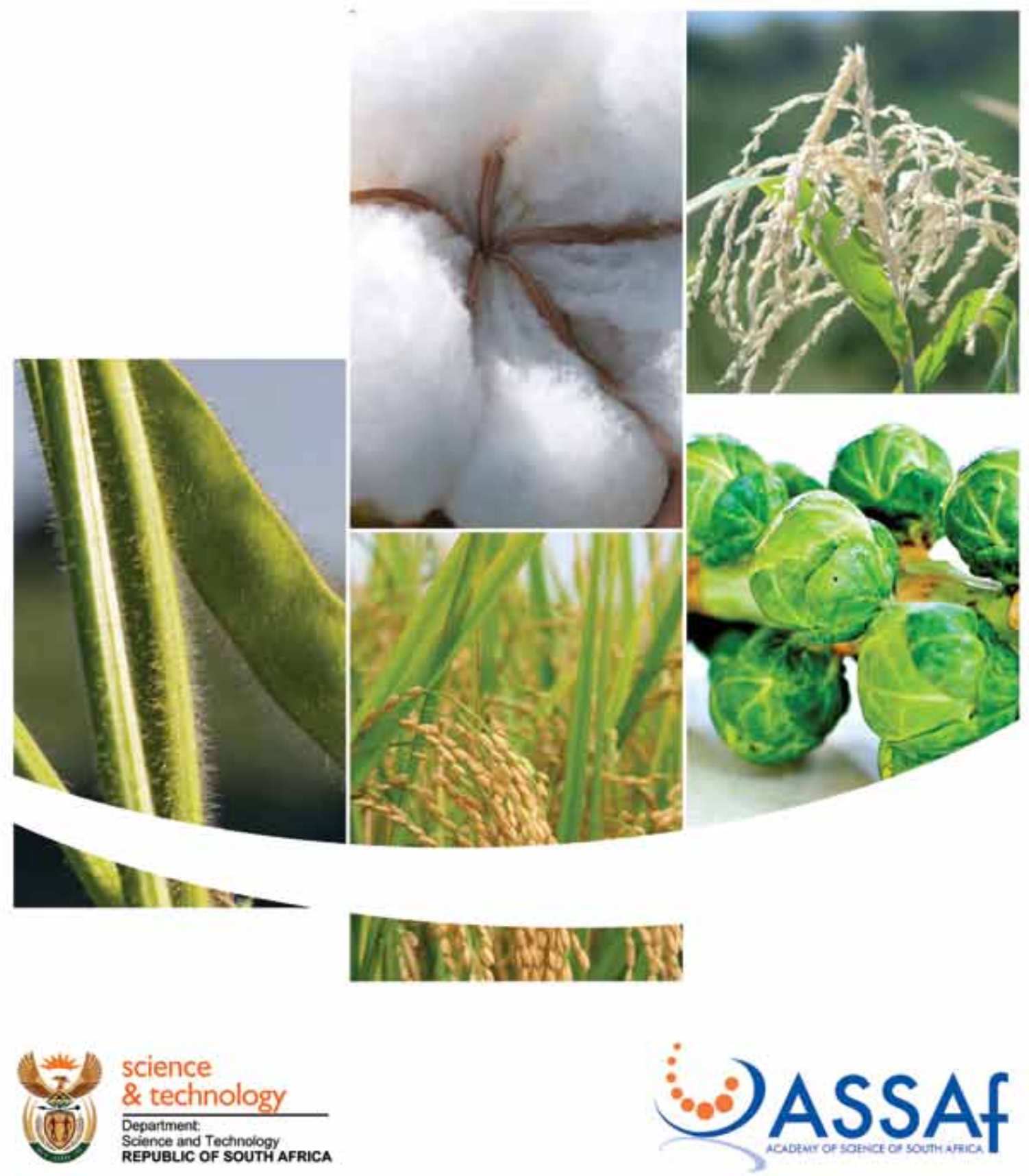
(C) Academy of Science of South Africa March 2017

ISBN 978-0-9947076-6-6

DOI: http://dx.doi.org/10.17159/assaf.2016/0011

Please use the DOI in citation.

Published by:

Academy of Science of South Africa (ASSAf)

PO Box 72135, Lynnwood Ridge, Pretoria, South Africa, 0040

Tel: +27 123496600 Fax: +27 865769520

E-mail:admin@assaf.org.za

Reproduction is permitted, provided the source and publisher are appropriately acknowledged.

The Academy of Science of South Africa (ASSAf) was inaugurated in May 1996. It was formed in response to the need for an Academy of Science consonant with the dawn of democracy in South Africa: activist in its mission of using science and scholarship for the benefit of society, with a mandate encompassing all scholarly disciplines that use an open-minded and evidence-based approach to build knowledge. ASSAf thus adopted in its name the term 'science' in the singular as reflecting a common way of enquiring rather than an aggregation of different disciplines. Its Members are elected on the basis of a combination of two principal criteria, academic excellence and significant contributions to society.

The Parliament of South Africa passed the Academy of Science of South Africa Act (Act 67 of 2001), which came into force on 15 May 2002. This made ASSAf the only academy of science in South Africa officially recognised by government and representing the country in the international community of science academies and elsewhere. 


\section{TABLE OF CONTENTS}
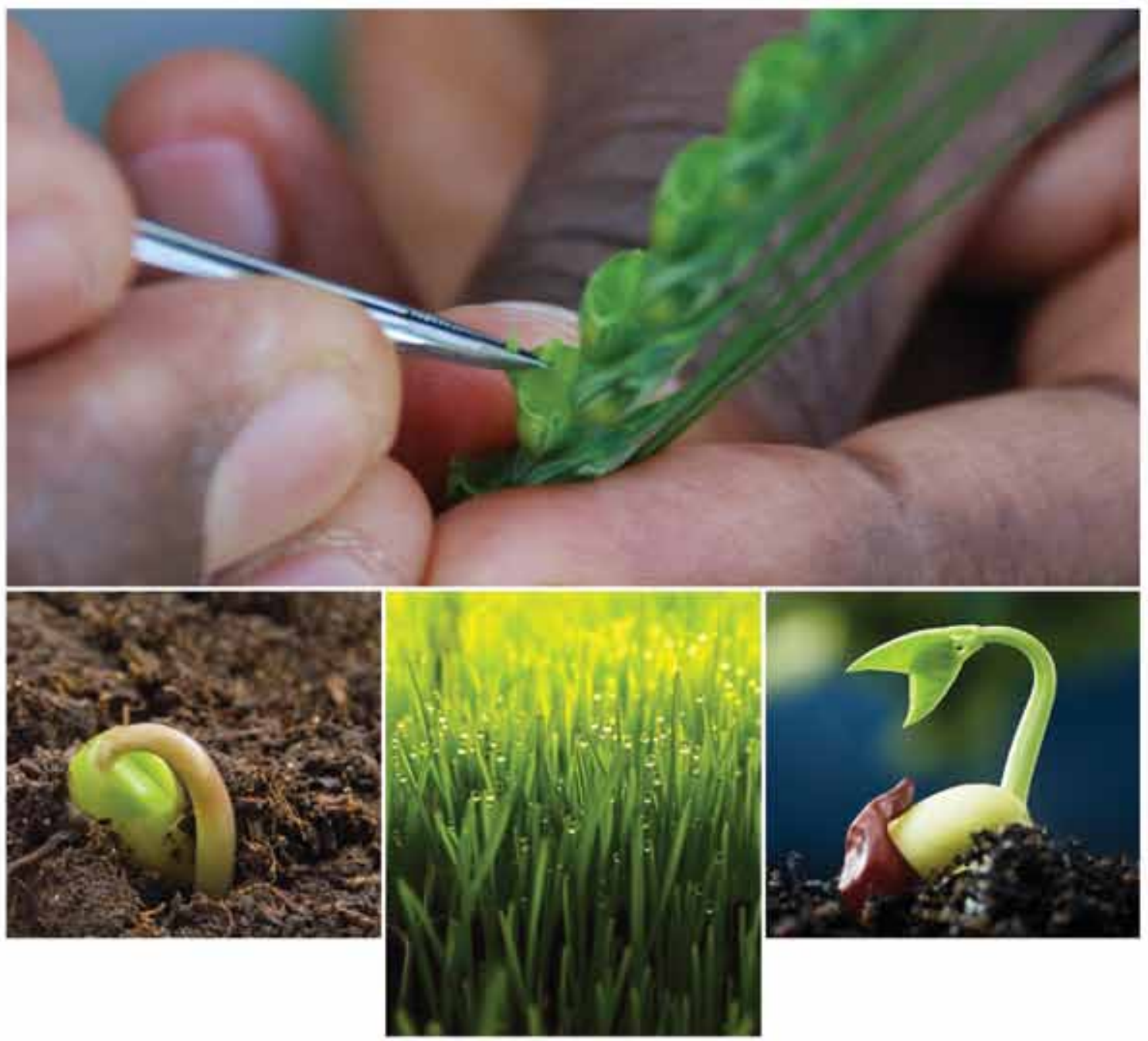
List of Tables 5

List of Appendices. 5

Foreword. 6

Acknowledgements. 7

Acronyms 8

Definitions 10

Executive Summary. 14

CHAPTER 1 Introduction and Background. 18

CHAPTER 2 The Evolution of Crop Breeding Techniques 26

CHAPTER 3 Overview of New Breeding Techniques (NBTs) 32

CHAPTER 4 Current Regulatory Framework for GMOs 46

CHAPTER 5 Current Global Approaches to the Regulation of NBTs. 52

CHAPTER 6 Regulatory Frameworks and Risk Analysis for NBTs 66

CHAPTER 7 General Conclusions and Recommendations 76

References 82

APPENDIX 1 Biographies of Panel Members 85

APPENDIX 2 Attendance Register: Regulatory Implications of New Breeding Techniques. 87

APPENDIX 3 Examples of the Application of New Breeding Techniques 88 


\section{LIST OF FIGURES}

Figure 3.1 Types of genome editing made possible using zinc-finger nucleases

(Urnov et al. 2010)

Figure 3.2 Schematic representation of the steps in a CRISPR-Cas9 adaptive immune response (https://www.neb.com) 36

Figure 3.3 Types of genome editing made possible using CRISPR-Cas9 (http://toolgen.com) 37

Figure 3.4 A diagram illustrating the oligonucleotide, directed mutagenesis process (http://www.brc.hu). 39

Figure 3.5 Schematic overview of the final outcomes of different breeding approaches (Modified http://european-seed.com)

Figure 3.6 Five techniques commonly used to generate new plant varieties - conventional plant breeding, mutation breeding, targeted mutagenesis, transgenesis and cisgenesis (Reproduced with the permission of Science \& Society)

Figure 3.7 Differences between transgenic, cisgenic and intragenic breeding (Reproduced with the kind permission of Science \& Society)

Figure 3.8 A diagram illustrating the two components of a graft - the non-GM scion and the GM rootstock (http://germination.ca) 43

Figure 7.1 Schematic summary of the basis for the regulation of GMOs 79

Figure 7.2 Proposed NBT decision tree for determining whether a specific NBT, or any other genetic engineering organism, should be subjected to regulation under the GMO Act or not 80 


\section{LIST OF TABLES}

Table 5.1 Summary of four potential options regarding the regulation of NBTs and their respective advantages and disadvantages according to the OGTR

Table 5.2 A summary on the status of certain NBTs as compiled by UK Advisory Committee on Releases to the Environment (ACRE) 60

Table 5.3 The status of certain NBTs per the 2012 position statement of the German Biosafety Commission.

Table 5.4 Novel plant breeding techniques, consequences of new genetic modificationbased plant breeding techniques

Table 5.5 The degree of concern regarding various aspects of gene edited plant products among US stakeholders (from Kuzma et al. 2016). .64

Table 7.1 The likely regulatory outcome for specific products of various NBTs based on the proposed product-based regulatory trigger and unnatural genetic variation threshold. 


\section{FOREWORD}

The Academy of Science of South Africa (ASSAf) has a mandate to provide evidence-based scientific advice to South African policymakers and this consensus report is in fulfilment of this mandate.

South Africa is one of only very few African countries that has commercialised GMOs. A plethora of recent developments in genetic engineering and related technologies has necessitated the reassessment of their possible value, biosafety implications and regulation. This led the Department of Science and Technology (DST) to commission this study by ASSAf. This study had two main objectives: to make sure South African policy appropriately and adequately addresses biosafety requirements of these new techniques to ensure safe and sustainable research, development and use of their products; and to ensure the regulatory requirements are appropriate to the technologies and/or their products.

This consensus report provides an overview of the so-called new breeding techniques (NBTs), as well as an overview of current global approaches to the regulation of these NBTs and then makes recommendations on:

- how to assess these new and future techniques and their products regarding their possible subjection to existing GMO legislation;

- how current biosafety policy and regulations may need to be amended to accommodate the varying biosafety implications of these products;

- if current risk analysis frameworks and practice are sufficient to assess the biosafety of these products.

This report is the product of the voluntary work of a six-member consensus study panel and I would like to extend appreciation to them, especially the chairperson, Dr Hennie Groenewald, for expert contributions and the production of this important and timely report.

The report was peer-reviewed by three experts: Dr Jane Morris, Prof Diran Makinde and Prof Stuart Smyth.

I hope the recommendations will be implemented in a manner that will benefit biotechnology in the country.

Appreciation is also extended to all Academy staff, personnel, stakeholders and researchers who contributed to this study and the writing of the report.

Funding from the Department of Science and Technology is also hereby gratefully acknowledged.

\section{Professor Jonathan Jansen}

President: Academy of Science of South Africa 


\section{ACKNOWLEDGEMENTS}

This consensus study report is the result of the collaborative work of a number of people, who are acknowledged as follows:

The members of the study panel: Dr Eugenia Barros, Council for Scientific and Industrial Research (CSIR); Dr Kingston Mashingaidze, Agricultural Research Council (ARC); Professor labal Parker, University of Cape Town (UCT); and Dr James Southern, Independent Consultant. These members volunteered their time and expertise for this study and are gratefully acknowledged. The panel met twice (physically) and also had many electronic discussions during the study period (May 2015 to January 2017).

The panel would also like to thank Goldamer Consulting, and Dr Dave Keetch in particular, for the desktop research and invaluable contribution in the writing of this report.

As part of the information gathering process a consultative workshop was held in October 2016; all participants and contributors are acknowledged.

The three independent peer-reviewers: Prof Diran Makinde, Dr Jane Morris and Prof Stuart Smyth are thanked for their thoughtful comments, which led to the improvement of the report.

Support and contributions from Academy staff, Ms Phakamile Mngadi, Prof Roseanne Diab, Mr lan Shendelana and Ms Patricia Scholtz are highly appreciated.

The DST commissioned the study and provided financial support for which they are gratefully acknowledged. In addition, the critical contributions of Mr Ben Durham to the content of the study are recognised.

\section{Dr Hennie Groenewald Panel Chairperson}




\section{ACRONYMS}

\begin{tabular}{|c|c|}
\hline$A B C A$ & Agricultural Biotechnology Council of Australia \\
\hline$A C$ & Advisory Committee \\
\hline ACRE & Advisory Committee on Releases to the Environment \\
\hline APHIS & Animal and Plant Health Inspection Service \\
\hline ARC & Agricultural Research Council \\
\hline ASSAf & Academy of Science of South Africa \\
\hline CBD & Convention on Biological Diversity \\
\hline $\mathrm{CO}_{2}$ & Carbon dioxide \\
\hline CPB & Cartagena Protocol on Biosafety \\
\hline CRISPR & Clustered regularly-interspaced short palindromic repeats \\
\hline CSIR & Council for Scientific and Industrial Research \\
\hline DAC & Department of Arts and Culture \\
\hline DAFF & Department of Agriculture, Forestry and Fisheries \\
\hline DEA & Department of Environmental Affairs \\
\hline $\mathrm{DH}$ & Double haploid \\
\hline DNA & Deoxyribonucleic acid \\
\hline $\mathrm{DoH}$ & Department of Health \\
\hline DoL & Department of Labour \\
\hline DSB & Double-strand break \\
\hline DST & Department of Science and Technology \\
\hline EC & Executive Council \\
\hline EFSA & European Food Safety Authority \\
\hline EPA & Environmental Protection Agency \\
\hline EU & European Union \\
\hline FDA & Food and Drug Administration \\
\hline GE & Genetic engineering \\
\hline GM & Genetically modified OR genetic modification \\
\hline GMO & Genetically modified organism \\
\hline gRNA & Guide RNA \\
\hline ha & Hectare \\
\hline HDR & Homology-directed repair \\
\hline ICGEB & International Centre for Genetic Engineering and Biotechnology \\
\hline IPR & Intellectual property tights \\
\hline ISAAA & The International Service for the Acquisition of Agri-biotech Applications \\
\hline
\end{tabular}




\begin{tabular}{|c|c|}
\hline $\mathrm{kg}$ & Kilogram \\
\hline LMO & Living modified organism \\
\hline MAS & Marker-assisted selection \\
\hline $\mathrm{MN}$ & Meganucleases \\
\hline NBT & New breeding techniques \\
\hline NHEJ & Non-homologous end joining \\
\hline NGO & Non-Governmental Organisation \\
\hline $\mathrm{NIH}$ & National Institute of Health \\
\hline NRC & National Research Council \\
\hline ODM & Oligonucleotide-Directed Mutation \\
\hline OECD & Organisation for Economic Co-operation and Development \\
\hline OGTR & Office of the Gene Technology Regulator \\
\hline ORF & Open Reading Frame \\
\hline OSTP & Office of Science and Technology Policy \\
\hline rDNA & Recombinant DNA \\
\hline R\&D & Research and development \\
\hline RdDM & RNA-dependent DNA methylation \\
\hline RNA & Ribonucleic acid \\
\hline RNAi & RNA interference \\
\hline SAGENE & South African Committee on Genetic Experimentation \\
\hline SDN & Site-directed nucleases \\
\hline SIRNA & Small (or short) interfering RNA \\
\hline SMES & Small and medium-sized enterprises \\
\hline SOP & Standard Operating Procedure \\
\hline TALEN & Transcription activator-like effector nucleases \\
\hline TALES & Transcription activator-like effectors \\
\hline $\begin{array}{l}\text { T-DNA } \\
\text { the dti }\end{array}$ & $\begin{array}{l}\text { Transfer DNA } \\
\text { Department of Trade and Industry }\end{array}$ \\
\hline UK & United Kingdom \\
\hline UNEP & United Nations Environment Programme \\
\hline USA & United States of America \\
\hline USDA & United States Department of Agriculture \\
\hline WTO & World Trade Organisation \\
\hline ZFN & Zinc-finger nucleases \\
\hline
\end{tabular}




\section{DEFINITIONS}

\begin{tabular}{|c|c|}
\hline Allele & A variant form of a gene. \\
\hline \multirow[t]{2}{*}{ Biosafety } & $\begin{array}{l}\text { General: The efforts and mechanisms to assess, manage and } \\
\text { communicate the potential risks resulting from biotechnology } \\
\text { and its products and in particular GMOs. }\end{array}$ \\
\hline & $\begin{array}{l}\text { GMO Act: The level of safety when risk management } \\
\text { measures must be taken to avoid potential risk to human } \\
\text { and animal health and safety and to the conservation of the } \\
\text { environment, as a result of exposure to activities with GMOs. }\end{array}$ \\
\hline Cas & A CRISPR associated protein. \\
\hline Chimeric gene & $\begin{array}{l}\text { A gene formed from a combination of portions of one or } \\
\text { more coding sequences to produce new genes. These } \\
\text { mutations are distinct from fusion genes which merge whole } \\
\text { gene sequences into a single reading frame and often retain } \\
\text { their original functions. }\end{array}$ \\
\hline Chromosome & $\begin{array}{l}\text { A thread-like structure of nucleic acids and protein found in } \\
\text { the nucleus of most living cells, carrying genetic information } \\
\text { in the form of genes. }\end{array}$ \\
\hline Cisgene & $\begin{array}{l}\text { An intact, functional gene sequence that occurs naturally in } \\
\text { a target organism or a sexually compatible species, including } \\
\text { its natural regulatory cis-sequences such as its promoter and } \\
\text { terminator. }\end{array}$ \\
\hline Cpfl & $\begin{array}{l}\text { A single RNA-guided endonuclease of a class } 2 \text { CRISPR-Cas } \\
\text { system. }\end{array}$ \\
\hline CrRNA & A small trans-encoded RNA. \\
\hline Epigenetic & $\begin{array}{l}\text { Cellular and physiological phenotypic trait variations that } \\
\text { are caused by external or environmental factors that switch } \\
\text { genes on and off and affect how cells 'read' genes instead } \\
\text { of being caused by changes in the DNA sequence. }\end{array}$ \\
\hline Episome & $\begin{array}{l}\text { A DNA molecule that replicates independently of chromosomal } \\
\text { DNA, e.g. a plasmid. }\end{array}$ \\
\hline Eukaryotic & $\begin{array}{l}\text { An organism whose cells contain a nucleus surrounded by a } \\
\text { membrane and whose DNA is bound together by proteins } \\
\text { (histones) into chromosomes. }\end{array}$ \\
\hline Exogenous (biology) & Originating from outside an organism. \\
\hline Gene & $\begin{array}{l}\text { A distinct sequence of nucleotides, the order of which } \\
\text { determines its function, and which is the basic unit of heredity } \\
\text { that is transferred from a parent to offspring and is held to } \\
\text { determine some characteristic of the offspring. In general, } \\
\text { includes appropriate regulatory sequences such as promoters } \\
\text { and terminator sequences. }\end{array}$ \\
\hline
\end{tabular}




\begin{tabular}{|c|c|}
\hline Gene drive & $\begin{array}{l}\text { Refers to a genetic element that promotes the inheritance } \\
\text { of a particular allele/gene to increase its prevalence in a } \\
\text { population (also used to describe the practice of inducing } \\
\text { such non-Mendelian inheritance). }\end{array}$ \\
\hline Gene therapy & $\begin{array}{l}\text { A technique for delivering functional genes (to replace } \\
\text { aberrant ones) into living cells by means of a genetically } \\
\text { modified vector or by physical means in order to genetically } \\
\text { alter the living cell (from GMO Act). }\end{array}$ \\
\hline \multirow[t]{2}{*}{ Genetic engineering } & $\begin{array}{l}\text { The deliberate process of design, editing and/or assembly } \\
\text { of genetic sequences aimed at changing the genetic } \\
\text { characteristics of living organisms. }\end{array}$ \\
\hline & $\begin{array}{l}\text { Note: The terms "genetic engineering" and "genetic modifi- } \\
\text { cation" are often used interchangeably. In this document the } \\
\text { term "genetic engineering" is used in a more general context } \\
\text { to refer to related techniques and processes, while "genetic } \\
\text { modification" is use in accordance with its legal definition in } \\
\text { the GMO Act, which relates more directly to a 'modified or- } \\
\text { ganism". }\end{array}$ \\
\hline Genetic trait & $\begin{array}{l}\text { A characteristic such as size, shape, taste, colour, increased } \\
\text { yields, or disease resistance - also referred to, individually or } \\
\text { combined, as phenotype. }\end{array}$ \\
\hline \multirow[t]{2}{*}{$\begin{array}{l}\text { Genetically modified organism } \\
\text { (GMO) }\end{array}$} & $\begin{array}{l}\text { An organism, the genes or genetic material of which, have } \\
\text { been modified in a way that does not occur naturally through } \\
\text { mating or natural recombination or both, and 'genetic } \\
\text { modification' has a corresponding meaning (from GMO Act). }\end{array}$ \\
\hline & Note: Also see "genetic engineering". \\
\hline Genome & The entire complement of hereditary material in a cell. \\
\hline Genome editing & $\begin{array}{l}\text { The precise modification of the nucleotide sequence of a } \\
\text { genome. }\end{array}$ \\
\hline Genotype & $\begin{array}{l}\text { The genetic makeup of an organism or group of organisms } \\
\text { with reference to a single trait, a set of traits, or an entire } \\
\text { complex of traits. }\end{array}$ \\
\hline Harm & Suffering injury, damage, loss, or any adverse effect. \\
\hline Hazard (i.t.o. GMOs) & $\begin{array}{l}\text { An intrinsic biological, chemical or physical characteristic } \\
\text { of a genetically modified organism which could lead to an } \\
\text { adverse impact on the environment (from GMO Act). }\end{array}$ \\
\hline Hazard, harm \& risk summary & 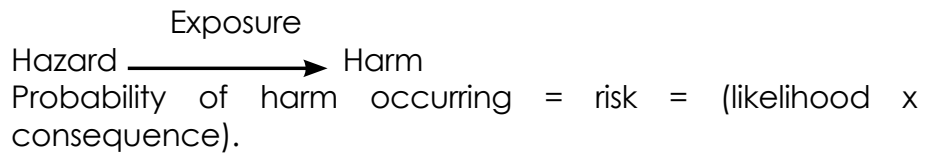 \\
\hline
\end{tabular}




\begin{tabular}{|c|c|}
\hline Heterologous genes & $\begin{array}{l}\text { A gene or part of a gene in a host organism, which does not } \\
\text { naturally have this gene or gene fragment. } \\
\text { Note: also see transgene and exogenous. }\end{array}$ \\
\hline Indel & A small insertion or deletion in a DNA sequence. \\
\hline Meiosis & $\begin{array}{l}\text { Cell division that produces reproductive cells (gametes) in } \\
\text { sexually reproducing organisms - the nucleus divides into four } \\
\text { nuclei each containing half the chromosome number ( } n \text { ), as } \\
\text { opposed to diploid ( } 2 n \text { ), somatic cells with two sets (one each } \\
\text { from each parent). }\end{array}$ \\
\hline miRNA & $\begin{array}{l}\text { Micro RNA - are small non-coding RNA molecules (containing } \\
\text { about } 22 \text { nucleotides) which have regulatory functions. }\end{array}$ \\
\hline Modern biotechnology & $\begin{array}{l}\text { The application of in vitro nucleic acid techniques, including } \\
\text { recombinant DNA and direct injection of nucleic acid into } \\
\text { cells or organelles or fusion of cells beyond the taxonomic } \\
\text { family. }\end{array}$ \\
\hline New breeding techniques & $\begin{array}{l}\text { A non-specific collective name for a wide and evolving } \\
\text { range of techniques aimed at modifying genomes and/or } \\
\text { gene expression. }\end{array}$ \\
\hline Null segregant & $\begin{array}{l}\text { Offspring in which the GM element used to engineer the } \\
\text { parent organism has been removed through conventional } \\
\text { breeding (GM traits are only used transiently). }\end{array}$ \\
\hline Open Reading Frame & $\begin{array}{l}\text { Part of a gene that has the potential to code for a protein or } \\
\text { peptide. }\end{array}$ \\
\hline Organism & $\begin{array}{l}\text { A biological entity, cellular or non-cellular, capable of me- } \\
\text { tabolism, replication, reproduction or of transferring genetic } \\
\text { material and includes micro-organisms. }\end{array}$ \\
\hline Phenotype & $\begin{array}{l}\text { The set of, or a specific, observable characteristic(s) of an } \\
\text { individual organism resulting from the interaction of its geno- } \\
\text { type with the environment. }\end{array}$ \\
\hline Pleiotropic & $\begin{array}{l}\text { When one gene influences two or more seemingly unrelated } \\
\text { phenotypic traits. }\end{array}$ \\
\hline Prokaryote & $\begin{array}{l}\text { A unicellular organism that lacks a distinct cell nucleus and } \\
\text { the DNA is not organised into chromosomes. It also lacks the } \\
\text { internal structures bound by membranes called organelles, } \\
\text { such as mitochondria. }\end{array}$ \\
\hline
\end{tabular}




\section{Recombinant DNA technology}

Reverse breeding

Risk management

RNA interference

Synthetic biology

Transgene
A series of procedures that are used to join together (recombine) DNA segments. A recombinant DNA molecule is constructed from segments of two or more different DNA molecules.

A novel breeding technique designed to produce homologous parental lines for a superior heterozygous plant. Subsequent hybridisation of the obtained homozygous parental lines will reconstitute the original superior heterozygous line.

Risk The probability of causing or incurring a loss or damage or an adverse impact or a misfortune (i.e. a harm).

A structured, reasoned process, based on the analysis of scientific evidence, for considering the likelihood and consequence of harm occurring.

The subjective judgement that people make about the characteristics and severity of a risk.

The evaluation of whether the risks identified by the risk assessment process are acceptable and manageable, then selecting and implementing the control measures as appropriate to ensure that risks are minimised or controlled.

RNA interference, or RNAi, refers to a set of biological processes that makes use of native cellular machinery to silence gene expression. Although there are several variations in the source and mechanism, they are all triggered by double-stranded RNA (dsRNA), with a sequence complementary to the gene targeted for silencing, which is processed by a protein complex into small, single stranded RNAs, i.e. small interfering RNA (siRNA).

A modern biotechnological approach that combines science, technology and engineering to facilitate the understanding, redesign, and/or modification of existing biological systems and components or the design and manufacture of new biological systems and components, based on the selective and purposeful use of genetic material. The application of synthetic biology principles results in novel biological systems and/or components thereof, including living organisms, cells, bio-molecules, pathways and/or assemblages thereof.

A heterologous gene that has been artificially inserted into the genome of an organism. 


\section{EXECUTIVE SUMMARY}

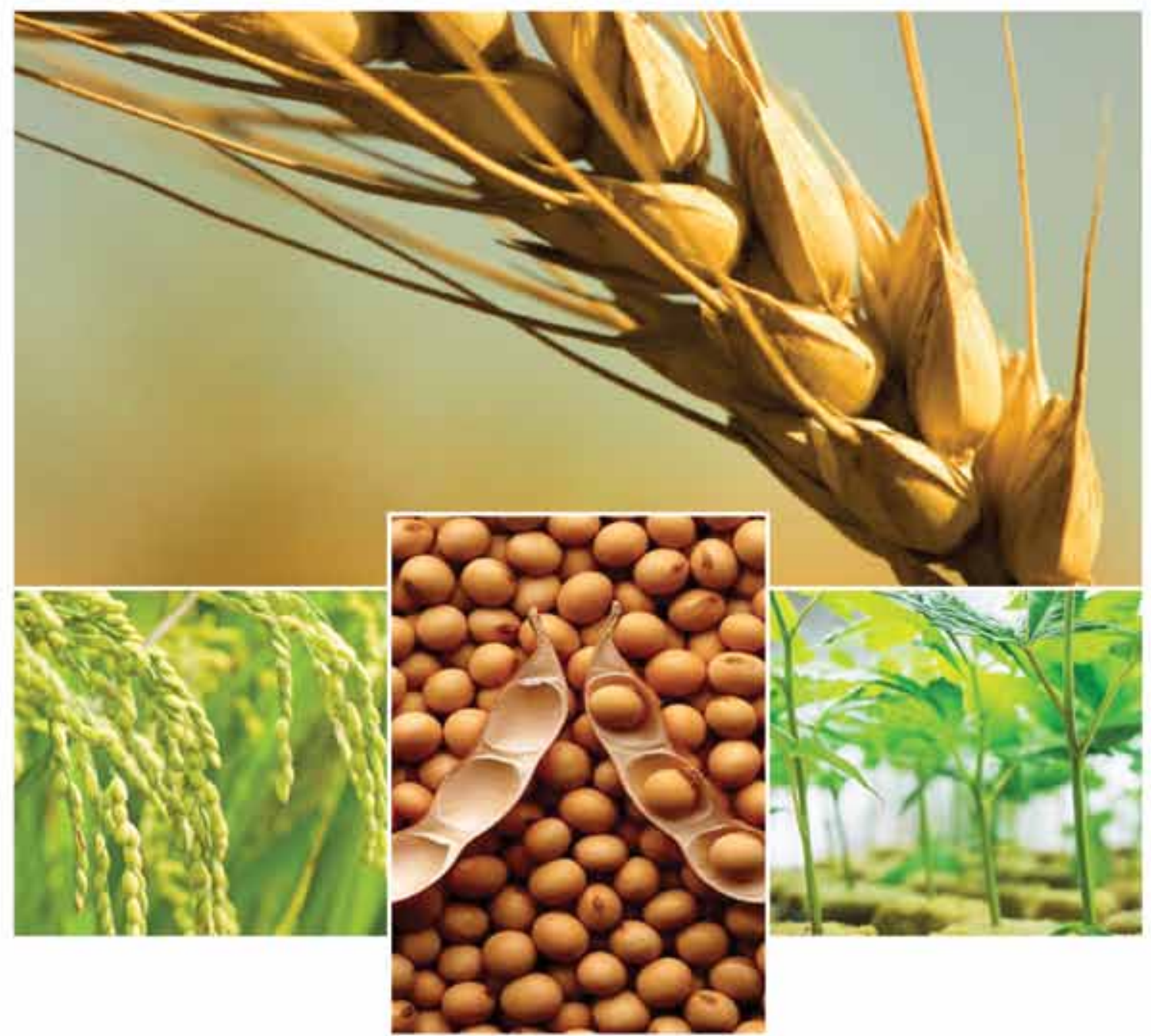


"New breeding techniques" (NBTs) are a wide and evolving range of techniques aimed at modifying genomes and/or gene expression and using these in particular ways on a wholeorganism level. It is becoming increasingly evident that these techniques hold great potential benefit in plant, animal and microbial breeding programmes. Indeed, the accessibility and utility of these techniques have already led to the commercialisation of the first products developed using these techniques. The conceptual and technical similarities and/or overlaps between these NBTs and genetic modification (GM) technology, which is regulated, have therefore initiated an international discussion on the regulatory status of these techniques and/ or their products. There is an urgent need to reach conclusions that will ensure the safety and sustainability of research, development and commercialisation work in this area as the field is developing rapidly. At the same time, it is important that regulations do not unintentionally inhibit innovation in the biotechnology sector.

This consensus study therefore examined the possible regulatory implications of NBTs within the South African context by considering the following:

- The relevance of NBTs to the South African biotechnology sector.

- The possible biosafety implications of NBTs.

- The possible fit (or differentiated fit) of these techniques and/or their products with existing GMO legislation.

- The robustness of the current biosafety risk analysis frameworks to accommodate these and possible future techniques and their products.

- The need for the GMO Act and its regulations to adapt in order to accommodate current and possible future genome modifying technologies.

The most critical findings of this study were:

- NBTs is a non-specific collective name for a wide and evolving range of techniques aimed at modifying genomes and/or gene expression, which have great potential as they allow the relatively quick, efficient, accurate and cost-effective modification of valuable genetic traits in crops, livestock and industrial microbes. These include gene editing techniques, null segregants, variations on genetic modification and transgrafting.

- Internationally, only Argentina has published an official, national framework on how to regulate the products of these techniques. In addition, in countries such as Canada, which has a strong product-base regulatory trigger, there is no need to make technique /process-based amendments. It is evident that the great majority of authors and organisations, who have considered this issue, consider the principle of case-by-case decision-making as an important component of any framework.

- When dealing with any type of genome modification, the principal source of risk, i.e. hazard, is the organism whose genome has been changed, i.e. the product, and not the process or techniques through which these changes were induced. This resulting product should therefore be the trigger and subject of regulation, i.e. risk management practices, and the regulatory requirements should be proportional to the possible risks it poses. 
- South Africa has a robust and experienced regulatory system for GMOs, which can without much change be applied to also effectively regulate the products of these new techniques and, in fact, any genome modifying techniques that may still be developed in the future. The key for allowing this is that the GMO Act (Act15 of 1997), as it stands,

- has a product-based trigger,

- sets genetic variation beyond that which may also occur naturally as the threshold for regulation.

- Applying the suggested framework will result in the products of NBTs simply being classified as either GMOs, which will be regulated under the GMO Act as per usual, or non-GMOs that will not be subject to regulation under this Act. The introduction of a succinct 'notification procedure' will ensure a mechanism allowing case-by-case decisions and appropriate oversight.

- The likely regulatory outcomes of the suggested framework are very well aligned with the currently available consensus discussions of other international risk assessment and relevant regulatory experts. Its implementation will ensure effective and appropriate oversight to ensure the safety and sustainability of all relevant products, without unduly impacting on innovation.

- Finally, it is also important to note that this study has NOT considered in detail all the possible practical regulatory and legal implications of the scientific recommendations made here, as these are the prerogative of the relevant regulators and therefore fall outside the mandate and expertise of this panel. All relevant technical legal and practical regulatory issues therefore still have to be considered by the appropriate authorities, including legal opinion on the science-based interpretation of definitions and associated implications, alignment with the Cartagena Protocol on Biosafety and international harmonisation.

This consensus study panel is of the opinion that the implementation of the recommendations contained in this report will provide effective and appropriate oversight to ensure the safety and sustainability of all relevant products, without unduly impacting on bio-innovation as encouraged in the Bioeconomy Strategy. It can also be implemented relatively quickly and easily, because it is based on established legislation. Finally, although very few countries have officially implemented NBT regulations, the likely regulatory outcomes of the proposed approach align very well with the consensus discussions of other international experts. 



\section{CHAPTER 1 \\ Introduction \\ and Background}
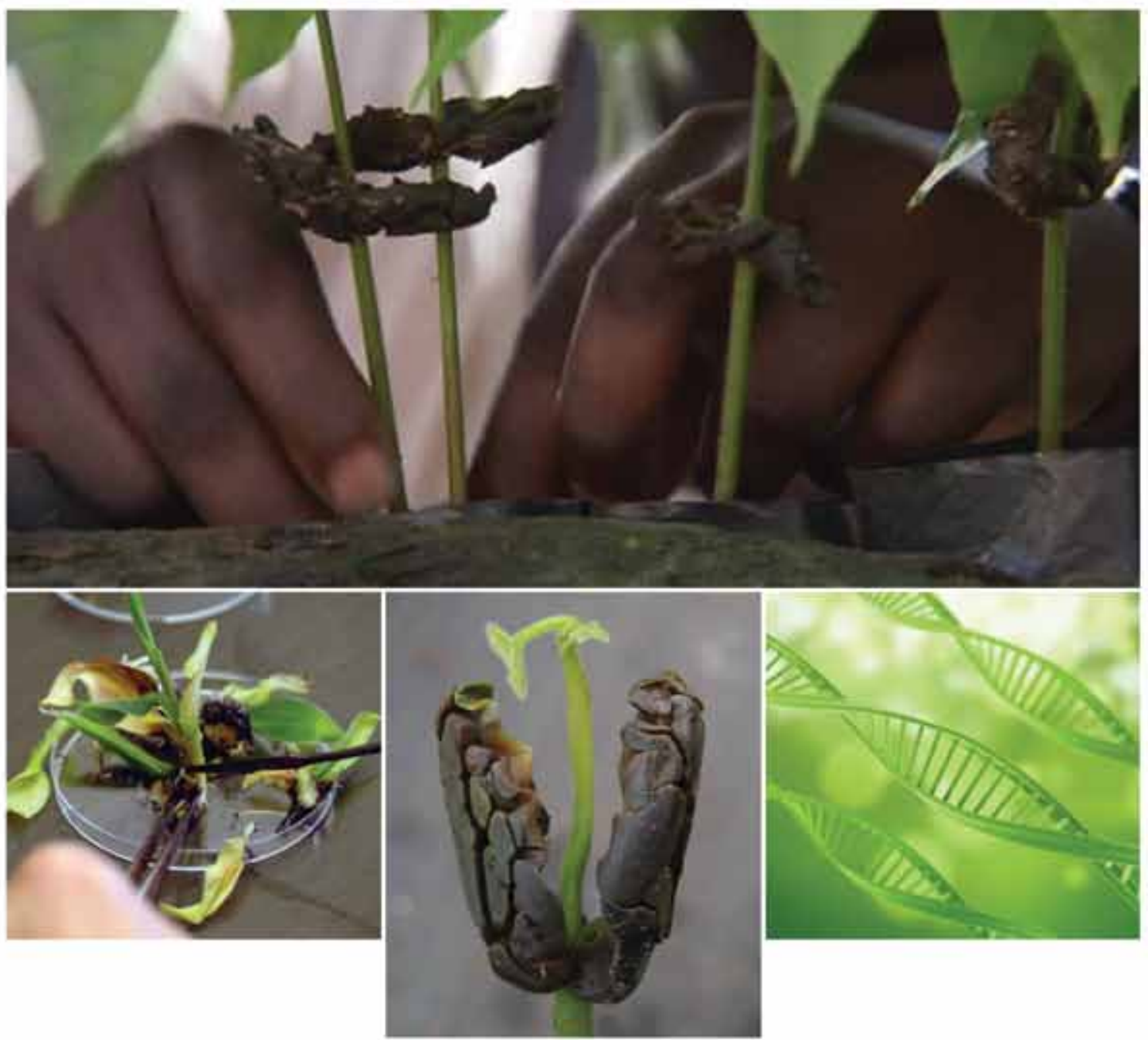


\subsection{Introduction}

Recent scientific and technological advances have led to the development of new techniques in animal, plant and microbial breeding, jointly referred to as new breeding techniques (NBTs). In turn, this has led to discussions as to whether these techniques may result in products that are subject to the regulatory framework applicable to genetically modified organisms (GMOs). Since South Africa is in the process of developing an official position with regard to the possible regulatory status of NBTs, it will be valuable to review the most commonly used NBTs, the national and relevant international frameworks for the regulation of GMOs and other countries' approaches to this issue, to provide insight into the possible regulatory status and approaches to these NBTs and their products.

The technologies originally used to develop transgenics - using viral vectors, T-DNA plasmids or "biolistics"/"gene guns" - were relatively crude techniques and were the most common methods for performing direct genetic modification when South Africa's GMO Act (Act 15 of 1997) was written. Since then molecular biology has developed a variety of new genome modification techniques. These include various tools for genome editing (such as zinc-finger nucleases (ZFNs), transcription activator-like effector nucleases (TALENs) and, in particular, clustered regularly-interspersed short palindromic repeats (CRISPR) that are more precise and predictable.

Consideration of new biotechnologies and the possible regulatory measures to which they may be subject is a necessary and ongoing process for three main reasons:

- to consider the possible evolving biosafety implications of these new techniques;

- to reflect on how regulatory frameworks may have to adapt to accommodate possible new products and/or techniques to ensure their sustainable development and use;

- to help ensure South Africa benefits from appropriate new biotechnologies that could make the country more competitive, create sustainable jobs, enhance food security and create a greener economy as contemplated in the National Government's Bioeconomy Strategy of 2013 (pp 6-8).

Given its role of providing objective, evidence-based scientific advice to the South African government and increasing public awareness of science, the Academy of Science of South Africa (ASSAf) is well placed to meet the challenge of providing objective advice on NBTs. This consensus study could also be used as a valuable guide by regulators and policymakers in other African countries on how to make informed decisions on the development, introduction and use of NBTs.

\subsection{Background}

Plant breeding started more than 10000 years ago when farmers began to select and multiply the best plants in their fields. Farmers domesticated crops through the continued selection and breeding of desirable traits. A major breakthrough in plant breeding occurred in 1865, when Gregor Mendel presented the results of his experiments on plant hybridisation at two meetings of the Natural History Society of Brno in Moravia. His discovery of the laws of genetics and the process of cross-breeding was followed by hybrid breeding in the 1930s, tissue and cell culture methods in the 1960s and recombinant DNA techniques and genetic engineering in the 1980s. However, the development of each subsequent new technique 
has not resulted in the older breeding methods being abandoned - in fact modern plant and animal breeders still use the full range of breeding techniques available to achieve their goals.

Plant breeding makes use of the natural variation in plant genomes which is an essential driver for plants to adapt to their changing environments. This variation has resulted in a wide variety of crops with a long history of safe use. Modern varieties of maize, wheat and rice are dramatic examples of the end result of human selection on agricultural crops. Improvement of the most desirable agronomic and yield enhancing traits has resulted in crop varieties that are safe, robust, and capable of growing under a wide range of environmental conditions

In addition, the use of advanced breeding techniques such as mutagenesis, ploidy manipulation and somatic hybridisation has introduced more useful genetic variation. Mutation breeding alone, which introduces additional genetic variation via radiation or chemical mutagenesis, has resulted in the development of more than 3200 improved crop varieties, which have been safely cultivated and consumed over the past 100 years. This long history of safe use of plant varieties produced by exploiting their natural endogenous and inducible endogenous genetic variation has demonstrated that the application of these techniques does not pose inherent safety hazards and they have therefore not been regulated.

The development of genetic engineering (GE) techniques for the first time enabled the routine transfer of genetic material across the sexual compatibility barrier. Consequently, the introduction of the first genetically modified (GM) crops in the early 1990s raised novel biosafety questions that subjected these products to specific regulations aimed at ensuring their food and feed safety, environmental safety and eventually even their socio-economic viability before they are commercially produced.

New risk analysis methods had to be developed to analyse these complex, living systems, as previous risk assessment methodologies were based on simple single compound, doseeffects. GMO risk analysis has evolved over the past 20 years into an effective tool based on the contextualised, comparative analysis of these organisms and their products; taking the nature of the introduced genetic sequences (the trait(s)), the characteristics of the crop and the receiving environment into consideration. Again, the absence of any documented evidence of unexpected adverse effects caused by GM crops over the past 20 years confirms the above conclusion that the exploitation of genetic potential is not inherently dangerous when applied in conjunction with robust regulatory and risk analysis frameworks. 


\section{THE HISTORY OF GMO REGULATION}

The development of a regulatory framework for genetic engineering began in 1975 at Asilomar, California. The first recombinant DNA techniques had just been developed and the scientific community recognised that apart from its benefits, this technology could also pose some risks to the environment and human health. The Asilomar meeting recommended a set of guidelines for the safe use of recombinant technology and any products produced by it. Initially, the Asilomar recommendations were voluntary, but in 1976, the United States of America's (USA) National Institute of Health (NIH) formed a rDNA advisory committee to regulate the technology.

In 1982, as the first transgenic plants were being developed, the Organisation for Economic Co-operation and Development (OECD) released a report on the potential hazards of releasing GMOs into the environment. The USA established a committee at the Office of Science and Technology Policy (OSTP) to develop mechanisms to regulate the developing technology and in 1986, the OSTP assigned regulatory approval of genetically modified plants in the USA to the United States Department of Agriculture (USDA), Environmental Protection Agency (EPA) and Food and Drug Administration (FDA) (OSTP, 1992).

South Africa's GMO regulatory system has its origins in the now defunct South African Committee on Genetic Experimentation (SAGENE), initiated and led by the research community, which governed research and development (R\&D) on GMOs from 1979. SAGENE was, for example, mandated in 1987 to advise on the possible effects of release into the environment of organisms with recombinant DNA (Government Gazette No 10535, Notice 532). The South African biosafety regulatory framework was formalised in 1999 in the form of the GMO Act (Act 15 of 1997), which allowed South Africa to be an early adopter of GM technology, with the first commercial planting of a GM crop in 1998. The Act and regulations have since been amended (2006) to accommodate the provisions of the Cartagena Protocol on Biosafety and the overall biosafety regulatory system expanded to include aspects regulated under health, environmental and trade legislation.

On 29 January 2000, the Conference of the Parties to the Convention on Biological Diversity adopted a supplementary agreement to the Convention known as the Cartagena Protocol on Biosafety. This Protocol is an international treaty that governs the transfer, handling, and use of GMOs. 170 countries, including South Africa, are now Parties to the Protocol and many use it as a reference point for their own GM legislation.

Until recently, whether a new product was considered a GMO, and therefore regulated, or not, was a relatively simple matter for regulators and biotechnology developers. NonGMOs were obtained by some or other historical breeding technique, which only exploits endogenous genetic potential - collectively classified as "conventional breeding" - while a GMO was defined as an organism that possessed a novel combination of genetic material, i.e. includes heterologous genetic material, obtained through the use of modern biotechnology. In the South African context (the GMO Act), GMOs were defined as "organisms the genetic material of which has been modified in a way that does not occur naturally" to introduce "unnatural genetic variation" as the threshold for regulation. The more recent development of the so-called "new breeding techniques" (NBTs) that started in the late 1990s with the use of molecular markers, genome mapping and sequencing, has however blurred these lines somewhat. 
NBTs is a non-specific collective name for a wide, evolving and expanding range of techniques aimed at modifying genomes and gene expression, and which are based on the advances made in genetics and molecular biology research and technology developments over the past 20 years. They can be used to introduce, remove or modify desired genetic traits more precisely and in less time than with conventional breeding or first-generation GMtechnology in a wide variety of organisms. The end result of these interventions can range from small insertions and deletions, indistinguishable from those that may occur naturally, to the introduction of multiple exogenous genes. Some of these techniques hold huge potential benefit as they would allow the relatively quick, efficient, accurate and cost-effective modification of valuable genetic traits in crops, livestock, industrial micro-organisms, etc. improving on many of the negative aspects associated with both conventional breeding and first-generation GM-technology. This will allow the breeding programmes of less affluent organisations, such as those in the public sector, and those for small, locally-relevant crops, livestock, etc. access to a technology that has the potential to be transformative, especially within a developing world context.

Unfortunately, the current lack of clarity on what regulatory control may be applicable to (some) NBTs is hampering investment in their development and application. Even in countries that do have functioning GMO policy and regulatory frameworks in place, the handling of these techniques and their products is not clear-cut, due to their diverse and varied nature. The great majority of countries are still debating the issue internally and have not yet drawn policy conclusions or established possible regulatory criteria. To date, only Argentina has formalised its regulatory approach to NBTs as (i) "triggered by the novel combination of genetic material" (and then regulated as a GMO) and (ii) "handled on a case-by-case basis" (to allow an acceptable level of flexibility while technologies evolve) (Whelan and Lema, 2015).

It is very important that the possible regulation of NBTs is considered as a matter of urgency and that countries worldwide harmonise their approach to this challenge. Harmonisation is necessary to prevent arbitrary decisions from creating regional and international asymmetries in scientific and technical development and barriers to trade that will limit farmers' and consumers' access to new opportunities and products. It should also be appreciated that disjointed and excessive regulatory approaches can impact risk perceptions, unduly raise public concern and negatively impact the application of beneficial technologies. Broadbrush regulation and oversight based on technique/process only, could result in undue, costly regulatory burdens, stifle innovation and prevent the uptake of scientifically advanced, innovative breeding applications by the public and private sectors. Due consideration should therefore be given to the actual source and the contextualised magnitude of potential risk when considering the regulation of NBTs.

\subsubsection{Approach and Methodology}

This study on regulatory implications of new genetic engineering technologies was commissioned by the DST. A six-member panel, chaired by Dr Hennie Groenewald, was appointed by the ASSAf Council to undertake the study. Biographies of the panel members are attached as Appendix 1. The panel was supported in its investigations by a researcher, $\mathrm{Dr}$ Dave Keetch, of Goldamer Consulting. 
The study was conducted between May 2015 and January 2017. A consultative workshop was held on 11 October 2016 in Pretoria. The workshop was attended by 22 key stakeholders from different organisations/institutions and government departments (See Appendix 2). The workshop discussions enriched this study.

The final draft report was submitted for peer review in mid-January 2017. Following the peer-review process by three experts, Dr Jane Morris of Morris Life Science Consulting, Prof Diran Makinde of African Biosafety Network of Expertise (ABNE) and Prof Stuart Smyth of the University of Saskatchewan Canada, the panel finalised the report and it was approved by the Executive Committee of the ASSAf Council in March 2017.

\section{Panel Membership}

\begin{tabular}{|l|l|}
\hline Panel Members & Affiliated Organisations/Institutions \\
\hline Dr Hennie Groenewald & Biosafety South Africa, Technology Innovation Agency \\
\hline Dr Eugenia Barros & Council for Scientific and Industrial Research (CSIR) \\
\hline Dr Kingston Mashingaidze & Agricultural Research Council (ARC) \\
\hline Prof labal Parker & University of Cape Town (UCT) \\
\hline Dr James Southern & Retired and Independent Consultant \\
\hline
\end{tabular}

\subsubsection{Rationale for Study}

The rationale for the study stems from recent scientific and technological advances that have led to the development of multiple new technologies involving genetic modification (GM) and the need to ensure that appropriate policies and regulations are in place to address biosafety requirements.

Originally, the technologies developed to perform genetic engineering - using viral vectors, T-DNA plasmids or 'biolistics'/'gene guns' - were relatively crude techniques and were the most common methods for performing direct genetic modification when the South African GMO Act (Act 15 of 1997) was written. The conceptual approach underpinning the Act was 'substantial equivalence', i.e. not being substantially different from the non-modified counterpart.

Since the emergence of recombinant DNA technology in the 1990s, molecular biology has developed a variety of new genetic modification techniques. These include various tools for genome editing such as zinc-finger nucleases (ZFNs), transcription activator-like effector nucleases (TALENs) and, in particular, clustered regularly interspersed short palindromic repeats (CRISPR) that are even more precise and predictable.

The consideration of regulatory controls for new technologies is thus a necessary and ongoing process for two main reasons:

- to identify the possible biosafety implications ("risks") of these new techniques;

- to ensure the regulatory requirements are appropriate to the technologies and/or 
products so as not to unduly constrain research, development and use of these products in South Africa.

Given its role of providing objective, evidence-based scientific advice to the South African government and increasing public awareness of science, ASSAf is well placed to meet the challenge of providing objective advice on biosafety implications and appropriate policy responses. This consensus study could also be used as a valuable guide by regulators and policymakers in other African countries on how to make informed decisions on the development, introduction and use of these new technologies.

\subsubsection{Study Brief}

The terms of reference of the study were to:

- Consider the relevance of NBTs to the South African biotechnology sector.

- Interrogate the possible biosafety implications of NBTs.

- Determine their fit with the existing GMO Act, specifying which of these new techniques and/or their products should fall under the GMO Act and which should not.

- Determine the robustness of current biosafety risk analysis frameworks to accommodate these new techniques and their products.

- Provide recommendations on how the GMO Act and its regulations may have to adapt to be able to accommodate current and possible future genome modifying technologies.

Topics that were considered and deemed to fall outside the scope of this study, for the reasons provided, are as follows:

- The ethics related to the application of NBTs

All biotechnology research, development and application are already subject to wellestablished ethics frameworks. As NBTs were considered to not present any immediate novel ethical implication, irrespective of the nature of any regulatory recommendations that may emanate from this study, it was decided to focus on the regulatory implications only.

- Synthetic biology

Although the regulation of synthetic biology is also currently discussed internationally, its goals, techniques and products are significantly different from those of NBTs and was therefore not considered. In addition, current applications are all clearly subject to existing GMO regulatory frameworks

- Gene drives

A gene drive is a designed outcome of a genetic intervention at a population level, rather than a genetic modification technique per se. It is also targeted at wild populations and not at domesticated or industrial organisms. Finally, current gene drive techniques necessitate the use of heterologous gene sequences, which subject these organisms to GMO regulation. 



\section{CHAPTER 2}

\section{The Evolution of Crop \\ Breeding Techniques}

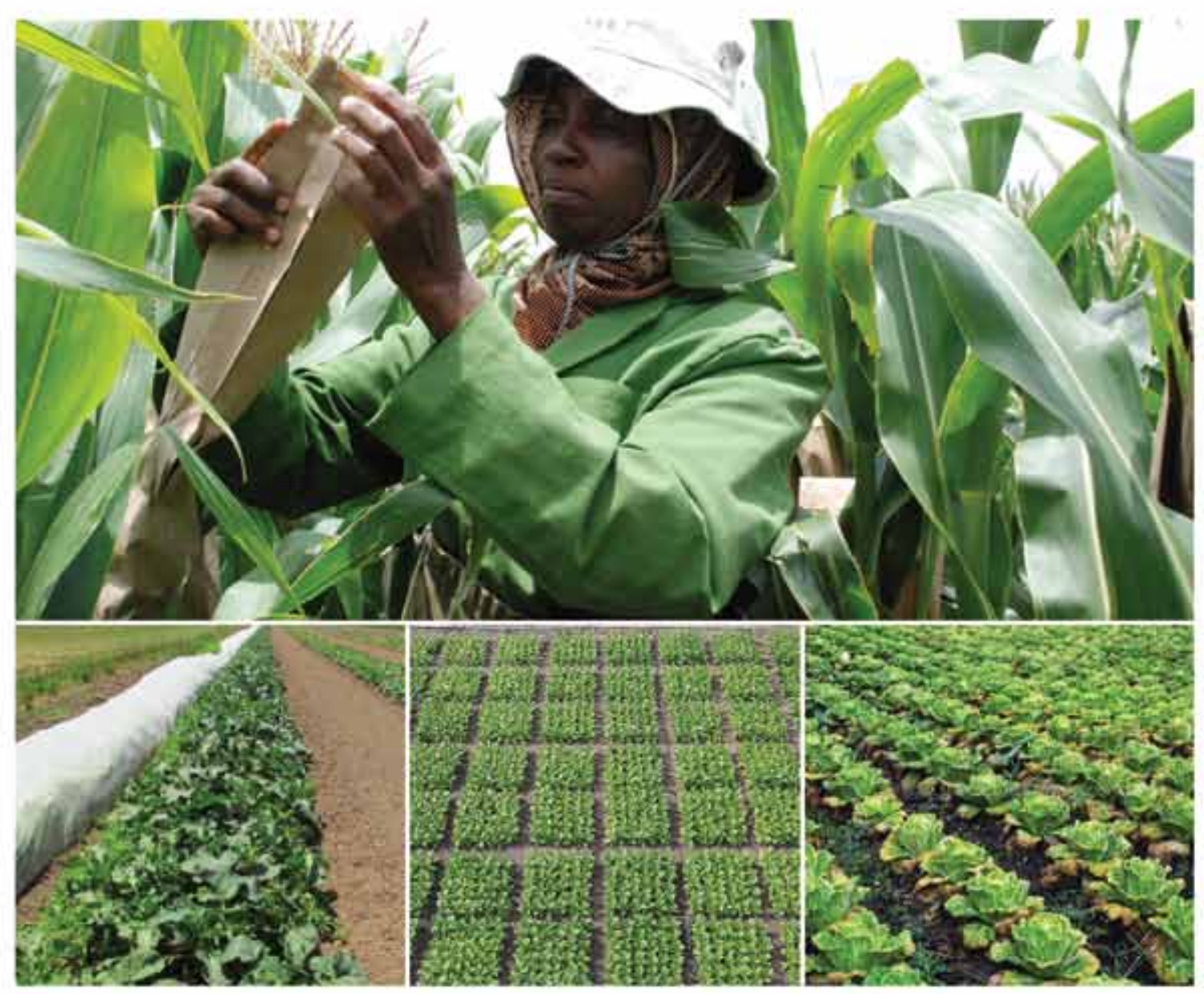




\subsection{Introduction}

It is widely believed that all foods developed by conventional breeding are 'natural' and 'safe' and, unlike GM foods, have not been modified by human intervention. However, genetic and phenotypic modification of food began as soon as humans started domesticating plants many thousands of years ago. Early farmers started saving seeds from plants that demonstrated useful traits such as size, taste, resistance to pests and disease and yield. Selected crops were then further improved by cross-breeding with related species, mutational breeding and/or hybridisation, which resulted in large-scale changes to the respective crops' genomes. As a result, none of the plant-based foods that we eat today existed in their current form before humans intervened and they have very little in common with the foods consumed by society many thousands of years ago. For example, wild maize was bred from a grass called Teosinte that originated in southern Mexico. Teosinte is composed of about a dozen small seeds in hard shells which are unpalatable. Wild potatoes originated from South America and were thin finger-like tubers with a bitter taste. Similarly, cauliflower, broccoli, kale, Brussels sprouts and cabbage have all been bred from wild mustard plants found in the northern Mediterranean region.

A brief, chronological overview of various crop breeding techniques follows to give some insights into the relevant underlying principles, constraints, impacts and evolution of mankind's endeavours to modify the traits, and the underlying genomes, of crop plants over the ages.

\subsection{Conventional Breeding}

Regulatory Status: EXEMPT FROM REGULATION

The breakthrough that enabled modern plant breeding occurred in 1865, when Gregor Mendel presented the results of his experiments on plant hybridisation at two meetings of the Natural History Society of Brno in Moravia. His discovery of the laws of genetics and the process of cross-breeding formed the basis of conventional breeding. In principle, parents with desirable traits are selected and crossed to yield offspring with variable combinations of those traits. Mendel's laws of segregation and independent assortment help breeders to understand the genetic principles behind their phenotypic observations and enabled them to breed crop plant varieties with desired traits more effectively. Because conventional breeding depends on sexual reproduction, its application is principally limited to sexually compatible individuals. Exploitable genetic potential is therefore limited to the natural endogenous genetic variation within closely related species that can interbreed. Genetic linkage, i.e. the fact that some genes are physically connected to each other, also results in a situation where 'beneficial' and 'detrimental' traits cannot always be separated from each other.

\subsection{Hybrid Seed Technology}

Regulatory status: EXEMPT FROM REGULATION

Hybrid seed development was one of the main contributors to the dramatic rise in agricultural output during the last half of the $20^{\text {th }}$ century and is based on the fact that plant crops, highly heterozygous for desired traits, perform very well. Elite, inbred parent lines that are highly homologous for desirable traits are developed and then crossed to produce a highly heterozygous, uniform population of $\mathrm{Fl}$ hybrid seed. Hybrids were used to dramatically improve crop traits such as yield, resistance to pests and diseases, grain uniformity, colour 
and time to maturity. Producing hybrids that are commercially viable can take many years to achieve but the end results can be impressive. Maize hybrids have been developed that together with improved farming practices have more than tripled maize grain yields over the past 50 years, while hybrid rice offers the possibility of increasing rice yields by up to $20 \%$.

\title{
2.4 Mutation Breeding, Ploidy Manipulation and Hybridisation
}

\author{
Regulatory status: EXEMPT FROM REGULATION
}

Random mutations in genomes are a source of natural genetic variation, but these occur only at very low frequency. Plant breeders have therefore developed techniques, e.g. exposure to high-energy radiation or certain chemicals such as sodium azide and ethyl methanesulphonate, to artificially induce random mutations, which may, in turn, result in desired phenotype changes. These techniques were popular in the 1940s when plants were exposed to a variety of radiation sources to induce random mutations in an attempt to produce more useful traits. Although generally considered to be a technique with very low efficiency, these mutation techniques are still being used today - of the approximately 2300 officially released mutation breeding varieties, almost half have been released over the past 15 years. Crops as diverse as ruby grapefruit, rice, sunflowers and pears have benefited from mutation breeding.

Ploidy refers to the number of sets of chromosomes in a cell. Gametes or germ cells, i.e. egg cells, sperm and pollen, are haploid - containing a single copy of each chromosome or a single full set of chromosomes. Consequently, when two gametes fuse during fertilisation, the newly formed zygote and all subsequent somatic cells will contain two copies of each chromosome and are therefore diploid. Manipulation of the ploidy number during breeding can yield organisms with multiple copies of its chromosomes, e.g. tetraploids (four copies, for example cotton) and hexaploids (six copies, for example wheat), with a wide variety of improved traits. Triploid (three copies) organisms are usually infertile because of their unequal number of chromosomes and have yielded products such as seedless watermelons and bananas.

Hybridisation generally refers to the breeding of two genetically distinct individuals, e.g. different breeds, varieties, species or genera, which usually results in offspring with a high degree of heterozygosity. Hybridisation breeding is often used to increase the genetic variation within a breeding population by crossing individuals with different genetic backgrounds, but which are still compatible. Plant tissue culture techniques have also made cellular hybridisation possible, which allows for the hybridisation of even more distantly related individuals via protoplast fusion and subsequent regeneration.

\subsection{Marker-Assisted Selection (MAS)}

Regulatory status: EXEMPT FROM REGULATION

Molecular markers are breeding tools that are particularly valuable for selecting recessive or stacked traits where phenotypic selection is not practically possible, e.g. multiple resistant genes cannot be selected for when the phenotypes overlap. A molecular maker is an arbitrary fragment of genetic material that can be 'genetically linked' to a specific genetic trait, i.e. it segregates with the trait since it is physically linked to the gene(s) of interest. The theory is that if the molecular marker is present then the desired gene(s) and therefore the trait is also present. For example, more than 40 genes that provide resistance to major tomato diseases have already been identified and through the use of MAS, this has resulted in a large selection of tomato varieties with resistance or tolerance to several pathogens. 


\subsection{Recombinant DNA Technology and Genetically Modified Organisms (GMOs)}

Regulatory status: REGULATED

Traditionally, a plant breeder exchanges genes between two sexually compatible plants to produce offspring that have desired traits - a male (pollen) haploid genome is combined with a female (egg cell) haploid genome during fertilisation to produce a new, genetically unique, diploid individual. This cross breeding, however, is limited to exchanges between the same or very closely related species; always resulting in a lot of variability because two complete genomes are integrated and undesirable traits may be linked to desirable ones.

Recombinant DNA technology allows the isolation and multiplication of individual genes (cloning), their pairing with selected regulatory sequences (recombination) and the transfer of such a functional genetic unit to a living plant cell (transformation), which can then be developed (regenerated) into a new, transgenic plant. These transgenic, or GM individuals then have a phenotype consistent with that of the original recipient plant plus the additional trait encoded for by the new transgene. GM technology enables plant breeders to introduce genes from any living organisms into crop plants, irrespective of their sexual compatibility. It is therefore a very powerful breeding tool that allows plant breeders to generate superior plant varieties with trait combinations beyond the limits imposed by conventional plant breeding.

\section{SELECTED HIGHLIGHTS OF THE IMPACT OF GM CROPS}

An analysis of 147 studies over the last 20 years reported that "on average, GM technology adoption has reduced chemical pesticide use by $37 \%$, increased crop yields by $22 \%$, and increased farmer profits by $68 \% "$. These findings are supported by the results of other global studies. From 1996 to 2014, biotech crops contributed to food security, sustainability and the reduction of environmental impact by: increasing crop production valued at US $\$ 150$ billion; providing a better environment by saving 584 million $\mathrm{kg}$ of pesticides; reducing $\mathrm{CO}_{2}$ emissions; conserving biodiversity by saving 152 million ha of land from cultivation; and helped alleviate poverty for $\sim 16.5$ million resource-poor farmers and their families totalling $\sim 65$ million people.

Source: ISAAA Brief 51-2015: Top Ten Facts about Biotech/GM Crops in their First 20 Years, 1996 to 2015.

The continued development and use of genetic engineering technologies in research and development has also led to the discovery and elucidation of many biological processes, which now form the basis for biotechnology innovations. RNA interference, or RNAi, in particular, is one such process with huge potential application. It refers to a collection of biological processes that makes use of native cellular machinery to silence gene expression. Although there are several variations in the source and mechanism, they are all triggered by double-stranded RNA (dsRNA), with a sequence complementary to the gene targeted for silencing. The ability to specifically down-regulate gene expression has many potential applications and has already been used to develop novel crops such as nicotine-free tobacco, decaffeinated coffee, nutrient-fortified and hypoallergenic crops and the commercially released low-acrylamide potatoes and non-browning apples.

In 1994, Calgene's delayed-ripening tomato (Flavr-Savr'M) became the first GM food crop to be produced and consumed. Today, GM varieties of maize, cotton, soybean and canola are planted by 18 million farmers in 28 countries and on 180 million hectares per annum. Ninety per cent of these farmers are resource-poor farmers in developing countries. 


\subsection{Genome Editing}

Regulatory status: UNDETERMINED

Genome editing refers to the precise modification of the nucleotide sequence of a genome and forms part of the so-called NBTs. Genome editing techniques started to develop in the late 1990s with the discovery of homing and zinc-finger endonucleases, which can direct DNA cleavage to very specific sites within a genome. While GM transformation techniques such as Agrobacterium and particle gun-mediated gene transfer depend on the random insertion of the transgene into the genome, the newly developed genome editing tools can direct insertions, replacements or deletions to specific sites within the genome. The site-specificity of these nucleases is achieved through sequence-specific protein-DNA or DNA-DNA interactions.

The three main genome editing tools that are currently being used are ZFNs, TALENs and the clustered regularly interspaced short palindromic repeats/Cas9 nuclease system (CRISPR/ Cas). These tools can be used to replace an aberrant gene sequence, delete specific sequences, introduce mutations, including base substitutions, insertions and deletion, or to insert new genes. Genome editing interventions can therefore result in widely different genetic outcomes, including some that are indistinguishable from those that can occur naturally.

\subsection{Synthetic Biology}

Regulatory status: UNDETERMINED

Its novelty, multi-disciplinarity and integrated nature and current, limited application results in synthetic biology being a vaguely defined entity. Little international consensus exists regarding the character and scope of synthetic biology and there is no universally acceptable definition. What is clear though is that synthetic biology is not a technique or tool, but rather a modern biotechnological approach that combines science, technology and engineering to facilitate the understanding, redesign, and/or modification of existing biological systems and components or the design and manufacture of new biological systems and components, based on the selective and purposeful use of genetic material. The application of synthetic biology principles results in novel biological systems and/or components thereof, including living organisms, cells, bio-molecules, pathways and/or assemblages thereof.

One of the goals of synthetic biology is the preparation of viable minimal genomes which will function as platforms for the biochemical production of chemicals with economic value. The production of biofuels, pharmaceuticals and the bioremediation of environmental pollution are expected to constitute the first commercial applications of this new technique. As a first step towards this goal, the genome of Mycoplasma genitalium, the smallest known bacterial genome, was assembled from commercially synthesised pieces in 2010 (Gibson et al., 2010).

Theoretically, the principles and tools of synthetic biology can be used to develop a wide spectrum of possible products, from simple in vitro biological pathways, originating from natural biological systems to completely artificial organisms. It is therefore not possible to consider/manage/regulate 'synthetic biology' effectively as a single entity. It is possible products will have to be grouped based on more relevant considerations and managed as such, i.e. a product-based approach. Moreover, there is at least some overlap between synthetic biology's possible products and those from other breeding techniques as discussed above. Synthetic biology will therefore also not form part of the further work of this consensus study. 


\subsection{Conclusion}

The techniques used to breed new varieties of plants and animals have evolved over many thousands of years from the simple selection and multiplication of naturally occurring genetic variation, through hybridisation, mutation breeding, marker-assisted selection, recombination DNA technology (GMOs) and more recently, genome editing. More recently developed techniques also increased the speed, accuracy and scope of genetic variation induction. During this evolutionary process, only GMOs have been subjected to strict regulatory control. Stakeholders must now consider to what extent the recently developed NBTs and/or their products should be regulated or excluded from regulation. 


\section{CHAPTER 3 \\ Overview of New \\ Breeding Techniques}

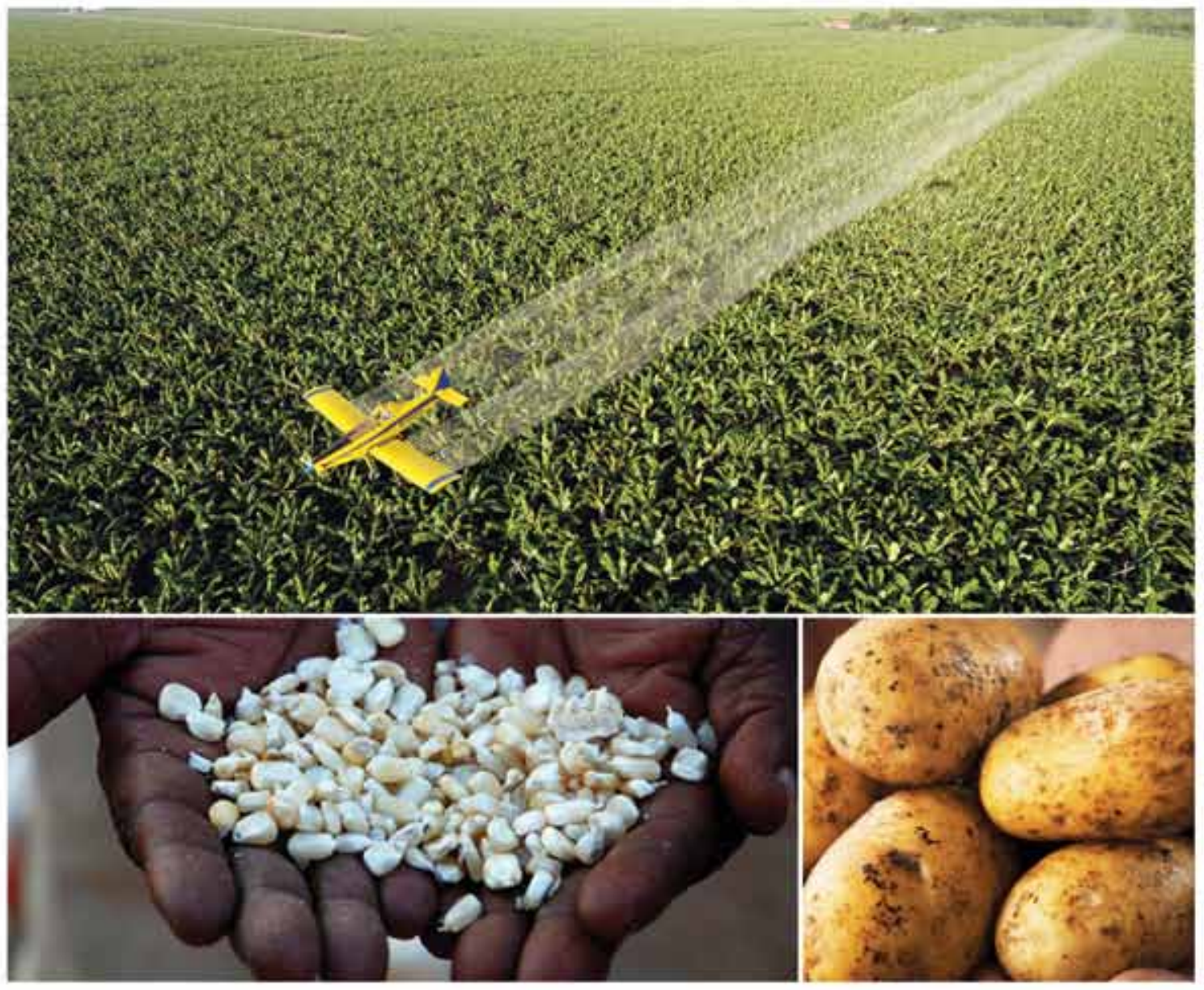




\subsection{Introduction}

Some variants of the techniques mentioned here are standard for the genetic modification of plants, animals and micro-organisms, although the term NBT is currently seldom used beyond plant breeding because of:

- the regulatory debate on the relationship of NBTs to plant products and GM plants which is more developed and sophisticated;

- the increasing quantity and variety of such products continually being submitted to regulatory authorities worldwide for evaluation.

Nevertheless, it is important to note that in most cases, regulatory frameworks begin with the same definition of GMOs irrespective of the biological kingdom.

As defined before, the term NBTs is a non-specific collective name for a wide and evolving range of techniques and approaches aimed at modifying genomes and gene expression. NBTs can be divided into the following three, non-exclusive categories:

\section{(1) Genome Editing/Targeted Mutagenesis}

Site-directed nucleases (SDNs)

SDNs, often also referred to as sequence-specific nuclease (SSN), use naturally occurring endonucleases to generate a double-strand break at an exact pre-defined location in the DNA. The subsequent repair of the break can then be directed to create a variety of targeted DNA sequence modifications, ranging from small deletions to the insertion of genes. SDN applications can be divided into three types:

In SDN-1 no donor DNA template is supplied that forces non-homologous end-joining (NHEJ), enabled by the naturally occurring DNA repair mechanisms. In most cases NHEJ introduces small insertions or deletions (indels) that lead to a loss in gene function, i.e. targeted gene knockouts.

In SDN-2 applications, a homologous donor DNA template, which is a copy of the target gene sequence with only a small modification, is used. During repair, this homologous, modified sequence will be introduced into the genome, causing a targeted mutation, which could restore or modify gene function.

SDN-3 applications are similar to SDN-2 applications, except that in this case the homologous donor DNA includes (a) complete gene sequence(s) - these could be cis-, intra- and/or transgene sequences. SDN-2 and 3 therefore enable targeted gene knock-ins.

Four main engineered nuclease families or 'SDN tools' have been developed, namely:

a) Zinc-Finger Nucleases (ZFNs).

b) Meganucleases (MNs).

c) Transcription activator-like effector nucleases (TALENs).

d) Clustered regularly interspaced short palindromic repeats/Cas9 nuclease system (CRISPR/Cas). 
An oligonucleotide (a small single strand DNA molecule) with a desirable point mutation, similar to the SND-2 donor DNA, is introduced into an animal cell or plant protoplast and incorporated into the target gene via the native DNA repair mechanisms of the cell.

$$
\text { Null (Negative) Segregants: }
$$

A genetically modified 'intermediate' plant is used in the breeding process, but the progeny released is lacking the transgene/GM event, e.g. reverse breeding, early flowering, etc.

RNA-dependent DNA Methylation (RdDM) in which the released variety inherits an epigenetic modification, but not any heterologous gene sequences.

\section{Variants of Genetic Transformation}

Cisgenesis - the DNA sequence inserted into the modified plant is an unchanged sequence found in the same species or from a sexually compatible species; usually refers to a complete, functional sequence including the native regulatory and gene sequences.

Intragenesis - DNA inserted into the modified plant is re-organised or is used in new combinations, but still from the same species or from a 'crossable' species.

Transgrafting - non-GM scion grafting onto GM rootstocks or vice versa.

\section{GENE DRIVES}

The breeding techniques discussed here introduce new genetic variation that will be inherited as normal by subsequent generations and should be clearly distinguished from gene drives. A gene drive is a genetic element (and the practice of using it) that alters the inheritance patterns of a particular allele/gene to favour its inheritance and thereby increase its prevalence in the population, even if that gene reduces the fitness of individual organisms.

Gene drives can for example be used to prevent the spread of insects that carry diseases, e.g. mosquitoes that transmit malaria, dengue and Zika, control invasive species, or eliminate herbicide or pesticide resistance. Since gene drives function only in sexually reproducing species, they cannot be used to engineer populations of viruses or bacteria.

Current gene drive techniques necessitate the use of heterologous gene sequences, which will subject these organisms to the GMO Act, but because gene drives are primarily aimed at changing the genetic composition of wild populations, i.e. the genetic trait is designed to become pervasive, their potential impact has raised many bioethical and risk concerns. The application of gene drives was therefore deemed to fall outside the scope of this study and not considered.

\subsection{Genome Editing: Site-Directed Nucleases (SDNs)}

These are a set of techniques based on the use of nucleases that introduce a break in the DNA helix near a defined target sequence. After the break is introduced the DNA repair mechanisms and, in some cases, the use of additional nucleic acid sequences, result in different kinds of site-specific modifications. These range from the deletion of a few nucleotides to the insertion of additional sequences. For example, ZFNs, MNs, TALENs and CRISPR. 


\subsubsection{Zinc-Finger Nucleases (ZFNs)}

ZFNs are artificial restriction enzymes generated by fusing two domains, i.e. a zinc-finger DNA binding domain and a catalytic nuclease domain. The zinc-finger binding domain typically constitutes of several zinc-finger protein repeats that each recognise three bases of DNA. Because individual zinc-finger repeats can be engineered to recognise any specific three base pair sequence, the complete binding domain, which contains three to six of these zincfingers, can be engineered to specifically target any unique sequence in a genome. Typically, the non-specific type lls restriction endonuclease Fok I is fused to the binding domain to act as the cleavage domain for ZFNs.

A ZFN-induced double-strand break (DSB) allows a range of possible alleles to be generated at endogenous loci as illustrated in Figure 3.1 from Urnov et al. (2010). The DSB generated by ZFN cleavage induces endogenous DNA repair processes that may be influenced by the absence or addition of repair template DNA. If the break is repaired via non-homologous end joining (NHEJ), i.e. in the absence of repair template DNA, the target gene can be distupted due to small insertions or deletions, a tag can be inserted or a large deletion can be introduced via two simultaneous, adjacent DSBs (left-hand side of Fig 3.1). In contrast, if the DSB is repaired via homology-directed repair (HDR), i.e. in the presence of repair template DNA, this can result in gene correction due to small mutations, the insertion of a single transgene or transgene stacking (right-hand side of Fig 3.1).
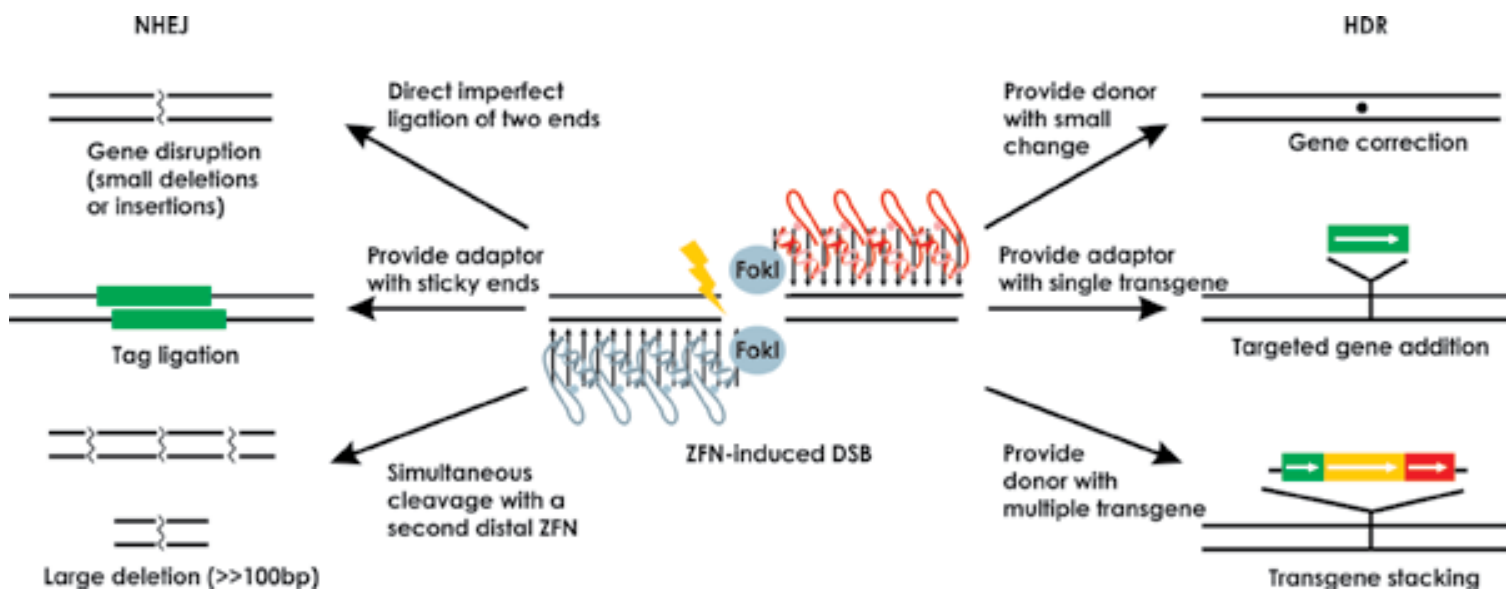

Figure 3.1 Types of genome editing made possible using zinc-finger nucleases (from Urnov et al. 2010)

\subsubsection{Meganucleases (MNs)}

MNs are endodeoxyribonucleases characterised by a large recognition site (double-stranded DNA sequences of 12 to 40 base pairs); as a result this site generally occurs only once in any given genome. MNs are, therefore, considered to be the most specific naturally occurring restriction enzymes.

Among the MNs, the LAGLIDADG family of homing endonucleases has become a valuable tool for the study of genomes and genome engineering over the past 15 years. MNs are 'molecular DNA scissors' that can be used to replace, eliminate or modify sequences in a highly targeted way. By modifying their recognition sequence through protein engineering, the targeted sequence can be changed. MNs are used to modify all genome types, whether 
bacterial, plant or animal. They open up wide avenues for innovation, particularly in the field of human health, for example the elimination of viral genetic material or the 'repair' of damaged genes using gene therapy (Honig et al., 2015).

\subsubsection{Transcription Activator-like Effector Nucleases (TALENs)}

TALENs are restriction enzymes that can be engineered to cut specific sequences of DNA. They are made by fusing a TAL effector DNA-binding domain to a DNA cleavage domain (a nuclease which cuts DNA strands). Transcription activator-like effectors (TALEs) can be engineered to bind practically any desired DNA sequence, so when combined with a nuclease, DNA can be cut at specific locations (Christian et al., 2010).The restriction enzymes can be introduced into cells, for use in gene editing or for genome editing in situ, a technique known as genome editing with engineered nucleases.

\subsubsection{CRISPR-Cas9 Systems}

CRISPR (clustered regularly interspaced short palindromic repeats) and Cas (CRISPR-associated) genes are responsible for adaptive immune responses in some prokaryotes, enabling the organisms to eliminate invading genetic material, e.g. bacteriophages. Three types of CRISPR mechanisms have been identified, of which type II, e.g. the Cas9 system, has been studied in most detail. In principle, invading DNA is recognised, cut into small pieces and integrated into the CRISPR locus from where it is subsequently transcribed in combination with associated small RNAs (trRNA and crRNA), which facilitate sequence specific targeting and association with the Cas9 endonuclease. This RNA/endonuclease complex (CRISPR-Cas9) has the ability to specifically recognise invading DNA based on sequence complementarity and subsequently cleave the target DNA (Fig. 3.2) - a system analogous to RNA-interference in eukaryotic organisms (Jinek et al., 2012).

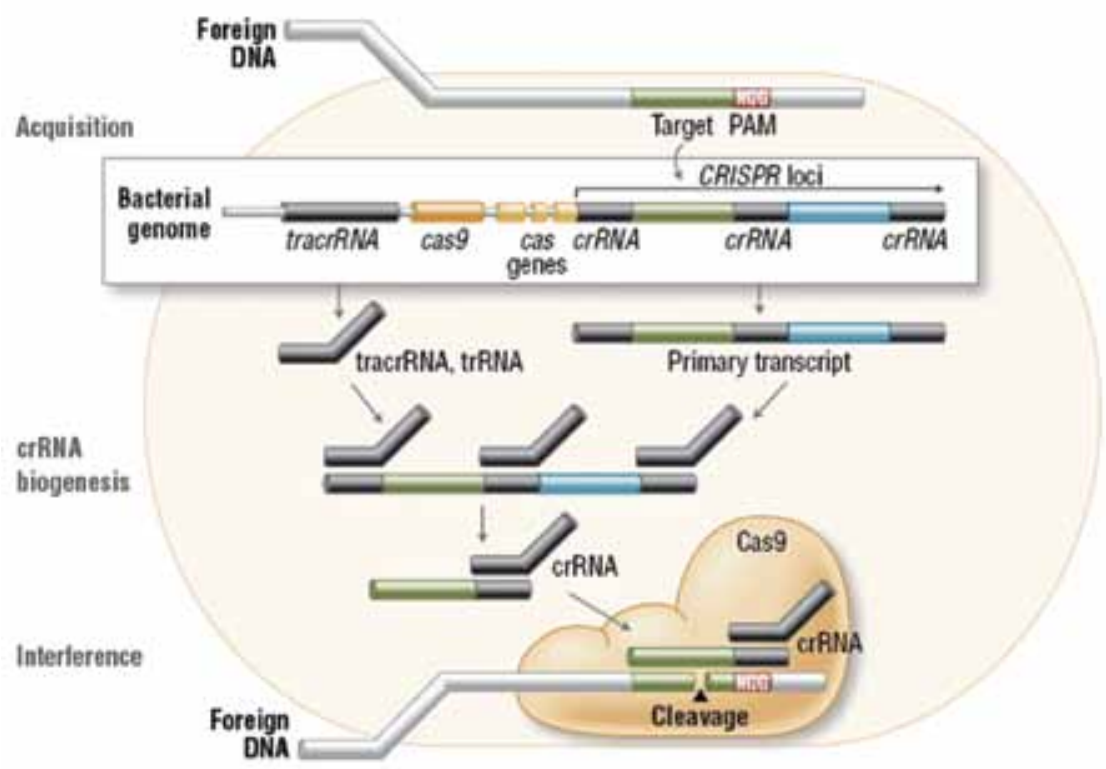

Figure 3.2 Schematic representation of the steps in a CRISPR-Cas9 adaptive immune response (https:// www.neb.com) 
The simplicity of the type II CRISPR-Cas9 system, with only three required components (Cas9, trRNA and crRNA), makes it amenable to adaptation for genome editing. In fact, it has already been simplified to a two-component system by combining the trRNA and crRNA molecules in a synthetic, single guide RNA (gRNA).

Similar to what was discussed for ZFNs, CRIPR-Cas9 can be used to induce site-specific double-stranded DNA breaks (DSBs), which can subsequently be repaired by the cellular non-homologous end joining (NHEJ) mechanisms, resulting in small insertions and/or deletions (indels), which could disrupt the targeted locus (Shan et al., 2013). Alternatively, if a donor template with homology to the targeted locus is supplied, the DSB may be repaired via homology-directed repair (HDR), allowing for precise replacement mutations or the insertion of heterologous gene sequences (Fig. 3.3).

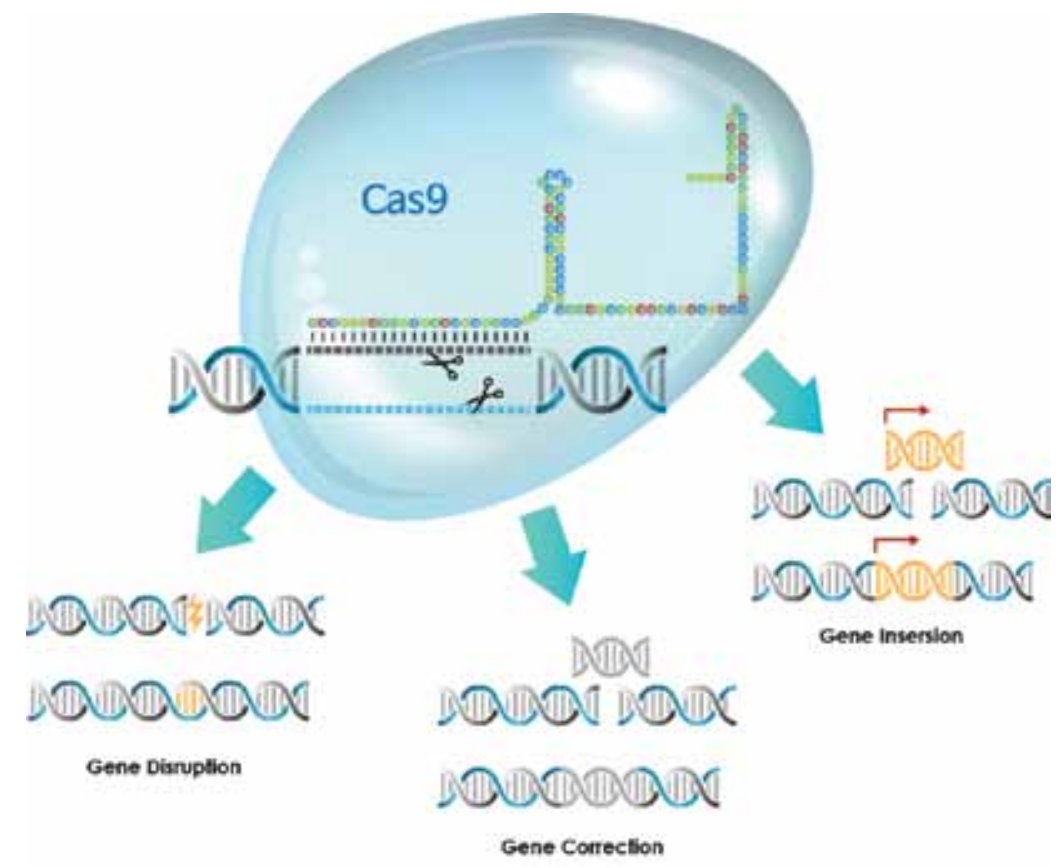

Figure 3.3 Types of genome editing made possible using CRISPR-Cas9 (http://toolgen.com)

The accuracy, flexibility, simplicity, relative low cost and efficiency of the CRISPR-Cas9 system has led to its wide adoption. It has already been successfully used to target important genes in a wide range of cell lines and organisms. The CRISPR-Cas9 system requires only the redesign of the crRNA to change target specificity, which contrasts with other genome editing tools, including ZFNs and TALENs, where redesign of the protein-DNA interface is also required.

The introduction of small mutations (indels and base substitutions) and heterologous genes into a specific target gene, via a single guide RNA (gRNA) is now routine and pairs of gRNAdirected Cas9 nucleases can be used to induce large deletions or genomic rearrangements, such as inversions or translocations. More recent developments also use a nuclease-deficient Cas9 version to modulate transcriptional regulation and epigenetic modification and also 
for the microscopic visualisation of specific genome loci. It is therefore clear that the CRISPRCas9-based tools hold great potential, not only for basic research, but also for improving the genetic traits of crops and domesticated animals, other industrial organisms and for treating disease.

\subsubsection{Possible Risks Associated with SDNs}

\section{IMPORTANT CONSIDERATIONS}

Before contemplating the broad possible biosafety risks that may be associated with all the techniques discussed in this chapter, two critically important contextual considerations should be explained.

(1) As discussed in subsequent chapters the actual source of risk, i.e. the hazard, in terms of GMOs is the modified organism and not the technique through which it was generated. It is therefore impossible to do a sensible, comprehensive risk analysis on a technique alone. This is further supported by the fact that the resulting GM trait of a modified organism is a critical input for both the food and feed safety and environmental risk assessments done on GMOs. Finally, because a single technique can be used to induce a wide variety of different traits and/or genetic changes, the only possible risks that may be directly associated with a particular technique, are limited to those associated with its molecular mechanisms and can at best be discussed comparatively to other techniques.

(2) The potential risks associated with NBTs should always be considered within an appropriate context, i.e. taking, amongst others, the following into consideration:

- compare the associated molecular mechanisms, e.g. their accuracy and efficiency, with the natural mechanisms responsible for inducing genetic variation;

- compare the induced changes with similar genetic variation and unintended effects that may occur during natural sexual reproduction;

- take past experiences with the risk assessment of GMOs into account;

- distinguish theoretical risks from those potentially present in a regenerated, healthylooking whole organism.

Possible risks of SDNs will be associated with the specific methods used to introduce the molecular components into the targeted organism or the methods used to regenerate organisms from the modified cells. However, with these technologies, the required proteins are usually expressed in trans (originate from a transient expression system) and then they target the region of interest to introduce the mutation. The delivery system and its selective genes are never incorporated into the genome as with the older technologies. In addition, unintended modifications, similar to those occurring in natural systems may occur.

Examples of unintended modifications, include:

- Mutations introduced at off-target genomic locations sharing homologous sequences with the target site.

- Potential expression of aberrant proteins for some types of knock-out mutations.

\subsection{Genome Editing: Oligonucleotide-Directed Mutation (ODM)}

ODM is a site-specific gene modification system based on synthetic oligonucleotides (single stranded DNA molecules) homologous to the target genomic sequence, except for a small mutation. When these are introduced into a cell they can modify the target sequence after 
homologous recombination and integration via the endogenous DNA repair mechanisms (Lloyd et al., 2005).

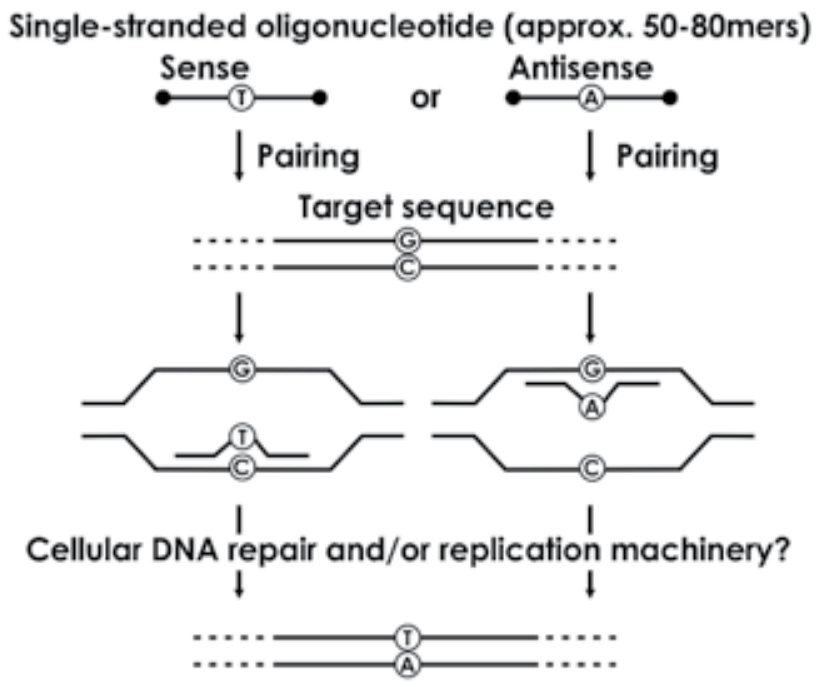

Figure 3.4 A diagram illustrating the oligonucleotide-directed mutagenesis process (http://www.brc.hu)

\section{KEY MESSAGE}

Genome editing techniques offer a unique set of advantages over conventional and GM crop breeding techniques in terms of accuracy, flexibility and relative simplicity, low costs and efficiency.

\subsection{Null (Negative) Segregants}

Null, or negative, segregants refer to the non-GMO offspring in a breeding programme where GM elements or traits were used transiently. For example, parents with GM traits that improve the efficiency of the selection and breeding process itself are used, but then these GM traits are segregated in the subsequent progeny and excluded from the selected lines.

\subsubsection{Reverse Breeding}

Until recently it was not possible to exactly reproduce a heterozygous plant via seeds. Reverse breeding, however, is a recently developed breeding technique designed to do so through the 'reverse' production of homologous parental lines from a superior heterozygous plant. Subsequent hybridisation of selected complementary homozygous parental lines will reconstitute the original superior heterozygous line in seeds (Wijnker et al., 2012).

Reverse breeding depends on the use of a genetic modification step that suppresses meiotic recombination, followed by a tissue culture step to create a range of homozygous (doubled haploid) parent lines. Complementary pairs of these newly developed parental lines are then used to stably produce the heterozygous elite plants through seed/hybrid breeding (Fig. 3.5). 

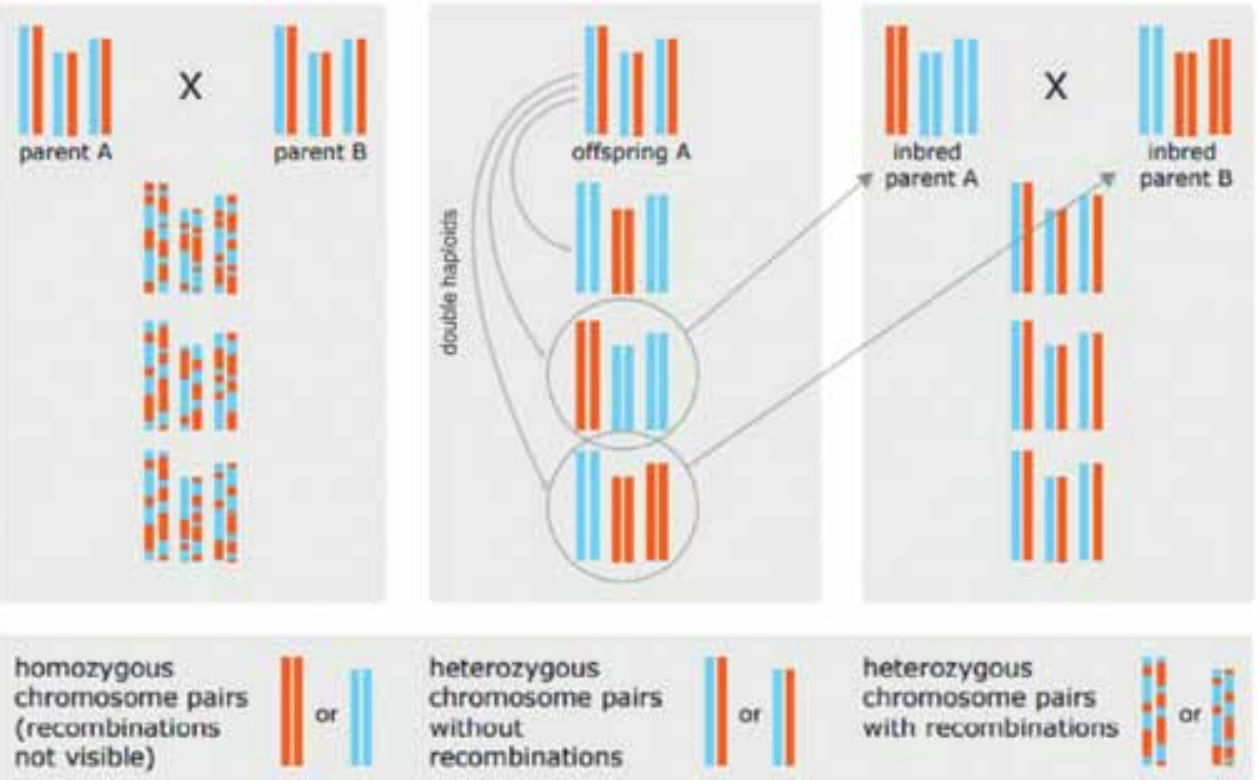

\section{heterozygous} chromosome pairs without recombinations heterozygous

chromosome pairs

with recombinations

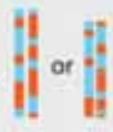

Figure 3.5 Schematic overview of the final outcomes of different breeding approaches. During conventional breeding, recombination in chromosome pairs results in the reshuffling of genetic material, which results in the loss of the original, unique combination of genetic characteristics. Reverse breeding starts with a selected heterozygous individual in which meiotic recombination is suppressed through RNA interference (GM). A full set of doubled haploid parental lines are generated from this plant each with a different set of homozygous chromosome pairs. For hybrid variety production, parental lines in which the genetic variation of the chromosome pairs complement each other, e.g. inbred parent A and B above, are selected and crossed to yield uniform offspring hybrid plants (seeds), which are genetically similar to the plants with which the reverse breeding was started (Modified from http://european-seed.com)

Reverse breeding holds great potential for introducing hybrid vigour/heterozygosity into crop breeding programmes and can do so without prior knowledge of the genetic constitution of the crop. It further allows for precision breeding, i.e. manipulating individual chromosomes, and the quick identification of QTLs. Although the generation of the homozygous parental lines is dependent on a GM trait, this can be segregated in subsequently out crossings, rendering the final lines non-GMO. Finally, reverse breeding is currently limited to crops with a haploid chromosome number of $\leq 12$ and where doubled haploid technology is routinely practised.

\subsubsection{Accelerated Breeding}

Accelerated breeding techniques involve the intermediate generation of GM organisms that contain a transgene to shorten the juvenile phase of the organism, thereby speeding up the breeding process, for instance in trees (Comeau et al., 2001). As with reverse breeding, the transgene is removed later by out crossing and segregation. In such a case no foreign genetic material is present in the final product. 


\subsubsection{RNA-dependent DNA Methylation (RdDM)}

RdDM relies on the plants' innate defence systems, specifically the RNA-induced silencing complex, which is activated by small double-stranded RNA molecules. The technique enables the release of varieties that have inherited an epigenetic modification, but not the inducing transgene itself. Many cellular processes, including gene expression and DNA replication, are controlled by elements such as promoters, enhancers, or binding sites for repressor proteins that are present or absent in the DNA sequence. Epigenetic modification in contrast involves the chemical modification of DNA without altering the genetic code itself and the proteins associated with DNA, which may result in changes to the conformation of DNA and accessibility of other factors to DNA, without a change to the primary sequence of the DNA.

Common types of epigenetic regulation are DNA methylation and hydroxymethylation, histone modification, chromatin remodelling, and regulation by small and large non-coding RNAs (Wu et al., 2010). As more factors influencing heredity are discovered, epigenetics is being used to decipher the roles of DNA, RNA, proteins, and environment in inheritance.

\subsubsection{Possible Risks Associated with Null Segregants}

As with conventional breeding, the products of all these techniques will require thorough phenotypic assessments to confirm their characteristics. With regards to the transient GM trait(s) a thorough characterisation of the final products is needed to exclude the unexpected presence of GM sequences and/or traits. As a result of these initial modifications the breeding products may also exhibit phenotypes transmitted as inheritable epigenetic traits. The final breeding products should therefore be assessed for traits associated with the initial GM, e.g. meiotic aberrations or early flowering. Epigenetic modifications may be unstable and revert after a few generations.

\subsection{Variants of Genetic Modification}

\subsubsection{Cisgenesis and Intragenesis}

In molecular biology, "cis" in general refers to "acting from the same molecule". A cisgene therefore refers to an intact, functional gene sequence that occurs naturally in the target organism itself or a sexually compatible species, including its natural regulatory cis-sequences such as its promoter and terminator (Figs. 3.6 and 3.7). Therefore, the gene belongs to the conventional breeder's gene pool and is the already existing result of natural evolution. In theory, the gene of interest could also have been moved from one species to the other using traditional breeding with the same result.

An intragene is a functional gene sequence that consists of functional elements, i.e. coding region, promoter and terminator, originating from different genes from the target organism itself or sexually compatible species. Therefore, all gene elements belong to the traditional breeders' gene pool but in contrast to cisgenesis, an intragene is an artificial genetic construct (Fig. 3.7).

In contrast, transgenes consist of functional elements from sexually incompatible species, which have been transferred to a host organism using genetic engineering techniques - i.e. transgenesis (Figs. 3.6 and 3.7). 

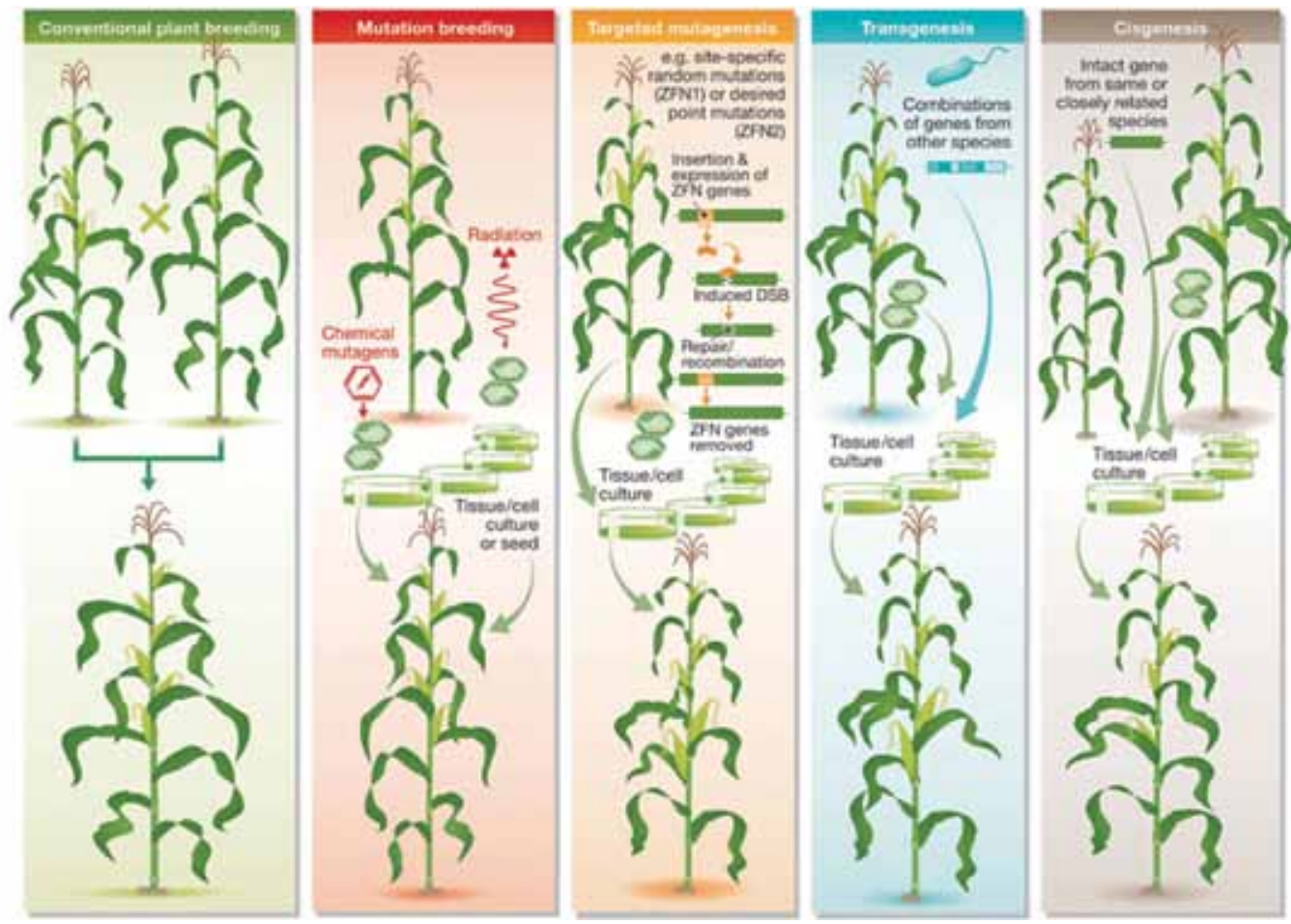

Figure 3.6 Five techniques commonly used to generate new plant varieties - conventional plant breeding, mutation breeding, targeted mutagenesis, transgenesis and cisgenesis (Reproduced with the permission of Science \& Society)
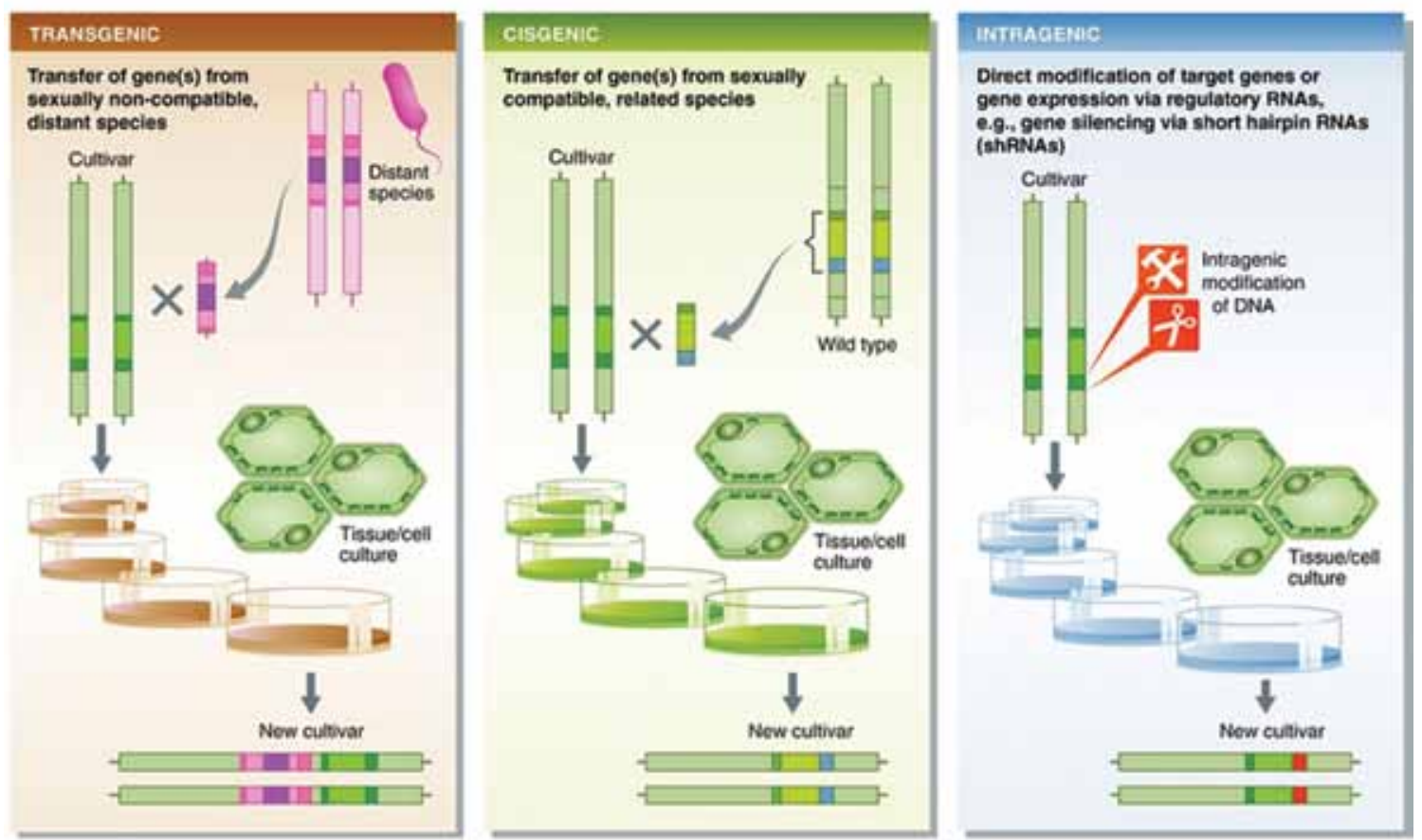

Figure 3.7 Differences between transgenic, cisgenic and intragenic breeding (Reproduced with the permission of Science \& Society) 


\subsubsection{Transgrafting}

Grafting has been used by plant growers for thousands of years to control growth and flowering in trees and some herbaceous plants by attaching a scion onto a suitable rootstock. In some cases, it may be beneficial to graft a non-GMO scion onto a GM rootstock (Fig. 3.8) or vice versa - called transgrafting.

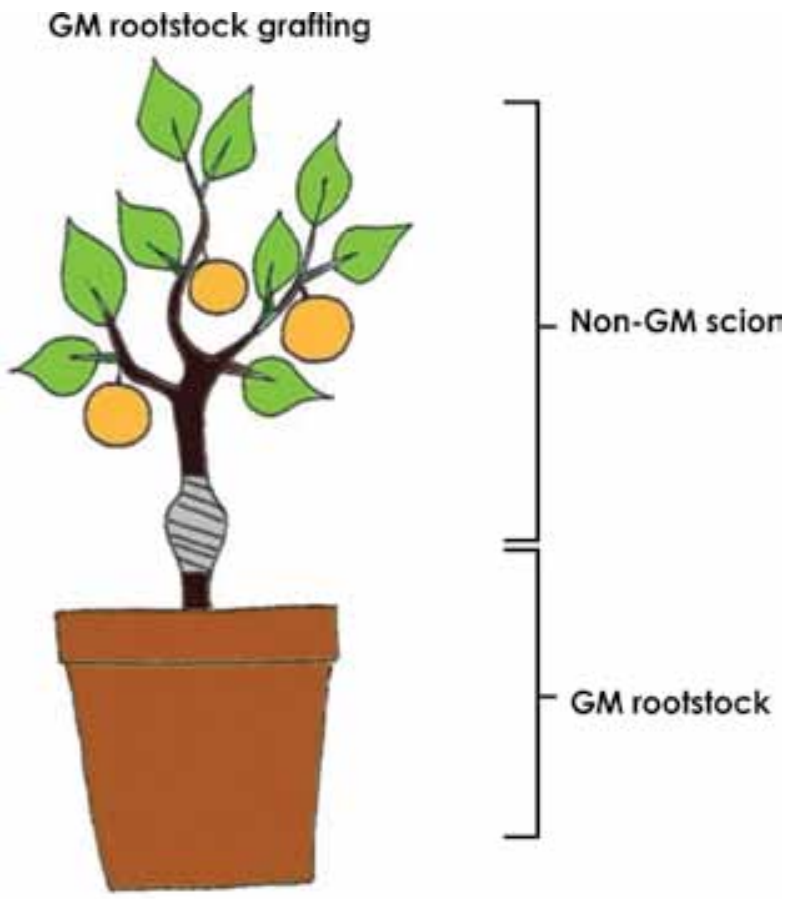

Figure 3.8 A diagram illustrating the two components of a graft - the non-GM scion and the GM rootstock (http://germination.ca)

This may, for example, be beneficial where a GM rootstock can convey beneficial characteristics, such as more efficient nutrient uptake from the soil, better rooting ability and/or resistance to soil-borne diseases. In such cases, the non-GMO scion and its harvest, e.g. flowers or fruit, remain free of transgenic DNA.

\subsubsection{Possible risks associated with GM variants}

The European Food Safety Authority (EFSA) Panel on GMOs compared the hazards associated with cisgenic, intragenic and conventionally bred plants and concluded that the possible hazards associated with these plants are similar to the ones associated with conventionally bred plants (EFSA, 2012). The Austrian Environment Agency came to a similar conclusion in a recent review of the risks associated with NBTs (Eckerstorfer et al., 2014).

In transgrafting there is a chance that mRNAs, proteins and other mobile molecules could move along the phloem long distance translocation system (See Song et al., 2015 for a review). Horizontal gene transfer between the rootstock and the scion is also theoretically possible via this mechanism (Liv et al., 2010), but this has not actually been recorded, except in the graft union itself (Anon, 2013; Song et al., 2015). 


\section{TRANSIENT EXPRESSION SYSTEMS}

In transient expression systems, somatic tissues or cells, e.g. plant leaves or animal cell cultures, are transformed with functional, heterologous gene sequences that are transiently expressed while remaining episomal, i.e. they do not integrate into the host genome. Transformation of the tissue can be done using Agrobacterium, a number of direct transfer techniques, such as particle bombardment or injection, or fit-for-purpose virus expression vectors. Several vectors have been designed on the basis of DNA and RNA-based plant virus genomes and these vectors are used as single or multicomponent expression systems in different combinations depending on the protein of interest.

The advantages that transient plant expression systems offer include speed, adaptability, scalability, relatively low production costs, high yields and low risk of mammalian pathogen contamination, which has led to predictions that transient plant expression systems could offer a major advance in the production of pharmaceutical proteins. The production of different recombinant proteins in transient systems compared with established standards has been described by Komarova et al. (2010) and Pogue et al. (2010)

Although transgene sequences are used in these systems they do not integrate with the host genome and, besides, the host tissues/cells are sacrificed after a few hours to extract the recombinant protein product. No GMOs are therefore produced during the production/ expression cycle. However, a GMO may be used for transformation, e.g. Agrobacterium, which will yield a GMO/non-GMO tissue mixture that may be subject to GMO regulation. The regulation of these systems will therefore have to be decided on a case-by-case basis, but because they fall outside the scope of this study they will not be discussed further here.

\subsection{Research, Development and Application Status of NBTs}

The techniques discussed above have sparked huge interest for application in bio-innovation. Not only do these techniques, and in particular CRISPR, promise to make genomic modifications more accurate and simple, but also do so quickly, efficiently and cost-effectively. For example, the number of publications and patents involving CRISPR has increased one hundred-fold over the past five years, while funding by the NIH increased ten-fold in only one year - 2013 to 2014 (Ledford, 2015).

Although much of the above-mentioned interest focuses on health and medicine innovation, the utility of these techniques in breeding programmes, which is the focus of this study, is clear. In fact, products bred using these techniques have already received commercial approval in certain territories. Moreover, non-browning mushrooms, high-amylopectin maize and herbicide-tolerant oilseed rape are just some of the genome edited products which were found to be exempt from GMO regulations in the USA and therefore free to enter the market (Anon, 2015; Gill, 2016). Other products close to market include herbicide-tolerant maize, fungal-resistant potatoes, drought-tolerant maize, scab-resistant apples and potatoes with reduced amylose content. Many of these products have been developed by small research and development laboratories in the public and academic sector or by small enterprises underlining the accessibility, utility and value of these techniques.

SDNs have been used to improve the nutritional quality maize and canola, produce higher yield tomatoes, diseases resistant wheat, bacterial blight-resistant rice, nematode-resistant soybean and in cell biology research in a multitude of organisms ranging from fruit flies and 
nematodes to zebrafish and cattle. ODM was used in the development of herbicide-tolerant oilseed rape, rice and flax. Cis and intragenesis have been used to developed products such as fungal-resistant papaya, improved forage ryegrass, scab-resistant apple, bacterial blight-resistant potato and rice, drought and cold-tolerant maize and a variety of improved vegetable crops, while transgrafting is used in fruit trees to combat diseases such as citrus greening and plum pox virus.

\subsection{Conclusion}

NBTs are emerging rapidly from advances in genomic research and are already being applied in crop improvement. These NBTs enable precise, targeted and reliable changes in the genome, distinguishing them from first generation GM technologies, and have significant potential for the sustainable intensification of agriculture and ensuring food security. Unlike chemical or radiation-induced mutagenesis, often traditionally used as a basis for crop improvement, the NBTs do not create multiple, unknown, unintended mutations throughout the genome.

For several of the techniques, the resultant plant products are free from exogenous gene sequences and are therefore indistinguishable from potential products generated by conventional breeding techniques. This necessitates greater clarity regarding the definition of GM and the evolution of regulatory approaches and frameworks.

\section{KEY MESSAGES}

- When using some NBTs, it will be impossible to tell what method was used to produce a new crop variety, because exactly the same DNA changes could be introduced using a variety of conventional breeding techniques. The boundaries between established GM and non-GM techniques will become increasingly blurred as techniques develop.

- It is important for policymakers to recognise that the NBTs are already widely used in research and development, and that commercial applications are likely to follow very soon. Regulatory processes therefore need to be able to accommodate them as a matter of urgency. 


\section{CHAPTER 4}

The Current Regulatory Framework for GMOs

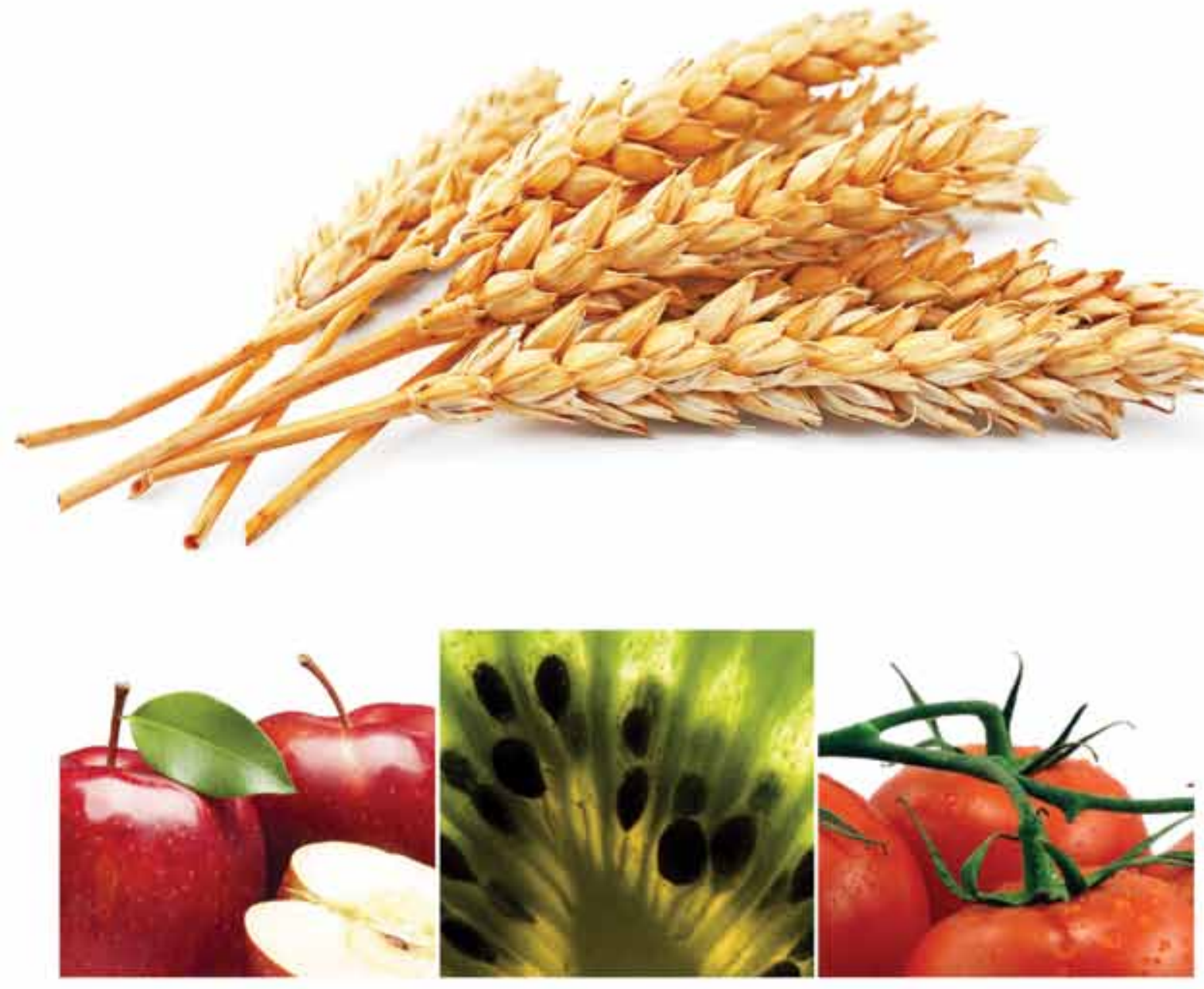




\subsection{Introduction}

NBTs are a wide and evolving range of interventions aimed at modifying genomes and/or gene expression to impact the phenotype of the resulting organism in a specific manner - some resembling GM technology to some extent. However, the varied nature of these techniques and their possible outcomes prevent their clear-cut categorisation in terms of GM technology alone. A prudent overview of the current regulatory framework for GMOs is therefore required to establish its scope and possible overlaps and/or differences in relation to the various NBTs. Such an analysis would also indicate if the current regulatory framework can be used to regulate, not only the current NBTs and their products, but also possible future breeding technologies (a concept that is further developed in Chapter 6).

\subsection{The South Africa Regulatory Framework for GMOs}

SAGENE was South Africa's first regulatory body for GMOs. Established in 1979, as a result of the initiative of the local scientific community, its members undertook laboratory inspections and provided guidelines for the assessment and evaluation of GMOs. In 1989, SAGENE advised the National Department of Agriculture on the field testing of Bt cotton, which was approved in terms of the Agricultural Pests Act (Act 36 of 1983). In 1992, SAGENE was given the remit to advise on legislation and/or controls on the importation and/or release of "organisms with recombinant DNA" and in January 1994, this was broadened to GMOs, defined in similar terms as used later in the GMO Act. SAGENE continued to act in this capacity until the GMO Act (Act 15 of 1997) came into effect on 1 December 1999.

Currently, South Africa regulates the development and use of GMOs primarily in terms of the GMO Act and the GMO Amendment Act (Act 23 of 2006). The aim of the GMO Act is to promote the responsible development, production, use and application of GMOs and further establishes the necessary operational procedures and infrastructure required for the regulation of GMOs, including:

- The Registrar (seated within the Department of Agriculture, Forestry \& Fisheries (DAFF)), responsible for administering the Act.

- Inspectors, responsible for ensuring adherence to permit conditions.

- The Advisory Committee (AC), a panel of independent scientists that evaluates all applications.

- The Executive Council (EC), the decision-making body that consists of ten members representing seven different state agencies, i.e. DAFF, Department of Health (DoH), DST, Department of Environmental Affairs (DEA), Department of Trade \& Industry (the dti), Department of Labour (DoL) and Department of Arts \& Culture (DAC).

In addition, the Regulations to the GMO Act establish:

- the appropriate administrative and decision-making procedures for permit applications for activities involving the use of GMOs;

- common measures and minimum requirements for the risk assessment and management of the potential risks associated with GMOs;

- minimum risk communication and public participation requirements;

- the appropriate linkages with other relevant national and international GMO regulations;

- provisions regarding appeals and penalties. 


\section{GMOs IN SOUTH AFICA}

Cotton was the first GM crop tested in South Africa in 1990. Approval for the commercial release of this crop was granted in 1997. Once full assessments had been carried out, adoption was very rapid and the present national cotton crop is $100 \%$ GM. GM maize was approved for commercial release in 1998 and the first application comprised some six yellow maize hybrids. In 2015, $90 \%$ of the 2 million ha of maize was GM. GM soybeans were approved in 2000 and about $5 \%$ of the $2001 / 2002$ crops was GM. In $2015,95 \%$ of the national soybean crop was GM (James, 2015).

South Africa's experience of the first 20 years of commercialisation of GM cotton, maize and soybean, 1997 to 2016, has confirmed the benefits of crop biotechnology GM crops, which have delivered substantial agronomic, environmental, economic, health and social benefits to farmers and, increasingly, to society at large.

To date, all the GMO products approved for general release in South Africa have been developed outside the Republic by large multi-national companies, which raises questions regarding the impact of complex and costly regulatory requirements on local innovation.

In the GMO Act a "genetically modified organism" is defined as "an organism the genes or genetic material of which has been modified in a way that does not occur naturally through mating or natural recombination or both, and 'genetic modification' has a corresponding meaning".

The GMO Act does not apply to techniques:

(a) involving human gene therapy;

(b) in which recombinant DNA molecules or genetically modified organisms are employed

1 in in vitro fertilisation in humans and animals;

2 in conjugation, transduction, transformation or any other natural process;

3 in polyploidy induction;

(c) in which genetically modified organisms as recipient or parental organisms are not employed

(i) in mutagenesis;

(ii) in the construction and use of somatic hybridoma cells;

(iii) in cell fusion (including protoplast fusion) of plant cells.

However, the Act does not define:

- Genetic recombination - the transmission genetic process by which the combinations of alleles observed at different loci in parental individuals become shuffled in offspring individuals.

- Mutagenesis - a process by which the genetic information of an organism is changed in a stable manner, resulting in a mutation.

- Mutation - a change in the structure of genetic material, resulting in a variant form that may be transmitted to subsequent generations, caused by the alteration of single-base units in DNA, or the deletion, insertion, or rearrangement of larger sections of genes or chromosomes.

- Naturally - happening or existing as part of nature.

- Novel-cannot conceivably occur naturally.

The current general consensus is that the South African regulators have principally adopted a process-based approach to GMO regulation (as opposed to a product-based one), 
based on the perception that the definition of a GMO in the Act, and therefore the trigger for regulation, hinges on how the organism was created, i.e. "... which has been modified in a way that does not occur naturally...", and not purely on its risk characteristics. However, the EC of the GMO Act's decision to also regulate breeding stacks of approved GMO lines, contradicts the above as it is clearly a product-based trigger. In practice, South African GMO regulators have therefore apparently taken an ad hoc approach, which may include both process and product-based triggers for GMO regulation. However, it can be argued that the relatively limited range of GMOs that have been evaluated to date has not really tested this supposition.

In addition to the GMO Act several other pieces of legislation make direct reference to the regulation of GMOs, including:

- Food labelling regulations under the Foodstuffs, Cosmetics and Disinfectants Act (Act 54 of 1972).

- Environmental impact and monitoring regulations under the National Environmental Management Biodiversity Act (Act 10 of 2004).

- Food labelling regulations under the Consumer Protection Act (Act 68 of 2008).

\section{KEY MESSAGE}

South Africa has a well-established, representative and robust regulatory framework for GMOs and a successful track record in science-based risk assessment, commercialisation and post-release management of GMOs.

\subsection{The Cartagena Protocol on Biosafety (CPB)}

The CPB is a legally binding global protocol that seeks to contribute to ensuring the safe transfer, handling and use of living modified organisms (LMOS) created through modern biotechnology. Currently 170 countries, including South Africa, are party to Protocol, which ratified it in 2003.

Article 1 of the Protocol states that it aims to "contribute to ensuring an adequate level of protection in the field of the safe transfer, handling and use of living modified organisms resulting from modern biotechnology that may have adverse effects on the conservation and sustainable use of biological diversity, taking into account risks to human health as well, and specifically focusing on transboundary movements". In short, it seeks to protect biodiversity from the potential risks of LMOs resulting from modern biotechnology.

The CPB defines a GMO, specifically called an LMO in the Protocol because it only applies to living modified organisms, as "any living organism that possesses a novel combination of genetic material obtained through the use of modern biotechnology".

While modern biotechnology is defined as any application of:

- in vitro nucleic acid techniques, including recombinant DNA and direct injection of nucleic acid into cells or organelles, or

- fusion of cells beyond the taxonomic family, that overcome natural physiological reproductive or recombination barriers and that are not techniques used in traditional breeding and selection.

If emphasis is placed on the second part of the definition for LMOs, i.e. "the use of modern biotechnology" it may suggest a process-based approach to regulation under the Protocol. 
However, "a novel combination of genetic material" is not clearly defined, which leaves the exactmeaning of the definition, and therefore the scope of the Protocol, open to interpretation. This fact was also highlighted in the deliberations of the Argentinian regulatory authorities when they considered the regulation of NBTs under the Protocol (Whelan and Lema, 2015). In addition, the term "novel combination of genetic material" is always used, with only one exception, in combination with the word "detectable" in the Protocol's text, i.e. "detectable novel combination of genetic material", which could have an impact when considering the Protocol's mandate over the wide and variable range of possible NBT products.

The Protocol covers the "transboundary movement, transit, handling and use of all living modified organisms that may have adverse effects on the conservation and sustainable use of biological diversity, taking into account risks to human health". It requires that decisions be based on risk assessments that are undertaken in a scientific manner based on recognised risk assessment techniques, taking into account advice and guidelines developed by relevant international organisations. In this regard, a lack of scientific knowledge or scientific consensus should not necessarily be interpreted as indicating a particular level or risk, an absence or risk, or an acceptable risk. Risks associated with LMOs or their products should be considered in the context of risks posed by the non-modified recipients or parental organisms in the likely potential receiving environment. Risk assessment should be carried out on a case by case basis.

\subsection{Conclusion}

In South Africa, GMOs are primarily regulated in terms of the GMO Act (Act 15 of 1997) and its amendments and the country has 20 years of experience in the development, use and 
regulation of GMOs. The definition of a GMO in the Act hinges on its "unnatural" character and stands central to defining the Act's mandate, but there is currently no clear consensus on whether it purports a process or product-based trigger and its possible knock-on effects. Clarifying this issue will allow for the accurate classification of the products of all current and possible future biotechnologies, including NBTs, and establish the GMO Act as the principle regulatory instrument for those products that do require regulatory oversight.

The CPB is the legally binding international Protocol that seeks to protect biodiversity from the potential risks of LMOs, in contrast to possible non-living products from GMOs, resulting from modern biotechnology. It promotes biosafety by establishing rules and procedures for the safe transfer, handling and use of LMOs and facilitates information and experience sharing, including, procedures for moving LMOs across borders, risk assessment practices, an international biosafety clearing house, capacity building and public awareness programmes.

In South Africa, the development and use of GMOs are subject to both national and international regulatory frameworks. However, the frameworks' definitions of GMOs and in other words, that which is subject to regulation, are not well-aligned. The advent of the NBTs has further exposed ambiguities within the various legal definitions of GMOs that are used around the world. When considering the possible regulation of NBTs and/or their products using current GMO frameworks, it will therefore be critically important to first define, within a context of risk management, exactly what constitutes a GMO or regulated entity to minimise possible international misalignment - a concept that is further developed in Chapter 6. 


\section{CHAPTER 5}

\section{Current Global Approaches to the Regulation of NBTs}

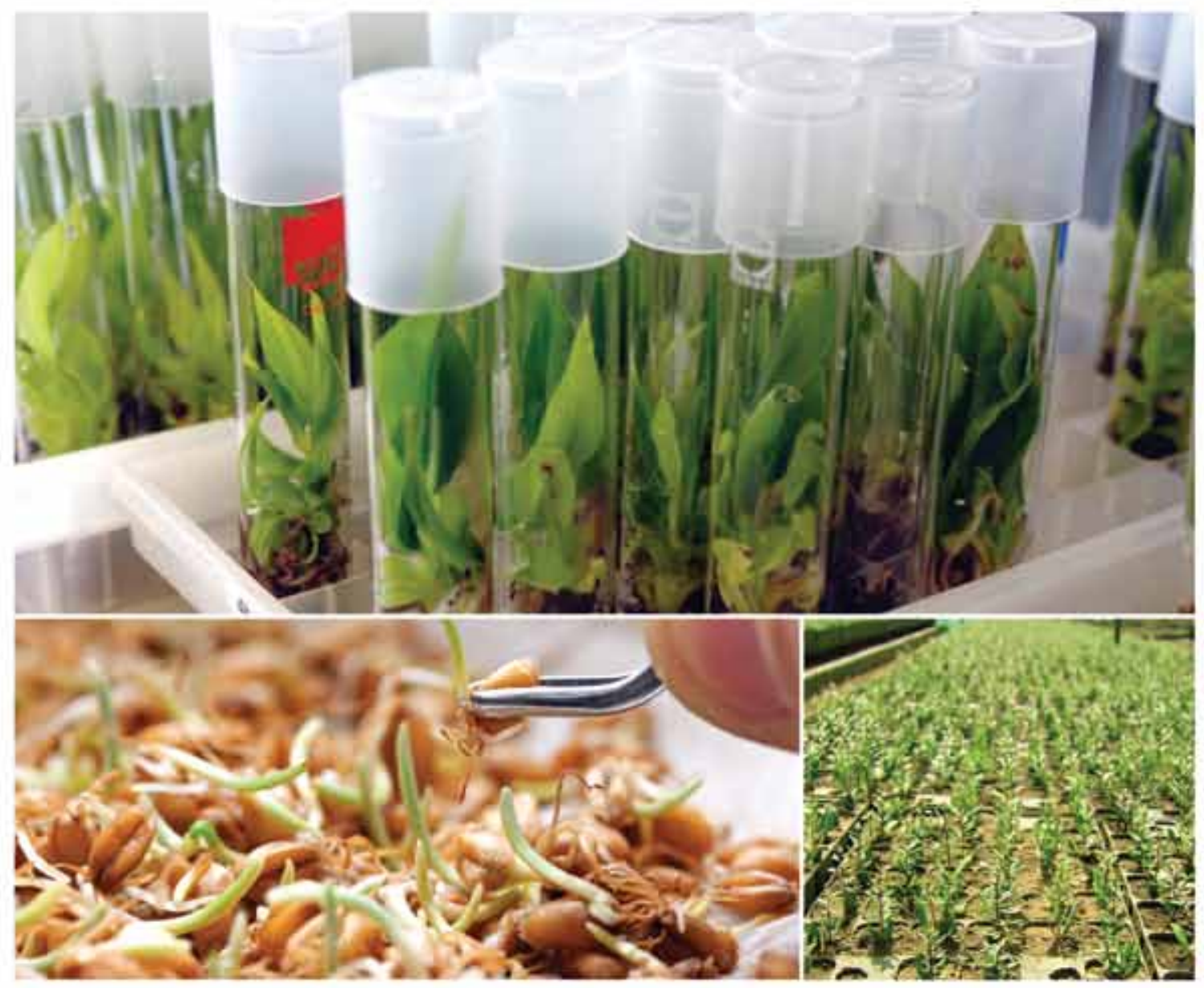




\subsection{Introduction}

To date very few countries have developed official policies to determine the regulatory status of products derived from NBTs, and where such instruments do occur, they are not very useful as a model because of the differences in legal frameworks and definitions between countries. Argentina is currently the only country where the regulators have made a formal pronouncement on the regulation of NBTs. Most countries are still debating the issue internally and have not yet reached a conclusion. The approaches used in various countries are considered below.

\subsection{Argentina}

Argentina based its regulatory system on the CPB definitions and as a result, the country's legislation is fully compatible with the Protocol (Whelan and Lema, 2015). Argentina concluded that the "novel combination of genetic material" should be the key trigger when deciding if a product derived from a NBT is to be considered a GMO or not. In this regard, therefore:

- Products derived from cisgenesis, intragenesis, SDN-3 and synthetic biology are considered to be GM.

- Grafting between GM and non-GM plants - the whole plant is regarded as GM, regardless of whether the GM part is the rootstock or scion.

- SDN-1, SDN-2 and reverse breeding - if the applicant can show evidence of the removal of the SDN or transgenic material from the final product the product would be considered a non-GM otherwise it is still a GMO.

- Epigenetic modifications such as RdDM are not considered a new combination of genetic material but in some cases the DNA insertions would have to be removed. However, because these modifications are often unstable and revert after a few generations they may have little commercial interest in practice.

- ODM - depending on the nature and extent of the modification, products derived from these techniques could be considered non-GM.

- Agro-infiltration - these techniques are unlikely to serve a practical purpose for commercial agriculture but may be of value in molecular pharming. The focus of any regulation should be on the GM micro-organism.

Notwithstanding the above conclusions, the Argentine regulators emphasise the principle of a 'case-by-case' approach, which affords the regulator the opportunity to make a final decision only once the details of any particular application have been considered. This also allows for the handling of any possible future derivatives or new techniques that may evolve.

\subsection{Australia and New Zealand}

While New Zealand is a party to the CPB Australia is not, but both countries have definitions and regulations that cover the regulation of GMOs.

Current Australian GMO legislation requires the determination of whether a NBT is covered by the GM regulations to be made on a case-by-case basis. In 2012 and 2013, Food Standards Australia/New Zealand convened an expert scientific panel to provide advice on how to regulate different NBTs. The panel grouped NBTs into three categories:

1 Cisgenesis, intragenesis, SDN-3 and GM rootstock grafting - any products derived from these NBTs should be regarded as GM.

2 ODM and SDN-1 - any products derived from these NBTs should not be regarded as GM. 
3 Reverse breeding - products derived from this NBT are not GM but the reliability of the breeding process needs to be confirmed.

In a recent statement, the Agricultural Biotechnology Council of Australia (ABCA, 2016) recognised the importance of new techniques in plant and animal breeding. In most cases, NBTs are innovative improvements and refinements of traditional plant and animal breeding methods. Breeders can now induce very specific changes in plant and animal genes in a way that mimics the changes that occur in nature or through traditional breeding methods. The use of NBTs can enable breeders to create the same, desired genetic variation with greater precision and efficiency than previous breeding methods. Genomic changes produced by NBTs should be viewed in light of the inherent natural variability of plant and animal genomes, the comparable genomic changes that occur with the use of traditional breeding methods, and the long safe history of the use of traditional breeding methods. ABCA added that regulatory oversight of products developed through NBTs, if needed, should be based on sound scientific principles and should be proportional to risk. Regulatory oversight that is not proportional to risk is not value adding and results in delays and higher costs, which limit the access of small and medium sized enterprises (SMEs) and public breeding institutions to the latest innovative breeding tools. ABCA stated that plant and animal breeders need regulatory certainty so they can reliably plan their breeding programmes, product development and market strategies. Consistent regulatory oversight of products developed using NBTs would facilitate innovation and allow the uptake of advanced, innovative breeding applications by both private and public sector breeders.

In October 2016, Australia's Office of the Gene Technology Regulator (OGTR) published a discussion paper on Opinions for Regulating New Technologies in which they requested public inputs on the proposed regulation of NBTs. They listed four possible options on how to approach NBT regulation; viz. (1) no amendment to the current GMO legislation, (2) regulate selected techniques, (3) regulate some selected techniques based on the process used and (4) exclude certain selected techniques based on the products they produce. The advantages and disadvantages of the respective approaches they listed could add value to the South African discussion and are therefore presented in Table 5.1. 


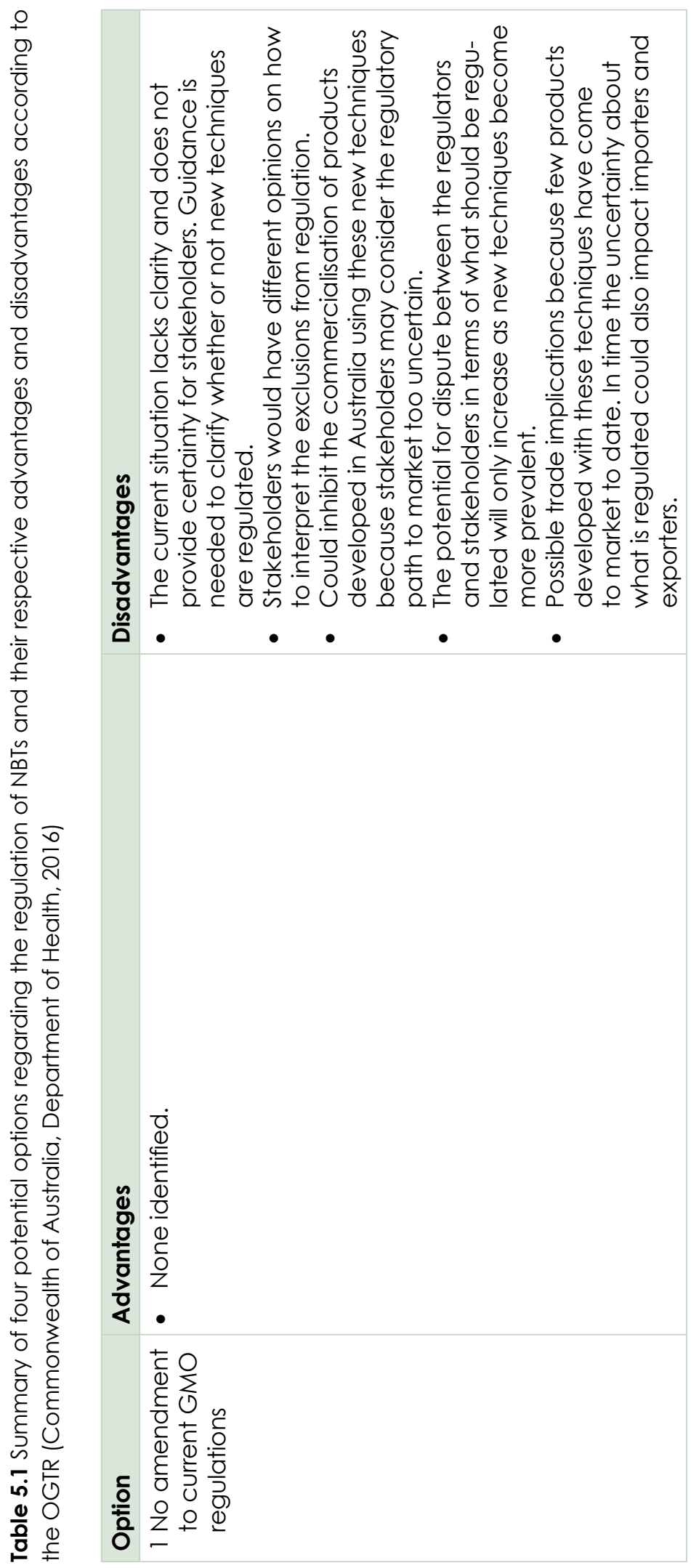




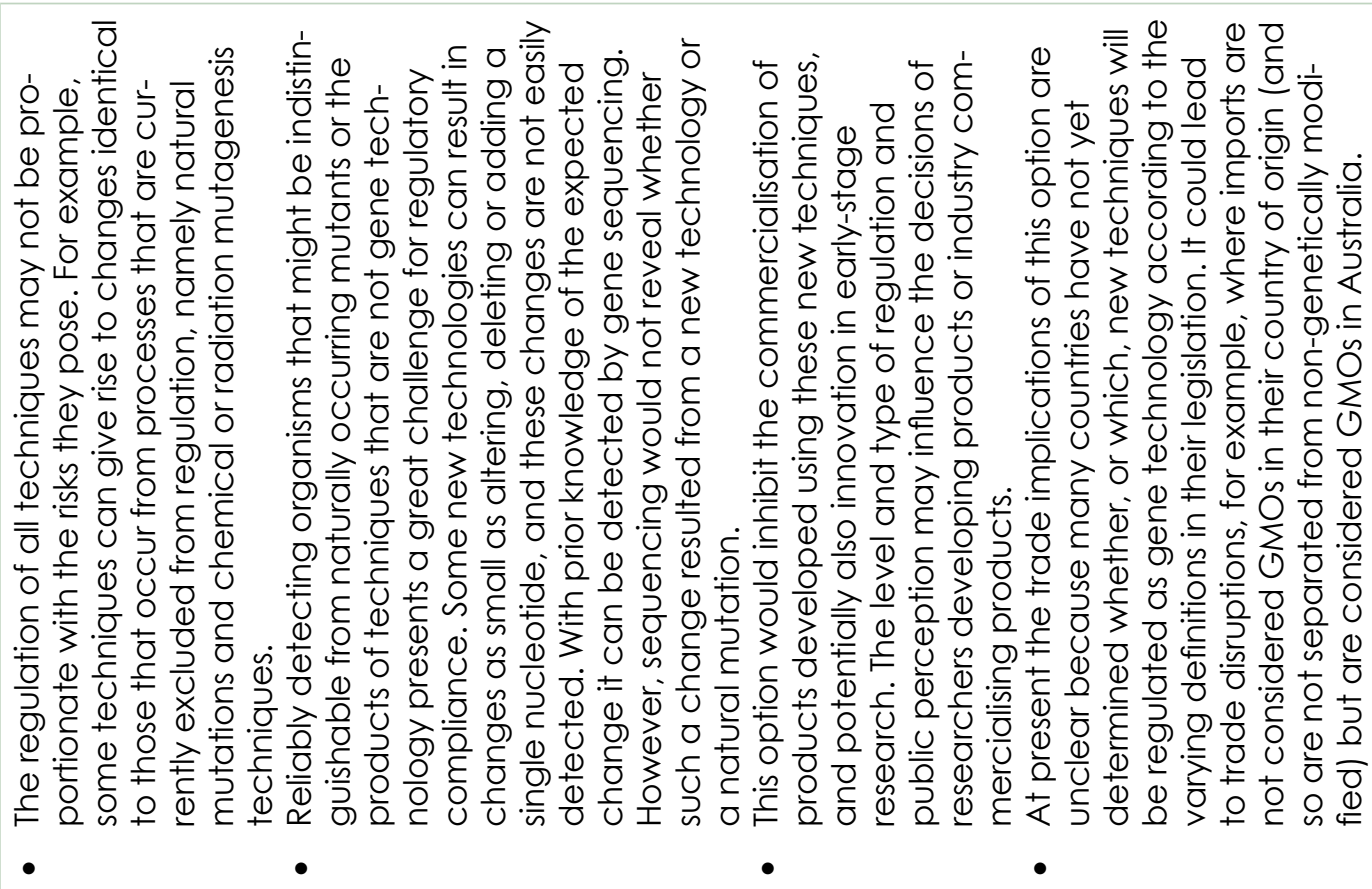

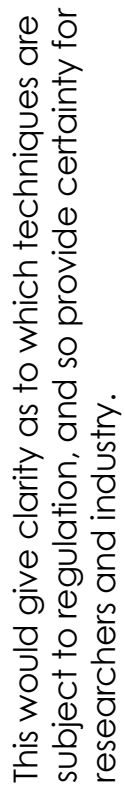

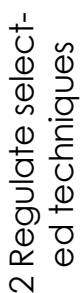




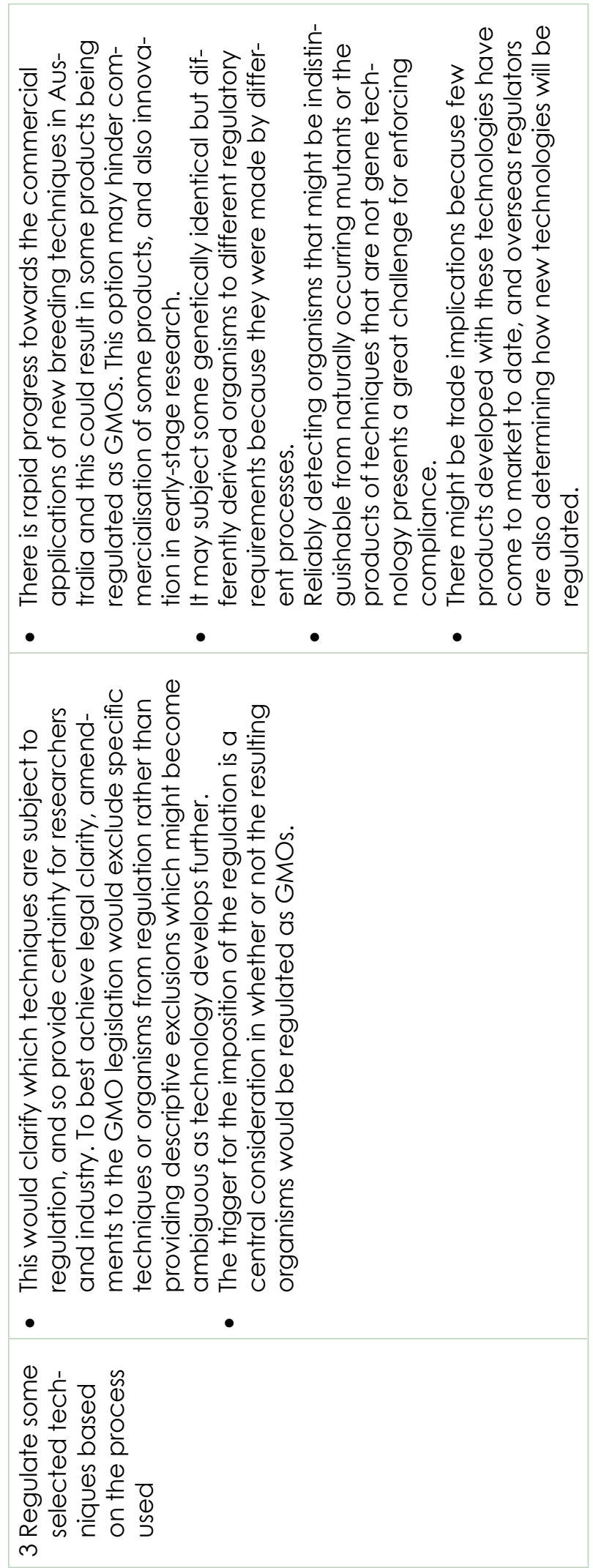




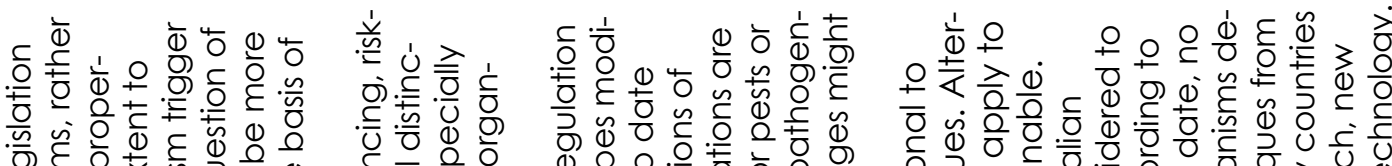

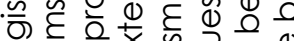
(1)

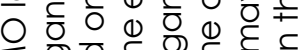

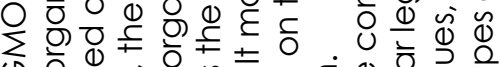

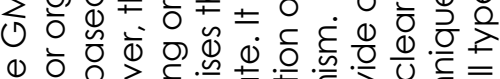

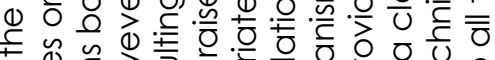

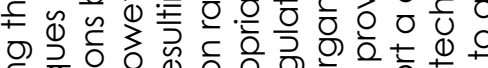

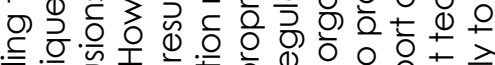

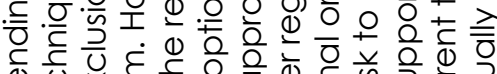

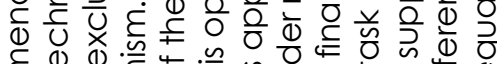

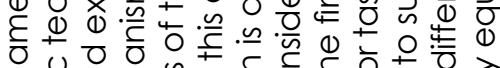

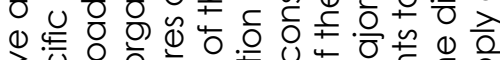

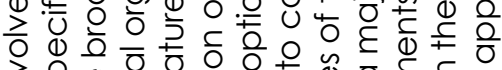

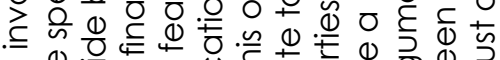

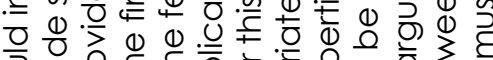

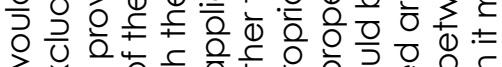

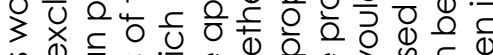

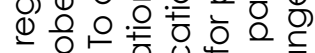

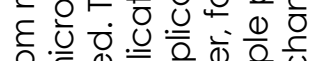

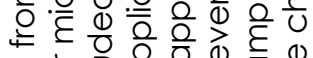
(1)

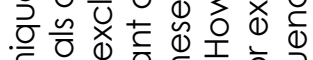

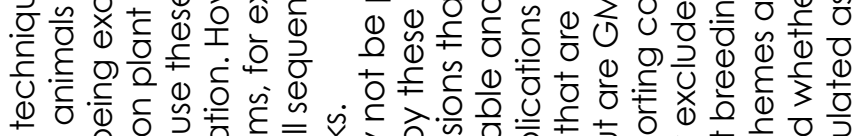

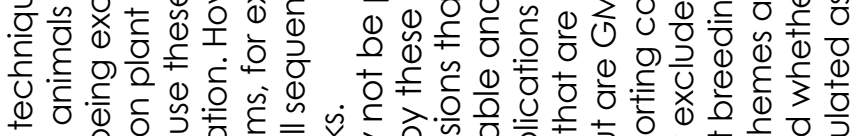
w⿳八人口 立

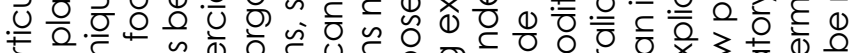

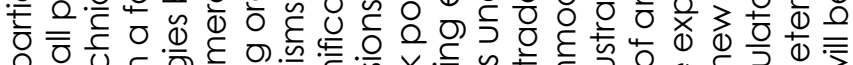

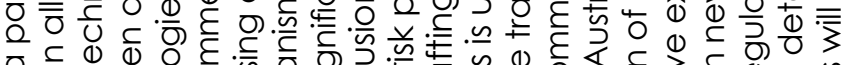

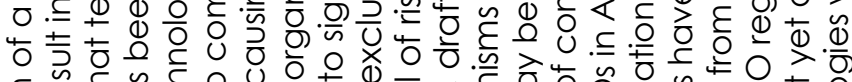

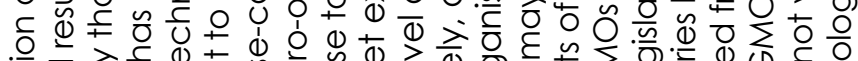

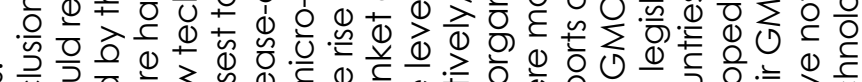

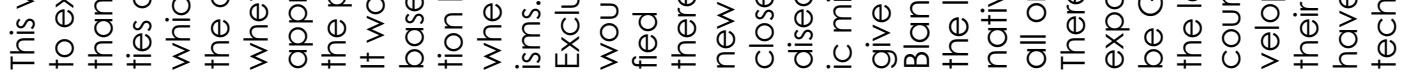

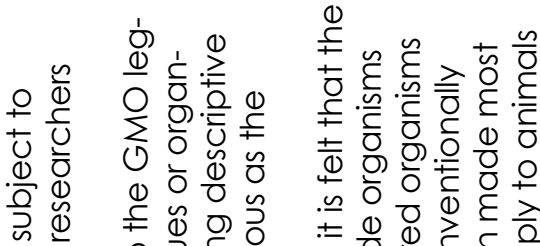

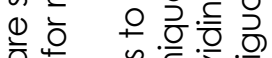

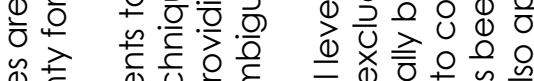 \\ D. \\ .당

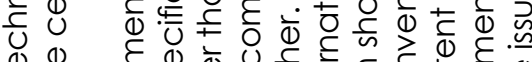 Q}

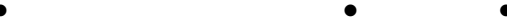

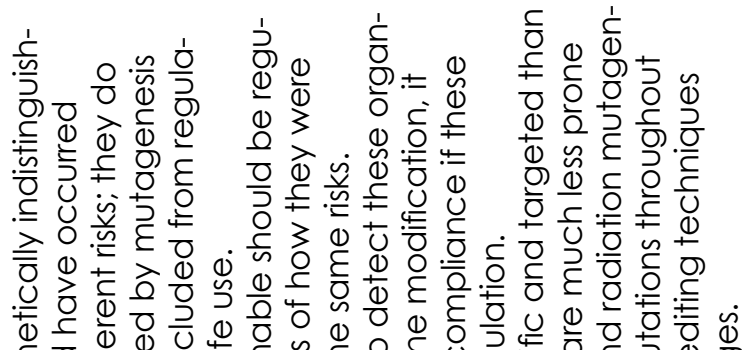

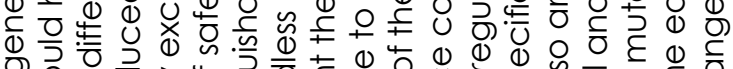
ठ गे ठ ग (1) 0 \&

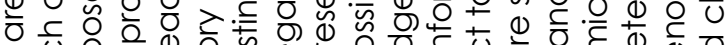

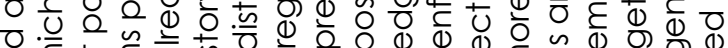
D

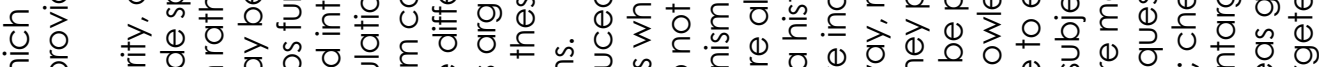

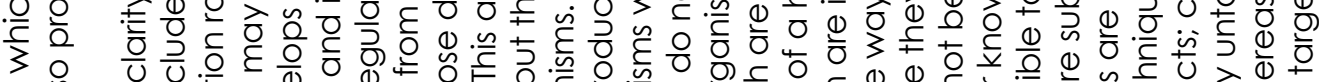

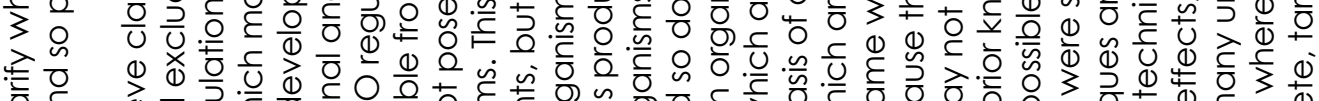

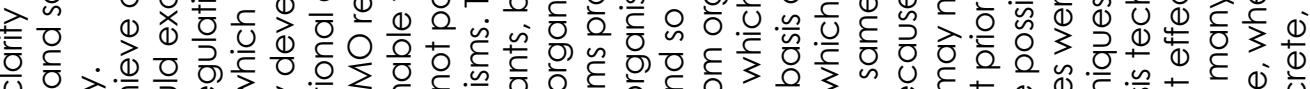

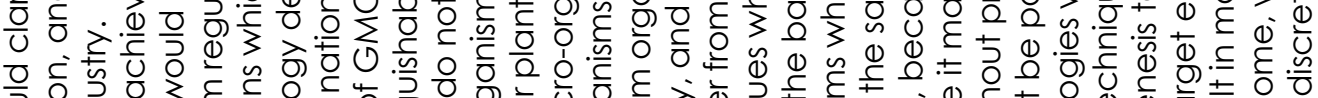

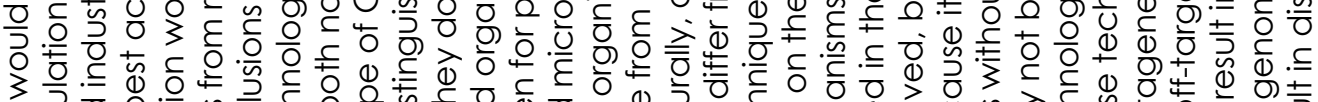

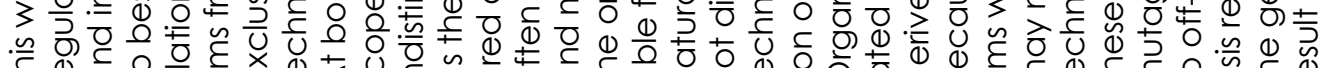

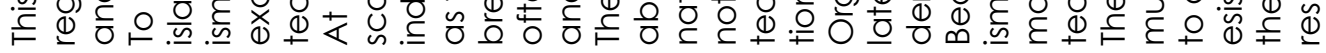

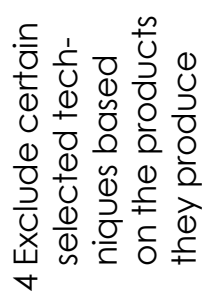




\subsection{Canada}

Canada's Biotechnology Regulatory Framework is product-based and is concerned with plants containing a trait not present in the same species already existing in Canada. Therefore, since Canada's regulatory system applies to novel products irrespective of breeding technique, it is not expected to require any amendment to accommodate case-by-case decisions on products derived from NBTs.

\subsection{USA}

Under the US Plant Protection Act (Public Law 106 - 224, Section 401, 20 June 2000), the USDA determines the regulatory status of products derived from NBTs based on a case-by-case analysis, but neither the EPA nor the FDA has specifically declared a policy approach on NBT products. Several products have already been identified by the USDA to not fall under the regulation usually applied to GMOs.

For example, in 2015, researchers at Pennsylvania State University developed a transgene free, anti-browning white button mushroom using the CRISPR-Cas9 technique to produce several small deletions in a specific polyphenol oxidase gene. These deletions disabled the enzyme polyphenol oxidase, which causes browning in some fruits when they are exposed to air, but otherwise lacks any major role in plant metabolism. The innovators responsible for this solution to the problem of food waste decided to consult the USDA before moving further towards commercialisation. They wanted to know whether their product would be considered a GMO, or be exempted from such due to the lack of any demonstrated potential for hazard, as are all varieties derived from 'conventional' breeding. After studying their application, Animal and Plant Health Inspection Service (APHIS) concluded that the anti-browning mushroom fell outside the scope of the regulations under which APHIS acts to prevent or manage risks to US. agriculture. However, it was still subject to FDA regulations which require all food placed on the market to be safe.

The US regulatory criteria for biotechnology are based on its very particular legal framework; a determination of regulated/non-regulated status can therefore not be readily transplanted to most other countries which base their regulation on language similar to that of the CPB. The USA has announced that it intends to carry out a major update of the regulatory system which will take into account the future development of biotechnology techniques and products.

\subsection{United Kingdom}

The United Kingdom's (UK) Advisory Committee on Releases to the Environment (ACRE) was requested to provide information on NBTs, the organisms they generate and arguments for and against their regulation under the GMO legislation (ACRE 2013a, 2013b, 2013c). This information was published in 2015 and Table 5.2 summarises the status of the techniques and the organisms generated by them. Note that a combination of these techniques may be used in the generation of a new plant variety.

Many of these techniques are not only used in the genetic modification of plants but also of animals and micro-organisms. 
Table 5.2 A summary of the status of certain NBTs as compiled by UK Advisory Committee on Releases to the Environment (ACRE)

\begin{tabular}{|c|c|c|c|}
\hline Technique & $\begin{array}{l}\text { Involves a GM } \\
\text { technique? }\end{array}$ & $\begin{array}{l}\text { Produces an intermedi- } \\
\text { ate product that is a } \\
\text { GMO? }\end{array}$ & Offspring are GMOs? \\
\hline Cisgenesis/intragenesis & Yes & - & Yes \\
\hline Reverse breeding & Yes & Yes & No \\
\hline Agro-infiltration & Yes & Questionable & No \\
\hline $\begin{array}{l}\text { Grafting (non-GM } \\
\text { scion/GM rootstock) }\end{array}$ & No & Yes & No \\
\hline \multirow[t]{2}{*}{$\begin{array}{l}\text { RNA-dependent DNA } \\
\text { methylation }\end{array}$} & $\begin{array}{l}\text { No - nucleic acid } \\
\text { molecules not in- } \\
\text { serted into genome }\end{array}$ & No & No \\
\hline & $\begin{array}{l}\text { Yes - nucleic acid } \\
\text { molecules inserted } \\
\text { into genome }\end{array}$ & Yes & No \\
\hline $\begin{array}{l}\text { Oligo-directed mu- } \\
\text { tagenesis }\end{array}$ & Yes & No & No \\
\hline $\begin{array}{l}\text { Zinc-finger nucleases } \\
\text { (mutagenesis) }\end{array}$ & Yes & No & No \\
\hline
\end{tabular}

ACRE highlighted the following three issues requiring legal clarification:

- Are the offspring of GMOs necessarily GMOs? The answer could affect the status of organisms produced by reverse breeding.

- It is not clear what "altering the genetic material of an organism in a way that does not occur naturally by mating or natural recombination" means. Does it require the formation of new combinations of genetic material that do not occur naturally? In which case, it would not include modifications that do not alter the nucleotide sequence of the genetic material, or changes that will result in nucleotide sequences that are likely to be present in nature or as a result of conventional breeding. This question has ramifications for other issues linked to interpreting the definition. In particular, the answer could affect the status of cisgenics and RNA-dependent DNA methylation.

- The relevance of referring to "recombinant nucleic acid molecules" where these molecules are not inserted into the genome of the host organism. This point has a bearing on the status of organisms produced by mutation, such as through the use of zinc-finger nucleases or oligonucleotides.

\subsection{Germany}

The position of the German Biosafety Commission (Anon, 2012), on whether the offspring of several NBTs should be considered GMO or not, is shown in Table 5.3. 
Table 5.3 The status of certain NBTs as per the 2012 position statement of the German Biosafety Commission

\section{Technique}

\section{Cisgenesis}

- border sequences and/or marker genes are present

- no border sequences present and marker genes removed

Intragenesis

Reverse breeding

- Step 1: trans DNA in parent organism

- Step 2: double haploid production

- Step 3: reverse bred organism with no trans DNA

Agro-infiltration (not GM itself, but contains a GMO)

Agroinoculation/Agroinfection

Floral Dipping

Grafting

- reproductive offspring from non-GM part

- reproductive offspring from GM part

RNA-directed DNA methylation

- for stably integrated recombinant DNA in the genome of the recipient organism

- for transient recombinant DNA

- when introducing isolate RNA

Oligo-directed mutagenesis

Zinc-finger nucleases

ZFN1

ZFN 2

ZFN 3
Are offspring

GMOs?

Yes

No

Yes

Yes

No

No

NA

No

Yes

No

Yes

Yes

No

No

No

No

No

Yes

\subsection{Sweden}

The Swedish Board of Agriculture was one of the first competent authorities that pronounced on the possible regulation of some types of genome edits, when they concluded in November 2015 that type 1 and 2 CRISPR-Cas9 edits, which may also occur naturally, do not fall under the European GMO definition.

\subsection{Switzerland}

In 2016, the Swiss Academies of Arts and Sciences concluded that the genetic makeup of plants can be modified precisely by means of new breeding techniques. Typically, these changes could also occur naturally and, in the process, no genetic material that is unrelated to the species remains in the plant. These techniques significantly broaden the possibilities for plant breeding, thereby potentially helping to make agriculture more environmentally friendly, economically viable and ultimately more sustainable. As some varieties developed by using the NBTs already exist and new ones are expected to follow shortly, it is imperative to determine whether or not plants engineered by means of these new techniques are subject to the Gene Technology Act. From a natural scientific point of view, the Swiss Academies found that there is no reason for a strict regulation of plants bred in this fashion. 


\subsection{European Union (EU)}

After inquiries from the academic sector as well as the biotechnology industry regarding the regulatory status of plants obtained by NBTs, an ad hoc working group was established by the European Commission. The working group finalised its report in 2012 but this report has not yet been released.

In 2012 the Joint Research Centre of the EU published safety assessment criteria on cisgenesis, intragenesis and ZFN 3, which are considered to be the NBTs with the best chance of their derived products being universally classified as GMOs.

\subsection{OECD}

The OECD has a permanent Working Group on Harmonisation of Regulatory Oversight in Biotechnology which is addressing NBTs as an emerging issue. In a report published in 2015, it was noted that in most member countries the development of NBTs is still at the research phase. National authorities are only now beginning to consider if and how NBT-derived products are to be regulated.

\subsection{Other}

Schaart and Visser (2009) described four classes of NBTs and indicated which plants or products produced by each should be considered as GMOs (Table 5.4).

Table 5.4 Novel plant breeding techniques, consequences of new genetic modification-based plant breeding techniques

\begin{tabular}{|c|c|c|c|}
\hline Class & Description & NBTs & GMO/Non-GMO \\
\hline 1 & $\begin{array}{l}\text { Plants and products do not contain any } \\
\text { genetic material that was used for the ini- } \\
\text { tial genetic modification, therefore, plants } \\
\text { and products are similar to traditionally } \\
\text { bred plants. Consequently, the environ- } \\
\text { ment and food and feed safety do not } \\
\text { differ from that of traditionally bred plants. } \\
\text { Proof should be requested that the plants } \\
\text { or product are Agrobacterium-free, virus- } \\
\text { free and transgene-free using accepted } \\
\text { standard techniques and/or methods. }\end{array}$ & $\begin{array}{l}\text { Agro-infiltration } \\
\text { Virus Induced Gene } \\
\text { Silencing } \\
\text { Reverse Breeding Ac- } \\
\text { celerated Flowering }\end{array}$ & $\begin{array}{l}\text { Non-GMO } \\
\text { Non-GMO } \\
\text { Non-GMO } \\
\text { Non-GMO }\end{array}$ \\
\hline 2 & $\begin{array}{l}\text { Although products from the non-genet- } \\
\text { ically modified part of the grafted plant } \\
\text { do not contain any genetic material that } \\
\text { was used for the initial genetic modifica- } \\
\text { tion, RNA molecules, proteins and me- } \\
\text { tabolites that are related to the genetic } \\
\text { modification may be present. Proof should } \\
\text { be requested that the plants or product } \\
\text { are Agrobacterium-free, virus-free and } \\
\text { transgene-free using accepted standard } \\
\text { techniques and/or methods. }\end{array}$ & Grafting & $\begin{array}{l}\text { Non-GM scion = } \\
\text { Non GMO } \\
\text { GM scion = } \\
\text { GMO }\end{array}$ \\
\hline
\end{tabular}




\begin{tabular}{|c|c|c|c|}
\hline 3 & $\begin{array}{l}\text { Plants contain DNA sequences that have } \\
\text { been introduced by genetic modification. } \\
\text { The introduced genes originate from the } \\
\text { species itself or from a cross-compatible } \\
\text { species. If the introduced genes show an } \\
\text { expression that corresponds to the base- } \\
\text { line, such cisgenic and intragenic plants } \\
\text { are regarded as similar to the baseline, } \\
\text { also in terms of environmental safety and } \\
\text { food and feed safety. If it is also proven } \\
\text { that the final product is free of agrobac- } \\
\text { teria and sequences that are foreign to } \\
\text { the species, such cisgenic and intragenic } \\
\text { plants are not considered to be GMOs. In } \\
\text { general, however, intragenesis is aimed } \\
\text { at differential expression of genes. If for } \\
\text { intragenesis an alternative promoter } \\
\text { was used to alter the expression of an } \\
\text { intragene, the intragene expression may } \\
\text { deviate from that of the baseline. In such } \\
\text { a case, additional studies are required to } \\
\text { assess the environmental and food and } \\
\text { feed safety. }\end{array}$ & $\begin{array}{l}\text { Cisgenesis } \\
\text { Intragenesis }\end{array}$ & $\begin{array}{l}\text { Non-GMO } \\
\text { GMO }\end{array}$ \\
\hline 4 & $\begin{array}{l}\text { Plants and products do not contain any } \\
\text { genetic material that was used for the } \\
\text { initial genetic modification. The genetic } \\
\text { modification was used as a tool to in- } \\
\text { troduce specific mutations. Plants and } \\
\text { products obtained through this class of } \\
\text { plant breeding technique are similar to } \\
\text { the plants obtained by traditional muta- } \\
\text { tion breeding, which are used as baseline } \\
\text { references, and the consequences for the } \\
\text { environment and food and feed safety do } \\
\text { not differ from that of traditionally mutated } \\
\text { plants. }\end{array}$ & $\begin{array}{l}\text { ZFN } 1 \\
\text { ZFN } 2 \\
\text { ZFN } 3 \\
\text { ODM } \\
\text { TALENs } \\
\text { CRISPR }\end{array}$ & $\begin{array}{l}\text { Non-GMO } \\
\text { Non-GMO } \\
\text { GMO } \\
\text { Non-GMO } \\
\text { Non-GMO } \\
\text { Non-GMO }\end{array}$ \\
\hline
\end{tabular}

In a recent US survey of academic and industry-based experts in biotechnology and gene editing techniques, representatives of regulatory agencies overseeing biotechnology, non-government organisations (NGOs) and consumer groups concerned with the health and environmental effects of biotechnology, Kuzma et al. (2016) identified the following regarding the respondents' concerns about targeted genetic modification as compared to traditional biotechnology:

\section{More problematic concerns}

- Communication and public understanding

- Greater public distrust due to negative experiences with GM

- Security issues may become more problematic

- Ethical oversight

- Fair distribution of benefits

- Fascination with gene editing may overshadow safety concerns

\section{Less problematic concerns}

- Animal welfare concerns

- Environmental safety

- Toxicity 


\section{Similar concerns}

- International harmonisation of regulation

- Fair distribution of benefits

- Public understanding and acceptance

- Regulatory capacity building in developing countries

- Mmaintaining crop variety

- Ownership of germplasm banks

- Intellectual property rights (IPR)-related impact on competition

- IPR-related impact on public research

- Impact on access in developing countries

- Impact on research relevant to the needs of developing countries

They also anticipated that gene editing may initiate the following regulatory changes:

- Greater speed of development, adoption, production may overwhelm the regulatory system.

- Faster approval processes.

- Greater variability in traits and products may not be successfully handled by the regulatory authorities.

- New definition of GM will be necessary.

- Greater access to technology will present issues for regulatory regimes and their coordination.

- Will fail the old process approach.

- Regulators will start to encourage the technique.

- New ethical concerns.

- New scientific capacity will be required from regulators.

- Less testing will be necessary.

Finally, respondents indicated their degree of concern regarding various aspects of gene edited plant products. This is summarised in Table 5.5.

Table 5.5 The degree of concern regarding various aspects of gene edited plant products among US stakeholders (from Kuzma et al. 2016)

\section{Concern}

Environmental risks

Human health safety

Intellectual property rights issues

The ability of farmers to afford products

The adequacy of public funding for basic research

The adequacy of public funding for product development

The adequacy of public funding for environmental and human health studies

The control exerted by industry

The technical performance of the products

\section{Degree of concern*}

1

$55.5 \%$

2

$33.3 \%$

3

\begin{tabular}{|l|l|l|}
\hline $66.6 \%$ & $22.2 \%$ & $11.1 \%$ \\
\hline
\end{tabular}

\begin{tabular}{|l|l|l|}
\hline $37.0 \%$ & $25.9 \%$ & $37.0 \%$ \\
\hline
\end{tabular}

\begin{tabular}{|l|l|l|}
\hline $51.8 \%$ & $25.9 \%$ & $22.2 \%$ \\
\hline
\end{tabular}

\begin{tabular}{|l|l|l|}
\hline $40.7 \%$ & $33.3 \%$ & $25.9 \%$ \\
\hline
\end{tabular}

\begin{tabular}{|l|l|l|}
$48.1 \%$ & $11.1 \%$ & $40.7 \%$ \\
\hline
\end{tabular}

\begin{tabular}{|l|l|l|}
$29.6 \%$ & $14.8 \%$ & $55.5 \%$
\end{tabular}

\begin{tabular}{|l|l|l|}
\hline $37.0 \%$ & $14.8 \%$ & $48.1 \%$ \\
\hline
\end{tabular}

\begin{tabular}{|l|l|l|}
\hline $61.5 \%$ & $23.1 \%$ & $15.4 \%$ \\
\hline
\end{tabular}

*1 - Somewhat or not at all; 2 - Moderately; 3 - Very to extremely 


\subsection{Conclusion}

The NBTs which have been developed since the introduction of GM legislation represent a clear challenge for regulators as their classification under current GMO legislation is not clear. Comparison of the situation in several countries and the remarks made by several other organisations show that:

(i) legislation, definitions and regulatory approaches differ significantly,

(ii) very few competent authorities have to date finalised their approach to NBT regulation,

(iii) decisions are currently taken on a case-by-case basis,

(iv) there has been very little focus on international harmonisation.

There also seems to be general consensus that:

(i) current GMO systems and approaches are relevant and sufficient to also accommodate those NBT products that may be regulated;

(ii) due to the large possible differences between different NBT products and the fact that new techniques will continue to be developed, it is highly inadvisable to base the definition of a regulatory trigger on techniques or technologies;

(iii) not all NBTs should be subject to regulation (although defining a coherent, principle and widely acceptable regulatory threshold/trigger will probably prove to be difficult);

(iv) an effective and adaptive regulatory framework, able to handle all current and possible future 'genome modification techniques' requires a well-defined regulatory trigger, based on risk management principles, and the ability to consider products on a case-by-case basis when necessary. 


\section{CHAPTER 6}

\section{Regulatory Frameworks and Risk Analysis for NBTs}

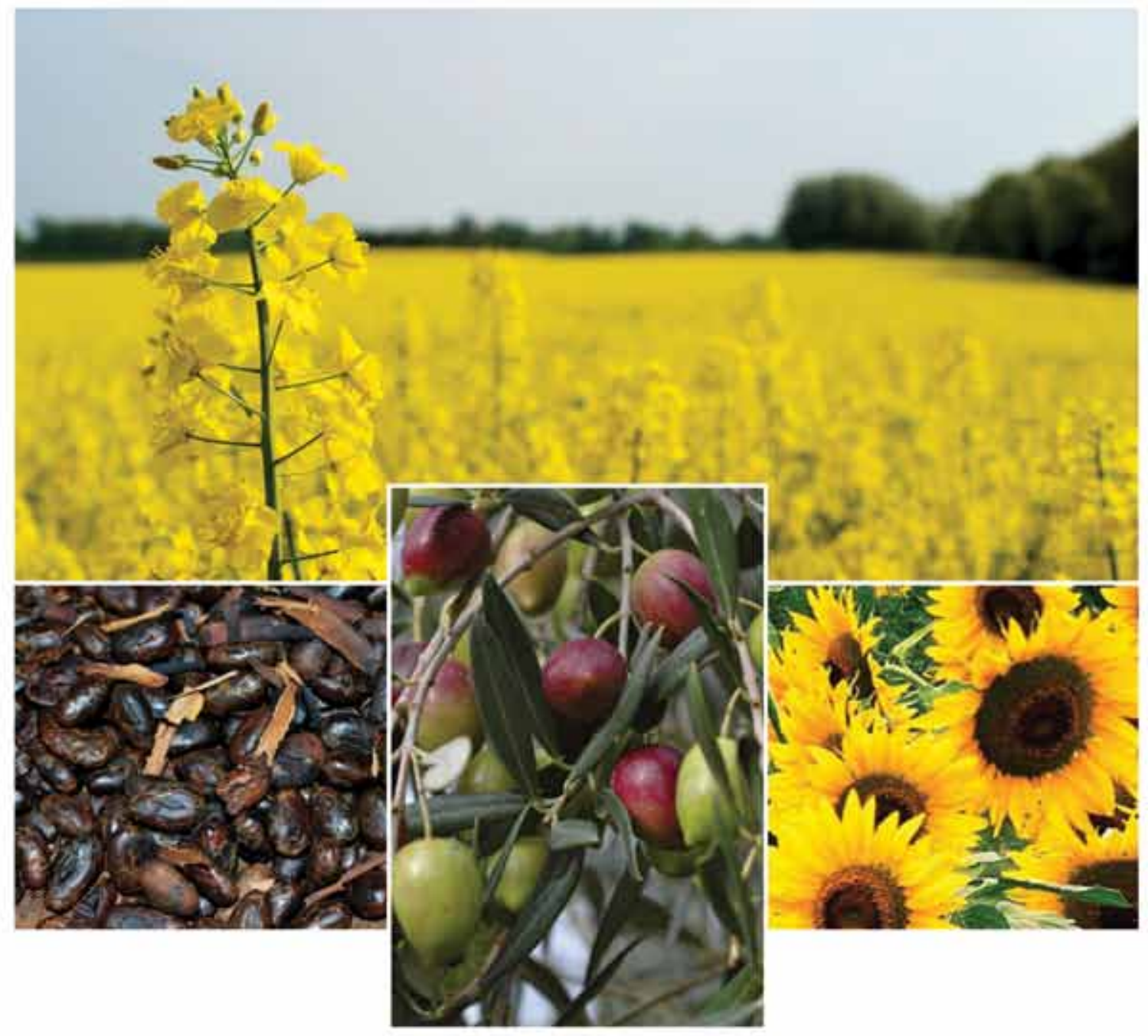




\subsection{Introduction}

The ongoing debate on the regulatory status of NBTs is complex because of the wide range of techniques deployed and their variable impact on the heritable traits of the target organism's genome. In addition, definitions for biotechnology-derived organisms, and GMOs in particular, were developed in the late 1980s to early 1990s and are still being applied without up-dates in most countries. As a result, the recently developed NBTs cause uncertainty for both developers and regulators as it is unclear whether organisms, developed using these techniques, fall under current GMO legislation or not.

A further complication is that the legislation, definitions and regulatory approaches for biotechnology-derived organisms, differ significantly between countries. As a result, there are concerns that the introduction of these new techniques could lead to further non-harmonised regulatory approaches and asynchronous development and marketing of such crops and animals, resulting in trade disruptions.

The two major questions that arise are:

(i) if and how NBTs should be integrated into current regulatory systems,

(ii) if the current risk analysis framework used for GMOs will be appropriate and sufficient to assess the potential risks that may be associated with these applications.

\subsection{Proportionate Regulation}

The accuracy, relative simplicity and low cost of some NBTs places the power of precise genetic engineering, and its huge potential gains, in the hands of a much wider spectrum of innovators, including those in the public sector, SMEs and those working with minor and orphan crops. However, the adoption of these technologies and reaping their benefits is highly dependent on the regulatory requirements for their resulting products. An under-appreciated impact of excessive regulation is that it disproportionately affects small enterprises and the public research environment, which lack the necessary appetite and resources to comply with burdensome and costly regulatory requirements (Conko et al. 2016). It is also well understood that regulatory approaches have the potential to influence the risk perceptions regarding these technologies and their products - potentially unduly raising public concern and negatively impacting the deployment of products produced through such technologies.

Unnecessary regulation and oversight of such products, based on the method of development, would result in undue, costly regulatory burdens, stifle innovation and prevent the uptake of scientifically advanced, innovative breeding applications by the public and private sectors. In addition, the regulatory status of NBTs will impact trade not only in plant propagating material but also in agricultural commodities derived from this material. Different government approaches risk disrupting international commodity trade flows, particularly in a scenario where various levels of regulation are applied to the same type of product, with asynchronous pre-market approvals.

Miller (2010) and Barton et al. (1997) presented the Stanford Model for regulation of field trials with GM plants, being unsatisfied with the lack of proportion between risk and regulatory scrutiny. This model stratifies organisms according to risk in field trials, and is analogous to existing regulatory regimes. The advantage of the Stanford Model is that it is sufficiently flexible to accommodate differences in regulatory authorities' preferences for greater or 
lesser regulatory stringency, as long as the risk factor of each category is coupled with an appropriate and relative regulatory requirement. Another similarly flexible model has been presented by Araki and Ishii (2015), setting up the continuum of genetic alterations in a range from minor (leaky or null mutations) to major (transgenesis) changes. Four levels of stringency in the regulation are imposed along this range, allowing policymakers to shift towards more permissive regulation for certain genetic alterations as evidence of safety accumulates. This model would also promote global harmonisation of regulatory frameworks. The benefit of this model is, that it has the flexibility to start off with a relatively process-directed system of regulation, that is politically acceptable to many stakeholders today while allowing a shift towards more product-based interpretations as scientific evidence accumulates and the products gain a safe history of use.

\section{KEY MESSAGE}

The regulation of any biotechnology and/or its products should only be considered when the risks they pose are significantly greater than those posed by comparable, natural biological systems and then it should be proportional to the risks it manages and balanced with the benefits the technology promises.

\subsection{Product versus Process-based Regulation}

In 1987, the US National Research Council (NRC) concluded that the product of genetic modification and selection should be the primary focus for making decisions about the risks of environmental introduction of a plant or micro-organism, not the process by which the products were obtained (NRC, 1989). Their report concluded that evaluation of experimental field testing should be based on:

- knowledge about the traits of the organism and the test environment;

- the ability to confine or control the spread of the organism, as necessary;

- the likelihood of harmful effects if the organism should escape control or confinement.

In 1992, the US National Biotechnology Policy Board concluded that the risks associated with biotechnology were not unique and tend to be associated with particular products and their applications, not with the production process or the technology per se. In fact, biotechnology processes tend to reduce risks because they are more precise and predictable (National Biotechnology Policy Board, 1992).

In addition, any regulatory scheme should also incorporate the general principles that:

- the degree of regulatory scrutiny should be proportionate with the level of risk, keeping in mind the difference between real and perceived risk;

- similar things should be regulated in a similar way;

- the scope of what requires regulatory review must make sense.

These principles have been the basis for all OECD regulatory guidance documents since 1995. They are further codified in the World Trade Organisation (WTO) Sanitary and Phytosanitary protection measures, to which WTO member states are bound.

The above conclusions confirm that all possible risks that could be associated with GM technologies are inextricably linked with the resulting GMOs, not the techniques that yield them. It therefore follows that the traits of these organisms/products should be the trigger for regula- 
tion and not the processes/techniques used to create them. In addition to this risk-rational, a regulatory trigger based on products rather than processes also makes more practical sense in terms of:

- the same process/technique can yield GMOs/products with widely differing genetic traits and risk profiles;

- although 'modern biotechnology' processes/techniques may be used, the resulting organisms/products may be indistinguishable from conventional/natural organisms;

- processes evolve while the acceptable risk profile of products can be defined in terms of principle parameters that are less likely to change over time - a product focus can therefore ensure regulatory consistency;

- with a product risk management focus it is possible to define clear, durable risk thresholds (beyond which regulation is required) to help ensure regulations remain relevant and appropriate.

\section{IMPORTANT NOTE}

It is important to realise that the term 'product' in this context does not only refer to a final product/GMO, i.e. that which is eventually commercialised, but rather to any and every organism/GMO, which may be produced during any research and development (R\&D) programme. The intention of using a 'product-based' regulatory trigger is therefore not to only regulate 'final products', i.e. to exclude early R\&D work from regulation, or to try to completely detach techniques/processes from products, but rather to focus regulation, and associated risk management interventions on the most relevant hazard (potential source of harm).

Despite these apparent obvious conclusions regarding the advantage of a product-based approach and the product-based systems implemented by the first adopters of the technology such as the USA and Canada, many national biosafety regulatory frameworks have evolved to use the GM process as the trigger for regulation. The underlying philosophical reason for this is probably the persistent, apparent controversial nature of GMOs, which has resulted in a significant divergence between the perceived and science-based risks associated with these organisms and their products. Considerable pressure has therefore been placed on regulatory frameworks to adopt a precautionary approach and to be 'all-inclusive' in an attempt to manage this broad spectrum of risk perceptions and to inspire confidence. Historically, this philosophy, heavily influenced by the European perspective, also impacted negotiations at the CPB, which eventually adopted a process focus, i.e. "...genetic material obtained through the use of modern biotechnology". The subsequent use of the CPB as the basis for the development of their national biosafety frameworks by many countries, contributed to the proliferation of process-based regulatory systems.

Although all policymakers and regulators are not in agreement that product-based systems have clear advantages to process-based systems, primarily in light of the possible legislative amendments that a new focus may require, there is growing support from risk assessors, technology developers and even regulators for an exclusive product-based approach (Marchant and Stevens, 2015, Van Eenennaam and Young, 2015, Huang et al., 2016, Sprink et al., 2016). NBTs now place even more emphasis on the advantages of a product or traitbased system, since the boundaries between GM and non-GM techniques are becoming increasingly blurred and, in some cases, impossible to detect. NBTs therefore provide additional motivation to ensure regulatory frameworks are consistent, proportionate, evidence-based 
and sufficiently robust to accommodate both existing and new technologies and agronomic practices as they arise.

It is important for policymakers to recognise that NBTs are already widely used in research, and that commercial applications have started to emerge. Regulatory frameworks should therefore adapt as a matter of urgency to be able to accommodate them (Lusser et al., 2012, 2013). Policymakers should further realise that there are also possible costs associated with not introducing appropriate regulatory processes. These include inhibition of the development of potentially important applications that could contribute to addressing some of the key challenges facing agriculture, deployment of novel traits without appropriate consideration of risks when new products fall outside the remit of existing regulatory processes and additional costs arising from the need to detect particular types of novel products in traded goods.

\section{KEY MESSAGE}

A product-based regulatory framework has distinct advantages over a process-based system. Product-based regulatory triggers ensure an appropriate focus on the actual source of possible risks, i.e. the hazard, and enable the establishment of suitable, resilient regulatory parameters, which will remain relevant and appropriate irrespective of future technological developments.

\subsection{The South African Regulatory Framework for GMOs}

In general, the principal reason for any regulation is to mitigate harm through risk management. Regulation is, therefore, only triggered at a point beyond which explicit risk management is required and the regulatory requirements should always be proportionate with the risk posed. In the South African context, the definition of a GMO in the GMO Act focuses on the 'unnatural' character of the introduced genetic change/variation and therefore introduces 'unnatural genetic variation' as the threshold beyond which risk should be managed/regulated. In the Act's definition of a GMO', 'unnatural' could be interpreted as referring to either the way in which the genetic variation was introduced, i.e. the process - 'artificial, human intervention', or the nature of the resulting genetic material/GMO, i.e. the product - 'genetic variation that could not conceivably have originated naturally'.

When considering the exclusions of the GMO Act, i.e. mutagenesis, ploidy manipulations and somatic hybridisation, it is clear that human intervention/process is not considered an absolute trigger for regulation, but rather the end result/product of the intervention. Moreover, although the excluded techniques can be used to artificially induce genetic variation, all possible resulting variation will be limited to modifications of only the endogenous genetic material - no exogenous genetic material is added and therefore variation that can conceivably also originate naturally. In contrast to this 'induced endogenous' genetic variation, GM, as contemplated in the Act, adds exogenous genetic material to the target genome, which results in genetic variation that could not have originated naturally based on sexual compatibility and therefore introduces the possibility of novel risk, which should be regulated.

It is therefore evident that a GMO under the Act, i.e. "...an organism the genes or genetic material of which has been modified in a way that does not occur naturally...", is defined in terms of its eventual genetic makeup and not the process through which it was established;

\footnotetext{
"Genetically modified organism - means an organism the genes or genetic material of which has been modified in a way that does not occur naturally through mating or natural recombination or both, and 'genetic modification' has a corresponding meaning".
} 
GMOs being organisms whose genetic variation has been increased beyond that which may likely also occur naturally, through the introduction of exogenous genetic material. The GMO Act, therefore, establishes a 'genetic variability threshold' for regulation, aimed at only managing the possible risks, associated with the introduction of genetic traits beyond those that may conceivably also originate naturally. Any induced genetic variation limited to what may conceivably also occur naturally, including any small insertions/deletions and recombinations/transformations with sequences/genes from compatible organisms, therefore falls below this genetic variation threshold and should not be regulated, as any risks this may pose are equivalent to those that also occur naturally. This natural genetic variation threshold is also prudent in light of the fact that these, even when induced using a bio-technique, will be undetectable/indistinguishable from natural variation, which will make regulation impossible to enforce.

When considering that the GMO Act has a product-based approach and that it establishes an appropriate threshold for regulation based on genetic variation, it is clear that the Act is sufficient to handle the regulation of all current and possible future techniques aimed at modifying the genetic material of living organisms. New genetic modification technologies, including NBTs, and all possible sub-sets thereof should be evaluated in terms of their ability to introduce novel risks (those that could not also conceivably arise naturally) within appropriate, well-defined parameters/limits to exclude/include them under the Act as a matter of principle or to be regulated on a case-by-case manner. Such an approach is also in line with Argentina's trigger for the regulation of NBTs, e.g. "novel combination of genetic material" the only formal pronouncement by a regulator on this issue thus far.

The preamble to the GMO Act states that its mandate is "to provide for measures to promote the responsible development, production, use and application of genetically modified organisms". When considering the evolution and performance of the regulatory framework over the almost 20 years of its existence, it is fair to say that the great majority of its dealing adhered to this spirit. During this time the Act was for example amended to ensure alignment with other national and international legislation, regulations were amended to mitigate extraordinary circumstances and ex post risk management practices were implemented effectively. The South African regulatory framework for GMOs will therefore most likely be able to seamlessly integrate any possible changes necessitated by NBTs.

\section{KEY MESSAGE}

The GMO Act has a product-based trigger and establishes genetic variability beyond that which may occur naturally, as the threshold for regulation. Within this context the Act is appropriate and sufficient to regulate all current and possible future techniques aimed at modifying the genetic material of living organisms.

\subsection{NBT Risk Assessment}

The risk assessment of GMOs is a structured, reasoned process, based on the analysis of scientific evidence, for considering the likelihood and consequence of harm occurring and is pro-actively used to facilitate decision-making regarding the development and use of GMOs. Biosafety risk assessments for GMOs focus on possible environmental and food/feed safety impacts. In addition, many countries also consider possible socio-economic impacts to ensure, cumulatively, the sustainability of a GMO before it is released for commercial 
production. Generally, all these assessments are comparative, done on a case-by-case basis and consider the host and donor organisms, genetic modification and receiving environment. Although different countries may use different regulatory triggers, terminology and detailed frameworks, the underlying principles are consistent and universally accepted.

NBTs refer to a wide and evolving range of techniques, including techniques that may permanently modify the target genomes and/or gene expression. In addition, these genetic changes may vary in a continuum from small mutations, indistinguishable from naturally occurring genetic variation, to the introduction of complex exogenous genetic pathways. In cases where the genetic traits of the resulting organism are impacted, the general risk assessment approaches, developed for GM crops, are in principle appropriate to address as well the potential risks of the NBT-derived organism (Eckerstorfer et al., 2014; Conka et al., 2016). Specifically, the principle of comparative case-specific risk assessment, takes into account the particular characteristics of the specific NBT event, e.g.:

- the modifications to the genome due to the NBT;

- the introduction into the NBT-genome of DNA which is ordinarily not found in this crop species;

- the traits generated by NBTs;

- modifications to gene expression due to the NBT or the trait(s) introduced by use of NBTs.

Other risk assessment issues that may be of particular importance to NBTs include:

- Whether genomic modifications were introduced into the genome of a particular organism in the course of application of a NBT, and if so, which type of modification.

- Whether such modifications are present only transiently, in certain intermediate steps of the breeding process or present in a stable inheritable manner in the final breeding product. An additional issue is whether such genomic modifications are present in all cells of the NBT or only in specific types of cells, e.g. somatic cells, reproductive cells or plant parts, e.g. transgrafting.

- Whether the NBT introduced non-native sequences into the context of the genome.

- The availability of sufficient knowledge on the modified genes and their function as well as experience with the traits generated by NBTs. This is also recognised in the concept of "history of safe use" which is an important element in the comparative risk assessment for GM plants.

- Verify whether available experience and data, e.g. those drawn from conventionally bred crops, are appropriate to address some of the risk assessment issues of particular NBTs.

- To be able to implement a comparative approach two considerations need to be taken into account:

- The definition of an appropriate 'unmodified' comparator - typically a crop line with a similar genetic background, such as an isogenic line.

Choice of a scenario for conducting the comparative approach.

\section{KEY MESSAGE}

GMO risk assessment has evolved over more than three decades into a robust framework that can be applied to any genetically engineered organism, irrespective of the techniques used as long as the principles of a case-by-case comparative risk assessment applies. 


\subsection{GMO Risk Experience}

GMO regulatory scrutiny is applied to individual 'transformation events' even when the same gene introduction has been evaluated many times previously, on the premise that the physical insertion of DNA into a genome could itself have potentially hazardous, unintended effects by interfering with the normal functioning of endogenous genes (Kessler et al., 1992.). Consequently, each time a given transgene is introduced into an organism, regulators consider that a new 'event' is created, which constitutes a unique product for the purposes of regulation, which in turn requires individual field testing, the preparation of a complete regulatory dossier and regulatory approval.

The case for re-evaluating these regulatory requirements has been strengthened by more than two decades of experience (Conko et al., 2016). A review by Weber et al. (2012) concluded that unintended DNA-level changes that could occur from GM are no different from those that occur in plant genomes naturally, a finding that was later substantiated in a review by Schnell et al. (2015). Likewise, Steiner et al. (2013) observed that novel toxins not known to occur at the genus level have never been known to arise spontaneously during conventional breeding. These findings are consistent with the prediction of the 1989 NRC analysis which concluded that crops modified by molecular and cellular methods pose risks no different from those modified by classical genetic methods for similar traits.

Some examples of the application of NBTs to achieve a beneficial genetic modification and the possible risk management and regulatory implications are given in Appendix 3.

\subsection{Conclusion}

The regulation of NBT-derived organisms can be comfortably incorporated under the GMO Act and any potential risks can be effectively governed if:

(i) the Act is interpreted as having a product-based trigger, i.e. the characteristics of the genetic change and resulting organisms;

(ii) genetic variation beyond that which may occur naturally is considered the threshold for regulation.

\section{IMPORTANT NOTE}

These two defining parameters, i.e. trigger and threshold, should always be interpreted in the same context, i.e. genetic variation beyond that which may occur naturally, refers to the actual genetic change/traits of the organism/product and does not relate to how they were introduced, i.e. the process.

This will, in effect, mean that the final genetic change becomes the primary indicator/trigger for regulation and the resulting organisms can simply be classified as either GMO or non-GMO and managed accordingly. If classified as GMO it will be regulated as legislated by the GMO and related Acts - i.e. the GMO status quo, if not, no regulation beyond that associated with conventional breeding will apply (Refer to Fig 7.1 and Table 7.2).

If deemed necessary, this final classification can still be done on a case-by-case basis by regulators within the current regulatory framework, e.g. as part of a succinct 'notification procedure' to the Registrar of the GMO Act (Also see Section 7.2 and Fig 7.2). This will ensure 
complete oversight without introducing excessive regulatory constraints on products that do not warrant risk management.

Within the South African context, no major legislative changes are considered to be necessary to accommodate NBTs or any possible future genetic engineering technologies. However, if the regulatory system is to ensure it remains fit-for-purpose, current and efficient, some significant issues will have to be addressed - including conceptual and operational issues related to definitions, exclusions, operational parameters, delegation of authority, standard operating procedures (SOPs), conformity to set time lines, etc. In addition, technical issues such as the type, quality and extent of the evidence and the identification of appropriate comparators required for different applications to ensure proportionate risk assessment and management will have to be considered, while allowing South Africans to benefit from these biotechnologies. 



\section{CHAPTER 7}

\section{General Conclusions and Recommendations}

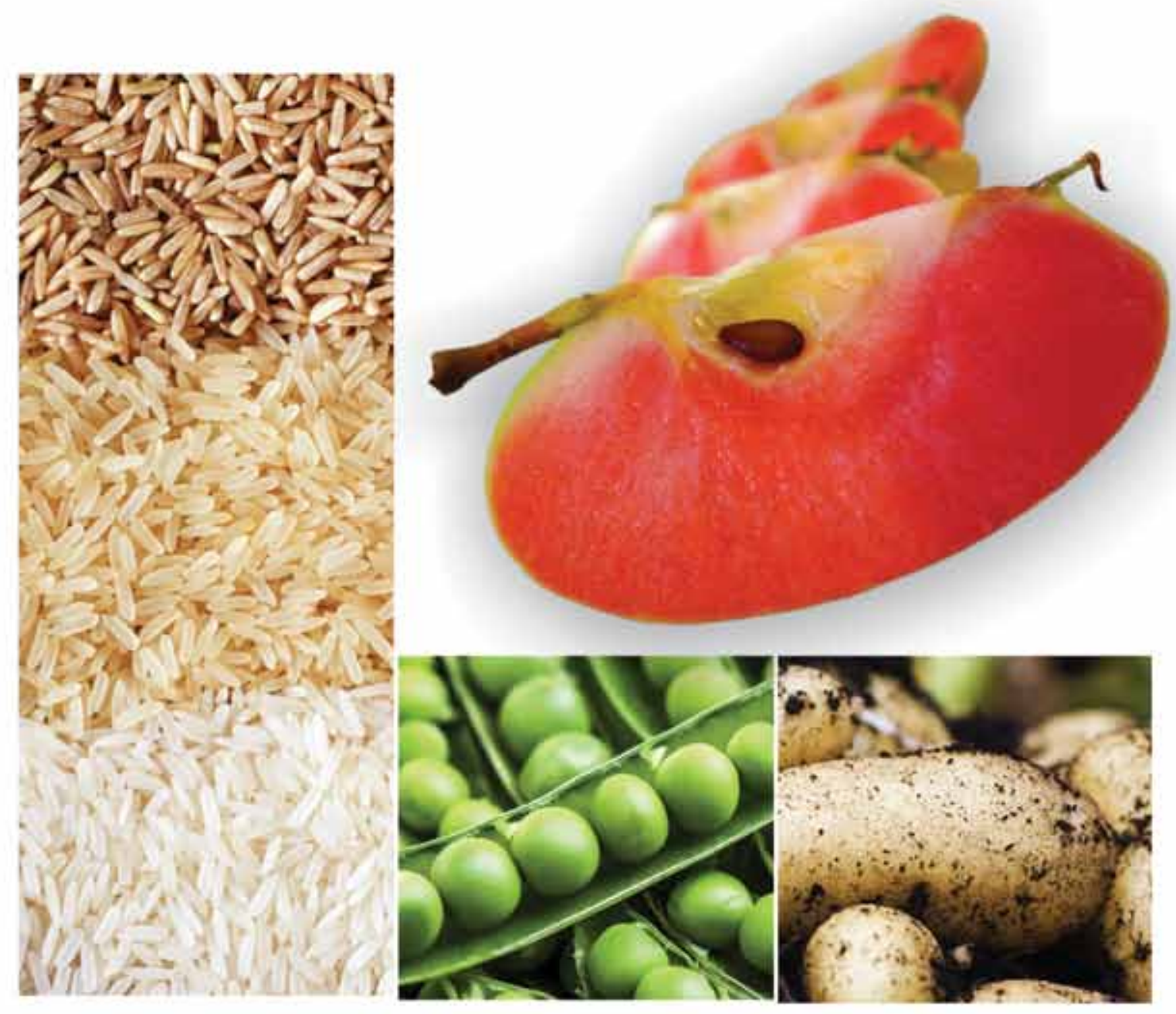




\subsection{Introduction}

At the time of drafting the GMO Act, it was generally understood that GMO refers to an organism into which exogenous genetic material was introduced using genetic engineering techniques. In other words, the introduction of genetic variation beyond that which may also occur naturally, which consequently clearly implies a product-based regulatory trigger (Pers. comm. J Morris, M Koch and D Keetch). Moreover, organisms developed using techniques which are limited to increasing only endogenous genetic variation, e.g. mutagenesis, ploidy manipulation, somatic hybridisation, conjugation, transduction, transformation and "any other natural process", were explicitly excluded from regulation (GMO Act). However, over time this distinction has become blurred, both in terms of "regulatory intent", i.e. a product vs. process-based regulatory trigger, and the continuum of possible genetic interventions that are now possible using newly developed techniques.

The concepts which guided the formulation of the original GMO definition and the list of exclusions in the GMO Act are still relevant and applicable to the questions we face now in 2017. The principle that organisms should be regulated according to the risks they may pose based on their modified genetic composition should remain the prime consideration. Genetic variation that may also occur in nature does not pose biosafety risks beyond that which may also occur naturally and therefore does not warrant regulation (Fig 7.1). There is also the practical requirement to be able to detect those organisms that are defined as GMOs to allow effective regulation. Reliably detecting organisms that might be indistinguishable from naturally occurring mutants presents an insurmountable challenge for enforcing compliance.

Based on the findings of this study, the following conclusions and recommendations are made. It is the panel's overall recommendation that these conclusions and recommendations should be considered and discussed by the Executive Council of the GMO Act in order for them to refine and implement them as appropriate. It is critically important to ensure that South Africa maintains and further develops a fit-for-purpose regulatory framework for genetic engineering technologies to optimally balance the requirement for safe, sustainable products and the need for a research and development environment conducive to bio-innovation. Failure to adapt the current regulatory procedures to fully enable the responsible utilisation of NBTs could have a negative impact on research and innovation in South Africa as contemplated in the Bioeconomy Strategy.

\subsection{Proposed Regulatory Framework for NBTs (and Other Genome Modifying Techniques) in South Africa}

South Africa has a robust GMO regulatory framework that has been used for more than 20 years to effectively regulate these organisms. The experience and expertise built up over this period should form the basis for the discussion regarding the regulation of NBTs, bearing in mind that:

(i) Regulation, where appropriate, should be based on sound scientific principles and be proportionate to the potential risks that are being managed.

(ii) The actual source of the risk that should be managed is the NBT-derived product, not the process through which it was developed (Fig 7.1). In addition, the same technique can often yield a wide variety of different products or different techniques can be used to develop the same product. A product-based regulatory trigger is therefore the rational choice. 


\section{IMPORTANT NOTE}

It is important to understand that although some techniques can be sub-categorised to define only a very specific genetic intervention-type, e.g. ZFN-1 that yields only small NHEJ indels, which could principally be excluded from regulation "as a technique", the relevant basis of that decision is still the induced genetic change/characteristics of the resulting product and not the technique (Discussed in detail in Section 6.3).

(iii) Induced changes to genomes need to be evaluated in light of the inherent natural variability of genomes and their associated impacts on the biosafety profiles of the related organisms. Moreover, it is not prudent to regulate NBT-derived products that are indistinguishable from products that could conceivably also be produced via more traditional methods as these products will not differ in their biosafety profiles.

(iv) The current definition of a GMO in the GMO Act can comfortably accommodate the above considerations regarding NBTs and clearly establishes genetic variation - beyond that which may occur naturally - as the threshold for regulation.

(v) South Africa's current regulatory framework for GMOs could therefore, with only minor updates to the GMO Act's Regulations and guidelines, be used to effectively regulate NBTs and all possible future genome modifying techniques.

(vi) The regulation of products derived from NBTs should be rational, clear and consistent in order to enable research institutes and the industry to adequately plan for the development and commercialisation of any regulated NBT products.

(vii) Internationally, governments should seek to harmonise their approach towards NBTs and avoid the unnecessary regulation of products developed through NBTs and other genetic engineering techniques.

As argued in Chapter 6, the products of various techniques which increase endogenous genetic variation have never been regulated under the GMO Act, because they are considered an extension of natural processes - their greatest possible biosafety risk impact will always be limited to what may also occur naturally. In other words, induced mutagenesis, in contrast to transgenesis, can never introduce genetic variation or risks that could not also originate naturally. In addition, recombination, which is also excluded from regulation under the GMO Act, is defined as any "shuffling of possible parental DNA", i.e. all possible combinations of genetic material from sexually compatible species. It therefore follows that neither the (induced) mutagenesis of a defined genome, nor the (induced) recombination of genetic material within sexually compatible species, e.g. cisgenesis, can introduce risks that could conceivably not also originate naturally - and the resulting products should therefore not be regulated.

The implications of this approach are that:

(i) Genetic change becomes the primary indicator and trigger for regulation - as it should, because it is the root source of risk.

(ii) Biosafety risk is simply divided into two categories - that which may occur naturally and that which may not.

(iii) Regulation/risk management is implemented only for organisms above this threshold of natural biosafety risk.

(iv) The GMO Act remains an adequate instrument for the regulation of all possible genetically engineered organisms.

(v) Regulated organisms are defined as GMOs, based on the GMO Act's definition of a GMO, while the rest are non-GMO. 
These points are summarised schematically in Figure 7.1.

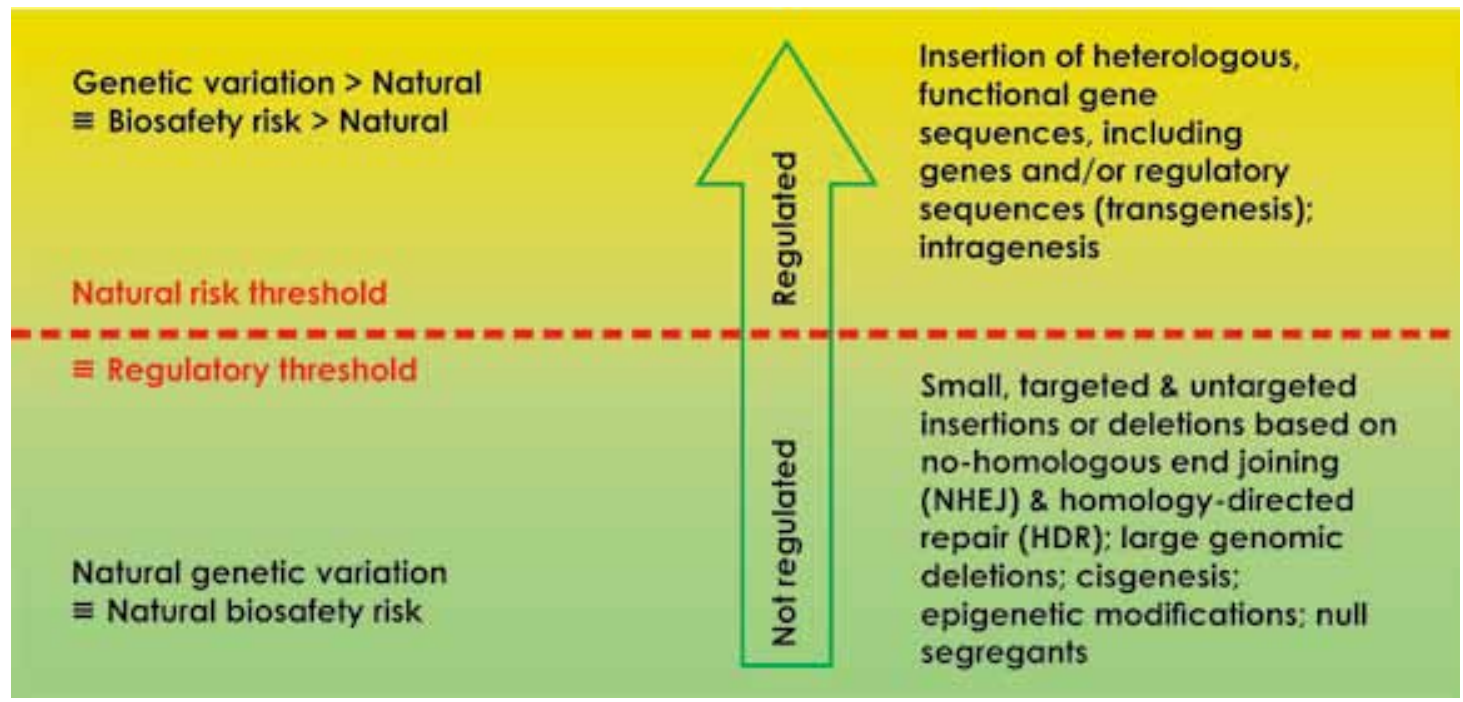

Figure 7.1 A schematic summary of the basis for the regulation of GMOs

It is important to note that although the GMO Act's mandate is clearly limited to managing the possible risks associated with genetic changes that may not occur naturally (GMOs), other relevant legislation, such as the Plant Improvement Act (Act 53 of 1976) and the National Environment Management Act (Act 107 of 1998), may still apply to non-GMOs generate through NBTs. Collaboration between the various regulators and harmonisation of all relevant regulatory instruments should therefore always remain a priority to ensure, overall, regulations are fair, prudent and consistent and do not introduce unnecessary overlap, inefficiencies and/or bias.

Within the context of this suggested framework, the final decision on whether an organism is a GMO or not, and therefore subject to regulation under the GMO Act or not, can be reached by asking only a few pertinent questions. These can be organised into a simple decision tree as proposed in Figure 7.2. This decision tree also permits developers to pro-actively anticipate the applicability of GMO legislation at the design stage of product development, to allow appropriate adjustment if required. 


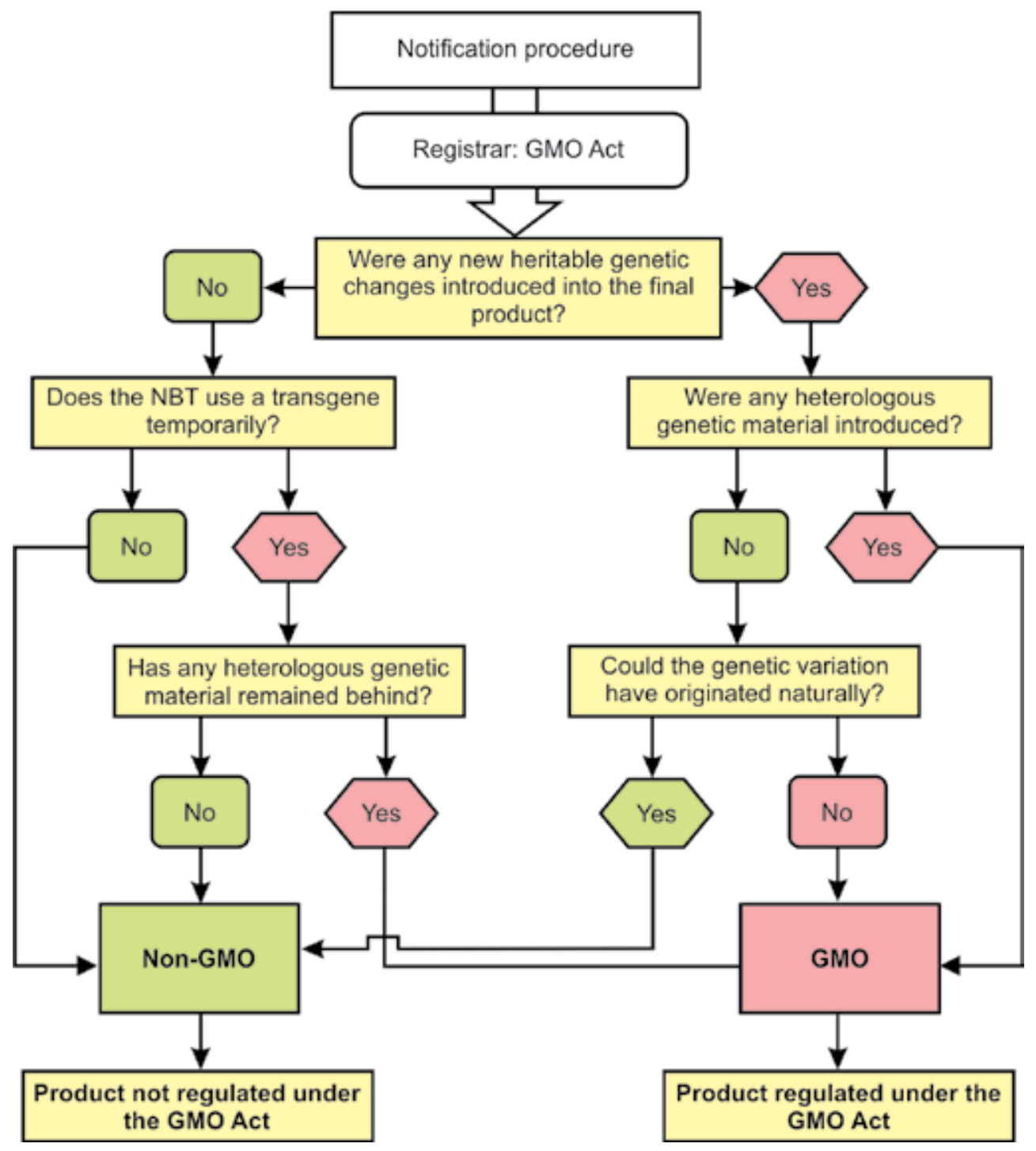

Figure 7.2 Proposed NBT decision tree for determining whether a specific NBT, or any other genetic engineering organism, should be subjected to regulation under the GMO Act or not

In practice, all relevant NBT products/lines could be subjected to a succinct "notification procedure" under the GMO Act, which requires the submission of the basic information required to answer the questions in the decision tree. Such a notification procedure will also introduce a mechanism which enables a case-by-case regulatory approach/decision-making by the EC of the GMO Act and appropriate oversight without introducing an excessive regulatory burden.

Finally, the likely regulatory outcome for specific products of the various NBTs assessed in this study, based on the proposed product-based regulatory trigger and unnatural genetic variation threshold, are summarised in Table 7.1. 
Table 7.1 The likely regulatory outcome for specific products of various NBTs based on the proposed product-based regulatory trigger and unnatural genetic variation threshold

\begin{tabular}{|c|c|c|c|}
\hline $\mathrm{Nr}$ & Genetic change & Technique used & $\begin{array}{l}\text { Regulated as } \\
\text { a GMO? }\end{array}$ \\
\hline 1 & $\begin{array}{l}\text { Small, targeted and untargeted inserts or deletions } \\
\text { based on non-homologous end joining (NHEJ) }\end{array}$ & $\begin{array}{l}\text { Site-directed nucleases } \\
\text { (SDNs) }{ }^{1} \text {, mutagenesis }\end{array}$ & No \\
\hline 2 & $\begin{array}{l}\text { Small, targeted inserts or deletions based on homolo- } \\
\text { gy-directed repair (HDR) }\end{array}$ & $\begin{array}{l}\text { SDNs, oligonucleotide- } \\
\text { directed mutation } \\
\text { (ODM) }\end{array}$ & No \\
\hline 3 & Large, targeted genomic deletions & SDN pairs & No \\
\hline 4 & $\begin{array}{l}\text { Targeted insertion of homologous, functional gene } \\
\text { sequences, including genes and/or regulatory se- } \\
\text { quences (cisgenes) }\end{array}$ & Cisgenesis using SDNs & No \\
\hline 5 & $\begin{array}{l}\text { Targeted insertion of reorganised, homologous, } \\
\text { functional gene sequences, including genes and/or } \\
\text { regulatory sequences (intragenes) }\end{array}$ & Intragenesis using SDNs & Yes \\
\hline 6 & $\begin{array}{l}\text { Targeted and untargeted insertion of heterologous, } \\
\text { functional gene sequences, including genes and/or } \\
\text { regulatory sequences }\end{array}$ & $\begin{array}{l}\text { Transgenesis, using } \\
\text { "conventional GM } \\
\text { technology" or SDNs }\end{array}$ & Yes \\
\hline 7 & Epigenetic modifications & $\begin{array}{l}\text { RNA-dependent DNA } \\
\text { Methylation }\end{array}$ & No \\
\hline 8 & Null segregants & Reverse breeding & No \\
\hline \multirow{2}{*}{9} & \multirow[t]{2}{*}{$\begin{array}{l}\text { Transgrafting - combination of a GM rootstock and a } \\
\text { non-GM scion or vice versa }\end{array}$} & $\begin{array}{l}\text { GMO part and its } \\
\text { products }\end{array}$ & Yes \\
\hline & & $\begin{array}{l}\text { Non-GMO part and its } \\
\text { products }\end{array}$ & No \\
\hline
\end{tabular}

'e.g. ZFNs, MNs, TALENs \& CRISPR/Cas

\subsection{Final Conclusion and Recommendation}

Regulation should only be triggered at a point beyond which explicit risk management is required and the resulting regulatory requirements should be proportionate to the risk posed so as not to unduly impact on innovation. South Africa already has a robust and effective GMO regulatory framework that is able to accommodate the regulation of NBT-products and, in fact, the products of any genome modifying techniques that may still be developed in future. In order to do so the GMO Act's:

(i) trigger should be interpreted as being product-based;

(ii) regulatory threshold should be interpreted as being genetic variation beyond that which may occur naturally.

The panel is of the opinion that the implementation of such an approach will provide effective and appropriate oversight to ensure the safety and sustainability of all relevant products, without unduly impacting on innovation. It can also be implemented relatively quickly and easily, because it is based on already established legislation. Finally, although very few countries have officially implemented NBT regulations, the likely regulatory outcomes of the proposed approach align very well with the consensus discussions of other international experts. 


\section{REFERENCES}

ABCA (Agricultural Biotechnology Council of Australia), 2016: Regulatory oversight of new breeding techniques. http://www.abca.com.au.

ACRE (United Kingdom Advisory Committee on Releases to the Environment), 2013a:

Towards an evidence-based regulatory system for GMOs. http://www.defra.gov.uk/acre/ files/Report-1.pdf.

ACRE, 2013b: Why a modern understanding of genomes demonstrates the need for a new regulatory system for GMOs. http://www.defra.gov.uk/acre/files/Report-2.pdf.

ACRE, 2013c: Towards a more effective approach to environmental risk assessment of GM crops under current EU legislation. http://www.defra.gov.uk/acre/files/Report-3.pdf.

Anon, 2012: Position statement of the ZKBS on new plant breeding techniques. Bundesamt für Verbraucherschutz und Lebensmittelsicherheit. Ref No. 402.45310.0104. June 2012. 15 pp. Anon, 2013: Chair of UK's Advisory Committee on Releases to the Environment. https:// www.gov.uk/government/publications/genetically-modified-organisms-new-plant-growingmethods.

Anon, 2015: Seeds of change. Nature, 520,131-132.

Barton, J., Crandon, J., Kennedy, D. and Miller, H. A., 1997: A model protocol to assess the risks of agricultural introductions. Nature Biotechnology, 15, 845-848.

Bio economy Strategy. 2013. Department of Science and Technology (DST). ISBN number 978-1-919966-06-9.

Christian, M., Cernak, T., Doyle, E.L., Schmidt, C., Zhang, P., Hummel, A., Bogdanove, A.J., and Voytas, D.F., 2010: Targeting DNA double-strand breaks with TAL effector nucleases. Genetics, 186 (2), 757- 761.

Comeau, A., Caetano, V.R., St. Pierre, C.A., and Haber, S., 2001: Accelerated breeding: Dream or reality? In Wheat in a Global Environment, Vol 9 in series, Developments in Plant Breeding, 671-679.

Commonwealth of Australia (Department of Health), 2016: Technical Review of the Gene Technology Regulations 2001, Discussion Paper: Options for regulating new technologies. October 2016. Communication Branch, Department of Health, GPO Box 9848, Canberra ACT 2601

Conko, G., Kershen, D.L., Miller, H., and Parrott, W.A., 2016: A risk-based approach to the regulation of genetically engineered organisms. Nature Biotechnology, 34(5): 493-503.

D'Halluin, K., Vanderstraeten, C., Van Hulle, J., Rosolowska, J., Van Den Brande, I.,

Pennewaert, A., D'Hont, K., Bossut, M., Jantz, D., Ruiter, R., and Broadhvest, J., 2013: Targeted molecular trait stacking in cotton through targeted double-strand break induction. Plant Biotechnology Journal, 11 (8), 933-941.

Eckerstorfer, M., Miklau, M., and Gaugitsch, H., 2014: New plant breeding techniques and risks associated with their application. Environment Agency Austria Umweltbundesamt $\mathrm{GmbH}$, Vienna. 90 pp.

EFSA Panel on Genetically Modified Organisms (GMOs) 2012. Scientific opinion addressing the safety assessment of plants developed through cisgenesis and intragenesis. EFSAJ. 10:2561. Gibson, D.G., Benders, D.A., Andrews-Pfannkoch, C., Denisova, E.A., Baden-Tillson, H., Zaveri, J., Stockwell, T.B., Brownley, A., Thomas, D.W., Mikkel A. Algire, M.A., Merryman, C., Young, L., Noskov, V.N., Glass, J.I. Venter, J.C., Hutchison lii, C.A., Smith, H.O., 2008: Complete chemical synthesis, assembly, and cloning of a Mycoplasma genitalium genome. Science, 319 (5867), 1215-1220. 
Gill, C., 2016: A CRISPR Mushroom. http://agsci.psu.edu/magazine/articles/2016/fall-winter/acrispr-mushroom.

Honig, A., Marton, I., Rosenthal, M., Smith, J.J. Nicholson, M.G., Jantz, D., Zuker, A., and Vainstein, A., 2015: Transient expression of virally delivered meganuclease in plants generates inherited genomic deletions. Molecular Plant, 8, 1292-1294.

Huang, S., Weigel, D., Beachy, R.N. and Li, J., 2016: A proposed regulatory framework for genome-edited crops. Nature Genetics, 48(2),109-111.

James, C., 2015: Global Status of Commercialised Biotech/GM Crops: 2015. ISAAA Brief No. 51. ISAAA: Ithaca, NY.

Jiang, W., Bi, H., Fromm, M., Yang, B., and Weeks, D.P., 2013: Demonstration of CRISPR/Cas9/ sgRNA-mediated targeted gene modification in Arabidopsis, tobacco, sorghum and rice.

Nucleic Acids Research, 41 (20), pp. el88.

Jinek, M., Chylinski, K., Fonfara, I. and Haver, M., 2012: A programmable dual-RNA-Guided DNA endonuclease in adaptive bacterial immunity. Science, 337, 816-821.

Kessler, D.A., Taylor, M.R., Maryanski, J.H., Flamm, E.L. and Kahl, K.S., 1992: The safety of foods developed by biotechnology. Science, 256, 1747-1749.

Komarova, T. V., Baschieri, S., Donini, M., Marusic, C., Benvenuto, E. and Dorokhov, Y.L., 2010: Transient expression systems for plant-derived biopharmaceuticals. Expert Review of Vaccines, 9(8), 859-76.

Krens, F.A., Schaart, J.G., Burgh, A.M.V.D., Tinnenbroek-Capel, I.E.M., Groenwold, R., Kodde, L.P., Broggini, G.A.L., Gessler, C., and Schouten, H.J., 2015: Cisgenic apple trees: development, characterisation and performance. Frontiers in Plant Science, 6, 286.

Kuzma, J., Kokotovich, A., and Kuzhabekova, A., 2016: Attitudes towards governance of gene editing. Asian Biotechnology and Development Review, 18(1), 69-92.

Ledford, H., 2015: CRISPR, the disruptor. Nature, 522, 20-24.

Liu, H., Fu, Y., Jiang, D., Li, G., Xie, J., Cheng, J., Peng, Y., Ghabrial, S.A. and Yi, X., 2010: Widespread horizontal gene transfer from double-stranded RNA viruses to eukaryotic nuclear genomes. Journal of Virology, 84(22), 11876-11887.

Lusser, M., Parisi, C.; Plan, D., and Rodriguez-Cereza, E., 2012: Deployment of new biotechnologies in plant breeding. Nature Biotechnology, 30, 231-239.

Lusser, M., and Davies, H.V., 2013: Comparative regulatory approaches for groups of new plant breeding technique. New Biotechnology, 30, 437-446.

Lloyd, A., Plaisier, C.L., Carrol, D., and Drews, G.N., 2005: Targeted mutagenesis using a zinc -finger nucleases in Arabidopsis. Proceedings of the National Academy of Sciences, 102(6), 232-7.

Marchant, G.E., and Stevens, Y.A., 2015: A new window of opportunity to reject processbased biotechnology regulation. GM Crops \& Food, 6(4), 233-242.

Miller, H. I., 2010: The regulation of agricultural biotechnology: science shows a better way. New Biotechnology. 27(5), 628-634.

National Biotechnology Policy Board, 1992: National Biotechnology Policy Board Report (National Institutes of Health). Biotechnology Law Report, 12, 127-182.

NRC (National Research Council), 1989: Field Testing Genetically Modified Organisms: Framework for Decisions. National Academy Press, Washington, DC, USA.

Okuzaki, A., and Toriyama, K., 2004: Chimeric RNA/DNA oligonucleotide-directed gene targeting in rice. Plant Cell Report, 22, 509-512.

OSTP, 1992: Exercise of federal oversight within scope of statutory authority: planned introductions of biotechnology products into the environment; Announcement of policy. Federal Register, 57, 6753-6762.

Pogue, G.P., Fakhrieh, Vojdani, F., Palmer, K.E., Ernie Hiatt, E., Hume, SA., Phelps, J., Long, L., Bohorova, N., Kim, D., Pauly, M., Velasco, J., Whaley, K., Zeitlin, L., Garger, S.J., White, E., 
Bai, Y., Haydon, H. and Bratcher, B., 2010: Production of pharmaceutical-grade recombinant aprotinin and a monoclonal antibody product using plant-based transient expression systems. Plant Biotechnology Journal, 8(5), 638-654.

Schnell, J. et al., 2015: A comparative analysis of insertional effects in genetically engineered plants: considerations for pre-market assessments. Transgenic Research, 24, 1-17.

Shan, Q., Wang, Y., Li, J., Zhang, Y., Chen, K., Llang, Z., Zhang, K., Liu, J. Xi , J.J., and Qiu, J.L., 2013: Targeted genome modification of crop plant using CRISPR-Cas system. Nature Biotechnology, 31 (8), 686-8.

Schaart, J. G. and Visser, R.G.F., 2009: Novel plant breeding techniques, consequences of new genetic modification-based plant breeding techniques. Wageningen University Research Centre. COGEM Report, 60 pp.

Sprink, T., Eriksson, D., Schiemann, J. and Hartung, F., 2016: Regulatory hurdles for genome editing: process- vs. product-based approaches in different regulatory contexts. Plant Cell Report, DOI 10.1007/s00299-016-1990-2.

Song, G., Walworth, A.E., and Loescher, W.H., 2015: Grafting of genetically engineered plants. Journal of the American Society of Horticultural Science, 140(3), 203-213.

Swiss Academies of Sciences, 2016: New plant breeding techniques for Swiss agriculture significant potential, uncertain future. Swiss Academies Factsheets. Vol 11 (4):

Urnov, F.D., Rebar, E.J., Holmes, M.C., Zhang, H.S. and Gregory, P.D., 2010: Genome editing with engineered zinc finger nucleases. Nature Reviews Genetics, 2, 636-646.

Van Eenennaam, A.L., and Young, A.E., 2015: Animal agriculture and the importance of agnostic governance of biotechnology. Agriculture \& Food Security, 4, 21.

Weber, N., Halpin, C., Hannah, L.C. and Jez, J.M., 2012: Crop genome plasticity and its relevance to food and feed safety of genetically engineered breeding stacks. Plant Physiology, 160, 1842-1853.

Whelan, A.I. and Lema, M., 2015: Regulatory framework for gene editing and other new breeding techniques (NBTs) in Argentina. GM Crops \& Food, 6(4), 253-265.

Wijnker, E., Dun, K.V., Snoo, C.B.D, Lelivelt, C.L.C., Keurenties, J.J.B., Naharudin, N.S., Ravi, M., and Chan, S.W.L., 2012: Reverse breeding in Arabidopsis thaliana generate homozygous parental lines from a heterozygous plant. Nature Genetics, 44(4), 467-470.

Wu, L., Zhou, H., Zhang, Q., Zhang, J., Ni , F., Liu, C., and Qi, Y., 2010: DNA methylation mediated by a MicroRNA pathway. Molecular Cell, 38(3), 465-475. 


\section{APPENDIX 1}

\section{Biographies of Panel Members}

\section{Dr Hennie Groenewald (Chairperson)}

Dr Groenewald is the Executive Manager of Biosafety South Africa, a national biosafety platform initiated by Department of Science and Technology. Biosafety South Africa supports innovation in biotechnology through the delivery of value-adding services and investment in biosafety research to help ensure the safety and sustainability of biotechnological products. He has a PhD in plant biotechnology and has over 20 years of experience in research and development, teaching, project management, entrepreneurship and business development. His research career has focused on aspects of plant molecular physiology, biosafety, tissue culture, molecular biology and biochemistry, and he has authored several peer-reviewed papers and patents on these subjects. Prior to joining Biosafety South Africa, he worked at Stellenbosch University. He has previously also worked at the South African Sugarcane Research Institute and has been a visiting researcher at the Texas Agricultural \& Medical University, Weslaco, USA, the Max Planck Institut für Molekuläre Pflanzenphysiologie and Golm, Germany, and the Commonwealth Scientific and Industrial Research Organisation (CSIRO), Plant Industry, Brisbane, Australia.

\section{Dr Eugenia Barros}

Dr Barros has a PhD in microbiology from the University of Cape Town and she is a Principal Researcher in the Biosciences Unit at the Council for Scientific and Industrial Research (CSIR). She has led many scientific projects in the field of molecular biology and has been instrumental in applying some of her research outcomes in the agricultural and food sectors. She has also been at the forefront of plant-made therapeutic antibodies through a collaborative project with European laboratories and has scaled-up the production of an HIV-AIDS monoclonal antibody. Her research interests' focus on the development of molecular markers linked to gene coding for important traits using cDNA-based marker technologies. She has more than ten years' experience in molecular marker technology in cereal crops and eucalyptus.

\section{Dr Kingston Mashingaidze}

Dr Mashingaidze is Research Team Manager for Plant Breeding at the Agricultural Research Council's (ARC) Grain Crops Institute in Potchefstroom. He is also the South African Country Coordinator and Principal Investigator of Water Efficient Maize for Africa (WEMA) and the Improved Maize for African Soils (IMAS) project.

\section{Prof lqbal Parker}

Prof Parker is the former Director of the International Centre for Genetic Engineering and Biotechnology (ICGEB) Cape Town Component. He is currently a Professor at UCT. Previously he was the Head of the Division of Medical Biochemistry and Director of Research in the Health 
Science Faculty at the University of Cape Town. He obtained his PhD in biochemistry in 1979, completed a postdoctoral fellowship with Gary Stein in the USA and returned to join the Department of Medical Biochemistry in 1981. He was President of the South African Society of Biochemistry and Molecular Biology (1998-2001), and founder Secretary-General of FASBMB (the Federation of African Societies of Biochemistry and Molecular Biology) from 1996 to 2003. $\mathrm{He}$ is a Founder Member of the Academy of Science of South Africa and served as General Secretary from 2000 - 2004 and Vice- President from 2010 to 2016 . He served on the international jury panel for the Loreal/UNESCO Awards for Women in Science for the period $1997-2002$. In 2006 he was elected to the Executive Committee of the International Union of Biochemistry and Molecular Biology and has served as the Chair of the Committee on Symposia. In 2004 he was awarded the South African Society for Biochemistry and Molecular Biology Gold Medal for his contributions to biochemistry and the National Science and Technology Forum (NSTF) award for Outstanding Contributions in Science, Engineering and Technology in 2003.

\section{Dr James Southern}

Dr Southern is currently a consultant to the biotechnology industry, Advisor to the National Medicines Regulatory Agency (Biological Medicines, Clinical Trials and Pharmacovigilance) and temporary evaluator for WHO Prequalification of Vaccines. He is also the Chair of the Developing Countries Vaccine Regulators' Network (DCVRN). He has worked in all aspects of vaccine development, production and control between 1968 and 2000 and he has been a member of the Biological Weapons Working Group reporting to the Non-Proliferation Council since 1993, and was a member of the Non-Proliferation Council from 1994 to 2009. He advises the Biosafety Directorate of the Department of Agriculture on the safety of medicines incorporating genetically modified organisms. 


\section{Appendix 2}

\section{Attendance Register \\ Regulatory Implications of New Breeding Techniques \\ (NBTs) Workshop, 11 October 2016}

\begin{tabular}{|c|c|c|c|}
\hline $\mathrm{Nr}$ & Surname & Names & Organisation \\
\hline & Becker & John, Dr & African Centre for Gene Technologies \\
\hline & Chetty & Lukeshni, Dr & South African National Seed \\
\hline & De Ronde & Kobie, Dr & Syngenta SA \\
\hline & Durham & Ben, Mr & Department of Science and Technology \\
\hline & Groenewald & Hennie, Dr & Biosafety SA \\
\hline & Jansen van Rijssen & Wilna, Dr & Private \\
\hline & Kandolo & Delphin, Mr & Bayer \\
\hline & Keetch & Dave, Dr & Goldamer Consulting \\
\hline & Kone & Tondani, Mr & Department of Environmental Affairs \\
\hline & Levesley & Allison, Ms & Monsanto SA \\
\hline & Machaba & Kulani, Mr & DuPoint Pioneer \\
\hline & Maseko & Bongani, Dr & AfricaBio \\
\hline & Mkhonza & Nompumelelo, Ms & $\begin{array}{l}\text { Department of Agriculture, Forestry and } \\
\text { Fisheries }\end{array}$ \\
\hline & Mngadi & Phakamile, Ms & ASSAf \\
\hline & Mogapi & Thato, Ms & DEA \\
\hline & Mokhothu & Sello, Mr & DAFF \\
\hline & Naidoo & Sanushka, Dr & $\begin{array}{l}\text { Forestry and Agricultural Biotechnology } \\
\text { Institute }\end{array}$ \\
\hline & Ntutela & Siyabulela, Dr & AfricaBio \\
\hline & Oelofse & Dean, Dr & Agricultural Research Council \\
\hline & Parker & lqbal, Prof & University of Cape Town \\
\hline & Southern & James, Dr & Independent Consultant \\
\hline & Van der Walt & Wynand, Dr & FoodNCropBio \\
\hline
\end{tabular}




\section{Appendix 3}

\section{Examples of the Application of New Breeding Techniques}

The following four studies illustrate the use of a NBT to achieve a beneficial genetic modification and the possible risk management and regulatory implications.

1 Insect-resistant and herbicide-resistant cotton

The introduction of Meganuclease and repair DNA for homologous insertion of two genes into GM cotton (D'Halluin et al. 2013).

Host: $\quad$ GM Cotton GHB1 19

Phenotype: Glufosinate tolerant (bar); Lepidoptera Resistent (cry2Ae)

Technique: Meganuclease

Biolistic introduction of Meganuclease and repair DNA for homologous insertion of two genes - epsps and hppd.

Background: Herbicide-tolerance and/or insect-resistance is the most widely used GM traits in cotton. Different herbicide-tolerance and insect-resistance genes with different modes of action are needed to provide for future combined, broad coverage weed and pest control. In addition to herbicide-tolerance and insect-resistance traits, there are several agronomic and quality traits being developed for multiple-trait introgression in cotton and other crop plants, including disease-resistance, abiotic stress-tolerance, yield enhancement and quality traits. Combining two or more traits in one variety can be performed either by conventional breeding stacks or by molecular trait stacking in a single transgene locus using a transformation vector carrying multiple-trait genes. With both technologies, the logistical challenges increase with the number of trait genes to be stacked. Either large breeding populations have to be screened to identify those individuals in which all trait genes are retained or large numbers of transformants have to be screened to identify the one expressing all traits as desired. Targeted molecular trait stacking could overcome many of these challenges by targeted insertion of the additional trait genes in close genetic vicinity of an already existing transgene locus.

In this study, the feasibility of precise targeted integration of transgenes at an elite locus in cotton is demonstrated. This was possible through the combination of targeted DNA cleavage by nucleases with tailor-made specificities and HR-mediated repair of the DSB by naturally occurring DNA repair mechanisms. Targeted molecular trait stacking will facilitate faster and economical trait introgression.

Possible risks: $\quad$ Mutations introduced at off-target genomic locations sharing homologous sequences with the target site.

Unintended modification due to methods applied during transfection and regeneration.

Unintended effects associated with GM modification that are introduced in intermediate steps. 
The introduction of RNA/DNA oligonucleotides into rice plants to confer resistance to acetolactate synthase (ALS)-inhibiting herbicides. (Okuzaki and Toriyama, 2004.)

\begin{tabular}{l|l|}
\hline Host: & Rice \\
\hline Phenotype: & Resistance to sulfonylurea and imidazolinone herbicides \\
\hline Technique: & $\begin{array}{l}\text { Particle bombardment by introducing chimeric RNA/DNA oligonucleotides de- } \\
\text { signed to target the independent codons for Pro-171, Trp-548 and Ser-627 of the } \\
\text { endogenous rice acetolactate synthase (ALS) gene so it would confer resist- } \\
\text { ance to ALS-inhibiting herbicides. }\end{array}$ \\
\hline Background: & $\begin{array}{l}\text { Chimeric RNA/DNA oligonucleotides (COs) have been used to cause site-spe- } \\
\text { cific base changes in chromosomal targets in mammalian and plant cells COs } \\
\text { consist of } 68 \text { synthesised oligonucleotides which have a DNA 'mutator' region of } \\
\text { five nucleotides complementary to the target site flanked by 20-O-methyl RNA } \\
\text { bridges of eight to twelve nucleotides each. This DNA 'mutator' region includes } \\
\text { a mutation that is introduced into the endogenous gene. The first use of COs } \\
\text { to cause site-specific base changes in plant cells was reported in maize and } \\
\text { tobacco. In both cases, gene targeting was directed towards generating base } \\
\text { changes that resulted in a chemically selectable phenotype. The targeted gene } \\
\text { was an acetohydroxyacid synthase (AHAS) gene in maize and an acetolactate } \\
\text { synthase (ALS) gene in tobacco. Both ALS and AHAS are the first common en- } \\
\text { zymes in the biosynthetic pathway of branched-chain amino acids, leucine, iso- } \\
\text { leucine and valine, and mutations of specific amino acids in these proteins have } \\
\text { been known to confer resistance to sulfonylurea and imidazolinone herbicides. } \\
\text { In this study, the feasibility of CO-directed gene targeting was examined in rice. } \\
\text { Three COS were designed to introduce single-point mutations in the rice ALS } \\
\text { gene. Five plants resistant to ALS-inhibiting herbicide were selected, and the } \\
\text { nucleotide sequence of the ALS gene of each was determined. Specific con- } \\
\text { versions were detected at the targeted bases. The ALS gene of rice was chosen } \\
\text { as a target gene. The ALS gene was shown to exist as a single-copy gene in rice. } \\
\text { CO-directed gene targeting is less complicated in rice than in tobacco and } \\
\text { maize because tobacco and maize have an allotetraploid genome, and thus } \\
\text { two copies of ALS genes. }\end{array}$ \\
\hline
\end{tabular}

In the current study, precisely the expected alterations were detected in all five plants examined. The results indicate that $\mathrm{CO}$-directed gene targeting is feasible in rice and creates opportunities for basic studies of functional genomics and the manipulation of agricultural traits in rice.

Possible risks: $\quad$ Mutations introduced at off-target genomic locations sharing homologous sequences with the target site.

Potential expression of fusion-proteins for some types of knock-out mutations.

Unintended modification due to methods applied during transfection and regeneration.

Unintended effects associated with GM modifications that are introduced in intermediate steps.

Unintended effects, e.g. position effects, associated with introduced transgenic constructs. 
Demonstration of CRISPR-Cas9/gRNA-mediated targeted gene modification in Arabidopsis, tobacCo, sorghum and rice. (Jiang et al., 2013)

Host: $\quad$ Rice

Phenotype: $\quad$ Resistance to bacterial blight

From the protoplast cells, it can generate a GM plant

Technique: $\quad$ Cas9/single guide RNA (gRNA) system

Transient expression in rice protoplast cells with Cas9/gRNA

The target of the modification generated a change in the promoter region of genes (OSSWEET1 4 and OSSWEET11)

Background: $\quad$ The clustered regulatory interspersed short palindromic repeat (CRISPR)/CRISPRassociated protein (Cas) system, has evolved from studies of a set of related defence systems that a number of bacteria use in warding off invasion by viruses and foreign DNA molecules that enter the cell. In cells containing type II CRISPR/Cas systems that successfully ward off invading viruses or foreign DNAs, 20-bp snippets of the invading DNA sometimes can be incorporated as short palindromic repeats into the CRISPR region of the bacterial chromosome. During future assaults, destruction of invading DNA is achieved by an RNA-directed process in which RNAs encoded by the short palindromic repeats of the CRISPR region are transcribed into CRISPR RNA (CrRNA) segments that are processed into short, functional RNA fragments with the aid of trans-activating RNA (tracrRNA). Once processing is complete, both crRNA and tracrRNAs become associated with a Cas protein. The Cas protein contains two nuclease domains that can cleave each strand of DNA when DNA becomes associated with the Cas/crRNA/tracrRNA complex. This complex is guided to viral DNA or exogenous foreign DNA by hybridisation of a 20-bp portion of the crRNA to one strand of the invading DNA. Action of the two independent nuclease domains within Cas results in a double-stranded DNA break (DSB) at a site on the foreign DNA just upstream of a protospacer adjacent motif (PAM) composed of a few (2-5) nucleotides depending on the CRISPR/Cas system involved. The type II CRISPR/Cas system most widely used for gene editing is derived from Streptococcus pyogenes and has the advantage of possessing a PAM recognition sequence of only two nucleotides in length (GG). This allows for creation of numerous 'guide' RNAs (i.e. crRNAs) for any particular gene because of the usually abundant presence of GG sequences in most genes.

The CRISPR-Cas9 system and the simpler Cas9/gRNA system have proven successful in gene disruption, gene activation/repression and genome editing in several cell types and organisms [e.g. in bacteria, yeast, zebra fish, fruit fly and human cells. However, to date, there are no reports of successful expression of the CRISPR/Cas system in plants or plant cells. In this report, three slightly different versions of the Cas9/gRNA system delivered by Agrobacterium tumefaciens or polyethylene glycol (PEG)-mediated transfection are demonstrated to be functional in Arabidopsis and tobacco (dicots) and rice and sorghum (monocots).

Data presented in this report provide unambiguous evidence that the Cas9/gRNA system for targeted gene modification functions in higher plant cells. Expression of Cas9 and gRNA genes in two dicot species, Arabidopsis and tobacco, led to targeted cleavage of a non-functional GFP gene, mutagenesis by NHEJ DNA repair (verified by DNA sequencing) with restoration of a correct reading frame to the GFP gene and production of a strong green fluorescence in transformed leaf cells. 
Methods, strategies and gene constructs developed in this study should be applicable to a wide range of higher plants. Indeed, successful development of the Cas9/gRNA system for targeted gene modification and genome editing holds significant promise for advancing fundamental knowledge of plant biology as well as for creating crop plants with valuable new agronomic, nutritional and novel traits for the benefit of farmers and consumers.

Possible risks:

Off-site effects - Mutation may be introduced at non-specific loci with similar, but not identical, homology to the target sites

Mosaicism - plants with a mutant allele in only some of their cells may be produced, because the nucleases may not necessarily cut the DNA at the correct stage of development

Multiple alleles - healing of the nuclease cleavage site by non-homologous end joining may produce plants with different mutations from the same targeting constructs, requiring genome sequencing to verify the nature and position of the specific mutation.

\section{$4 \quad$ Red-fleshed apples with high level of antioxidants}

The development of two methods for the generation of cisgenic apples. (Krens et al., 2015) Host: Apple

Phenotype:

Red-fleshed apple fruits with an appealing red appearance and an increased level of anthocyanin-based antioxidants

Technique: $\quad$ Cisgenesis

Agrobacterium tumefaciens

The construction contains MdMYB10 (gene from a red-fleshed apple coding for a transcription factor involved in regulating anthocyanin biosynthesis), flanked by its native promotor and terminator.

Background: $\quad$ There is a great need for faster breeding tools, especially in woody plant species or others with a long generation time, and in vegetatively propagated heterozygous crops such as apples, pears, potatoes, and tulips. Crosses with 'wild' relatives require several rounds of back-crossing with the elite parent in order to get rid of undesired, negative traits originating from the wild parent. In apple, true back-crosses cannot be done because of self-incompatibility, adding to the complexity of apple breeding. So, once a high quality, elite variety has been bred after many years, a new crossing for the introduction of a single trait will make it disappear without a chance of ever being able to breed a similar variety again. Introduction of a single trait in an elite variety maintaining all good characteristics through GM, therefore, seems a perfect solution for these crops. However, the perceived risks of GM have severely hampered large-scale applications of this technology in apple or other food crops. To accommodate to some of the major objections, with the aim of reducing as much as possible public concerns and biosafety issues, the concept of cisgenesis was formulated in which the introduction of desired traits is still achieved by GM as a tool but the origin of the gene(s) is from sexually compatible plants, and the structure of the gene with native promoter, terminator and exons and introns is as it is present within the related donor plant. No foreign genes are present in the final product, particularly no antibiotic resistance genes of bacterial origin. 
Background: $\quad$ There are three methods to generate cisgenic plants. One is to avoid the use of any selection genes of any other source than the recipient organism (e.g., apple) whatsoever. Second is to use two separate T-DNAs, one delivering the necessary selectable marker genes and the other carrying the genes-of interest from cross-compatible species followed by segregation of these two T-DNAs in the progeny. The third method is to use excision of selectable marker genes by inducing recombination.

In this study the development of new cisgenic apple lines was achieved by recombination-induced excision of non-apple gene sequences from the T-DNA of the transgenic lines.

A new series of cisgenic apple lines were generated using an entirely different approach. Using the apple MYB transcription factor gene, MdMYB10, carrying the natural rearrangement in the promoter as found in red-coloured, red-fleshed apple varieties originating from var. "Niedzwetzkyana", a minimal vector was constructed containing within the T-DNA borders only this MdMYB10 gene, flanked by its native promoter and terminator. Red, cisgenic "Gala" and "Junami" apple lines were produced by selecting solely on anthocyanin production and red staining of callus, shoots, and plants.

This paper contributes to the accumulating evidence that cisgenic crops are similar to conventionally bred crops, as was already concluded for hazards associated to both breeding methods by the EFSA Panel on Genetically Modified Organisms.

Possible risks: $\quad$ Proteins may be expressed that have never been part of the human or animal diet.

Increased expression of endogenous plant genes may affect the food and feed safety via altered biochemical properties.

Disruption of existing ORFs or creation of new ones due to random insertion of the cisgene in any part of the genome which in turn may lead to changes in the chemical composition of the plant

Due to position effects, the expression of the cisgene may differ from expression of the endogenous gene in its natural genomic position.

Insertional mutagenesis (e.g. deletions, rearrangements) may occur at the insertion site of the cisgene.

As transformation methods usually are applied in cell cultures unintended changes in the plant genome may occur as a result of the in vitro culture. 
2016

\section{The Regulatory Implications of New Breeding Techniques}

\section{Academy of Science of South Africa (ASSAf)}

Academy of Science of South Africa

Academy of Science of South Africa (ASSAf), (2016). The regulatory implications of new breeding techniques. [Online] Available at: DOI http://dx.doi.org/10.17159/assaf.2016/0011 http://hdl.handle.net/20.500.11911/29

Downloaded from ASSAf Research Repository, Academy of Science of South Africa (ASSAf) 